\title{
Site Study Plan
}

\author{
For \\ TRANSPORTATION \\ Deaf Smith County Site, Texas
}

Preliminary Draft

June 1987

Office of Nuclear Waste Isolation

Battelle Memorial Institute

505 King Avenue

Columbus, Ohio 43201

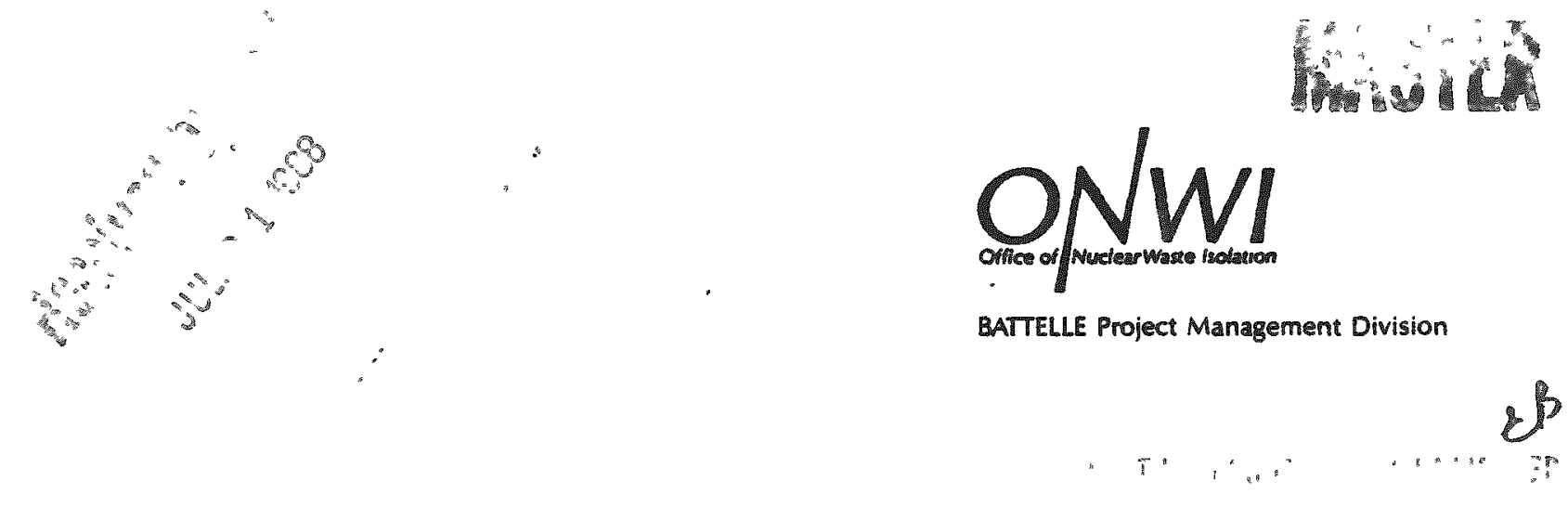




\section{DISCLAIMER}

This report was prepared as an account of work sponsored by an agency of the United States Government. Neither the United States Government nor any agency Thereof, nor any of their employees, makes any warranty, express or implied, or assumes any legal liability or responsibility for the accuracy, completeness, or usefulness of any information, apparatus, product, or process disclosed, or represents that its use would not infringe privately owned rights. Reference herein to any specific commercial product, process, or service by trade name, trademark, manufacturer, or otherwise does not necessarily constitute or imply its endorsement, recommendation, or favoring by the United States Government or any agency thereof. The views and opinions of authors expressed herein do not necessarily state or reflect those of the United States Government or any agency thereof. 


\section{DISCLAIMER}

Portions of this document may be illegible in electronic image products. Images are produced from the best available original document. 


\section{DISCLAIMER}

This report was prepared as an account of work sponsored by an agency of the United States Government. Neither the United States Government nor any agency thereof, makes any warranty, expressed or implied, or assumes any legal liability or responsibility for the accuracy, completeness, or usefulness of any information, apparatus, product, or process disclosed, or represents that its use would not infringe privately owned rights. Reference herein to any specific commercial product, process, or service by trade name, trade mark, manufacturer, or otherwise, does not necessarily constitute or imply its endorsement, recommendation, or favoring by the United States Government or any agency thereof. The views and opinions of authors expressed herein do not necessarily state or reflect those of the United States Government or any agency thereof.

\section{IECHNICAL STATUS}

This technical report is being archived in advance of DOE technical review because of Congressional shutdown of the Salt Repository Project. Because of project termination, DOE has expedited the report clearance process to ensure availability of project data. A sumary of the review status of this report is attached. 
This site study plan describes transportation field studies to be conducted during the characterization of the Deaf Smith County; Texas, site for the U.S. Department of Energy's Salt Repository Project. The studies are needed to identify and assess potential project impacts to transportation infrastructure and systems in the project vicinity and along potential transportation routes to the site across the State of Texas. The studies are also needed to locate and design project transportation facilities, and to evaluate and design impact mitigation.

After identifying the transportation information requirements needed to comply with Federal, State, and local regulations and repository program requirements, the site study plan describes the study design and rationale, the field data collection procedures and equipment, the data analysis methods and application of results, the data management strategy, the schedule of field activities, the management of the study, and the study's quality assurance program.

The field data collection activities are organized into programs for the characterization of site vicinity rail corridors and highway corridors, characterization of alternative statewide transportation routes, monitoring of site characterization effects on transportation, characterization of aircraft overflight patterns and hazardous material transportation patterns, and assessment of emergency response preparedness along alternative statewide transportation routes.

Transportation field activities will begin after receipt of site access authorization. Ideally, transportation field assessments of existing road traffic in the site vicinity would precede all other site characterization field activities. All field activities in the site vicinity will be completed within thirty-nine months of site access except for monitoring of site characterization effects on transportation, which will continue throughout site characterization. All statewide field activities will be completed within 5 years. 


\section{THIS PAGE WAS INTENTIONALLY LEFT BLANK}


The National Waste Terminal Storage Program was established in 1976 by the U.S. Department of Energy's predecessor, the Energy Research and Development Administration. In September 1983, this program became the Civilian Radioactive Waste Management (CRWM) Program. Its purpose is to develop technology and provide facilities for safe, environmentally acceptable, permanent disposal of high-level waste (HLW). HLW includes wastes from both commercial and defense sources, such as spent (used) fuel from nuclear power reactors, accumulations of wastes from production of nuclear weapons, and solidified wastes from fuel reprocessing.

The information in this report pertains to the environmental studies of the Salt Repository Project of the Office of Geologic Repositories in the CRWM Program. 


\section{THIS PAGE WAS INTENTIONALLY LEFT BLANK}


1.0 INTROOUCTION ....................................... 1-1

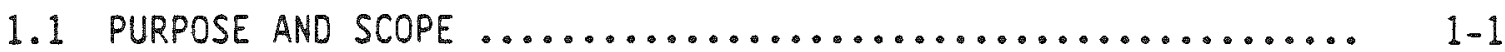

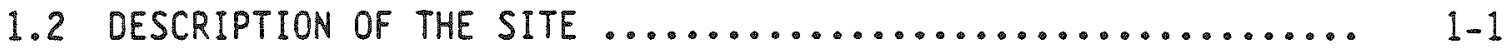

1.2.1 Description of the Deaf Smith County Site .......... 1-2

1.2.2 Regional Transportation Systems ................. 1-2

1.3 PREVIOUS STUDIES .................................. 1-6

1.4 ORGANIZATION OF THE SITE STUDY PLAN ...................... 1 .

2.0 STUDY RATIONALE AND INFORMATION REQUIREMENTS $\ldots \ldots \ldots \ldots \ldots \ldots . . . \ldots 2-1$

2.1 FEDERAL, STATE, AND LOCAL REQUIREMENTS ................. 2-1

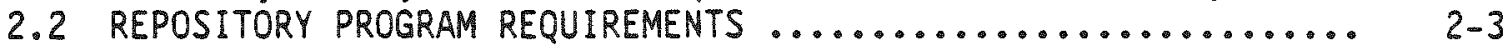

2.2.1 Purpose and Relationship of Programmatic Requirements .................... 2-3

2.2.2 Relationship of Programmatic Requirements
to the Transportation SSP ........................ 2-4

3.0 TECHNICAL DESIGN OF THE STUDY ......................... 3-1

3.1 DESCRIPTION OF THE STUDY DESIGN .................... $3-1$

3.1.1 Design of Rail-Corridor-Characterization Studies ..... 3-3

3.1.1.1 Survey of Existing Rail Systems in the Project Vicinity ...................... 3-3

3.1.1.2 Assembiy of Repository-Generated Traffic Data .......................... 3-7

3.1.1.3 Identification of Rail-System Alternative Corridors .................. 3-7

3.1.1.4 Determination of Alternative Rail-Corridor Environmental Conditions ................ 3-8

3.1.1.5 Collection of Data to Confirm Preferred Rail Corridor ......................... $3-8$

3.1.2 Design of Highway-Corridor-Characterization Studies .. 3-9

3.1.2.1 Survey of Existing Roadway Systems in the Project Vicinity ................... $3-9$

3.1.2.2 Assembly of Repository-Generated Traffic Data ............................. $3-12$ 
TABLE OF CONTENTS

(Continued)

Page

3.1.3 Design of Alternative Statewide Route

Characterization Studies .................... 3-12

3.1.3.1 Identification of Statewide Multi-Modal-

Transportation Routes ................. 3-12

3.1.3.2 Survey of Existing Statewide

Transportation Infrastructure ............ 3-13

3.1.3.3 Survey of Accident and Incident Data........ 3-19

3.1.3.4 Determination of A1ternative Multi-Modal

3.1.3.5 Collection of Data to Confirm Preferred

Statewide Multi-Modal Routes ............ 3-20

3.1.4 Design of Monitoring Studies ................. 3-20

3.1.4.1 Monitor Public Road Congestion in the

Project Vicinity ..................... 3-20

3.1.4.2 Assembly of Site Characterization Project

Transportation Data .................... 3-22

3.1.5 Design of Aircraft-Overfight, Hazardous-Material-

Transportation, and Emergency-Response-Preparedness

Characterization Studies

3.1.5.1 Survey Aircraft-Overflight Patterns ........ 3-24

3.1.5.2 Survey Hazardous-Materials Transport

Patterns .......................... 3-26

3.1.5.3 Assemble Emergency-Response Data Along

Statewide Multi-Modal Routes ............ 3-28

3.2 RATIONALE FOR THE STUDY DESIGN .................... 3-30

3.2.1 Rationale for Rail-Corridor-Characterization

Study Design ................................ 3-30

3.2.1.1 Survey Existing Rail Systems ............ 3-30

3.2.1.2 Assemble Repository-Generated

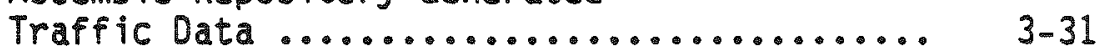

3.2.1.3 Identify Alternative Corridors ............ 3-31

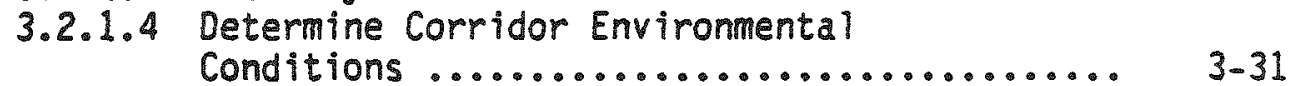

3.2.1.5 Confirm Preferred Corridor Selection ....... 3-31 
TABLE OF CONTENTS

(Continued)

Page

3.2.2 Rationale for Highway-Corridor-Characterization

Study Design ............................ 3-32

3.2.2.1 Survey Existing Roadway Infrastructure ...... 3-32

3.2.2.2 Assemble Repository-Generated Traffic Data .. 3-32

3.2.3 Rationale for Design of Alternative Statewide

Route Characterization Studies ................ 3-32

3.2.3.1 Identify Alternative Statewide Routes ....... 3-33

3.2.3.2 Survey Existing Transportation

Infrastructure for Alternative

Statewide Routes .................... 3-33

3.2.3.3 Collect Accident and Incident Data Along

Alternative Statewide Routes ............. 3-34

3.2.3.4 Determine Environmental Conditions Along

Alternative Statewide Routes .............. 3-34

3.2.3.5 Select Preferred Statewide Routes .......... 3-34

3.2.3.6 Collect Environmental Data for Preferred

Statewide Routes .................... 3-35

3.2.4 Rationale for Design of Repository-Characterization

Monitoring Studies ......................... 3-35

3.2.4.1 Rational for Monitoring of Public Road

Congestion in the Project Vicinity ........ 3-35

3.2.4.2 Rationale for Assembly of Site

Characterization Project Trans-

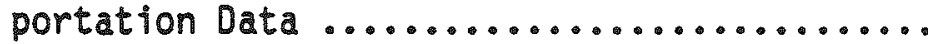

3.2.5 Rationale for the Design of Aircraft-Overfight, Hazardous-Material-Transportation, and Emergency-

Response-Preparedness Characterization Studies .......

3.2.5.1 Define Aircraft-Overflight Patterns ........ 3-37

3.2.5.2 Define Hazardous-Materia1-Transportation

3.2.5.3 Assess Emergency-Response Preparedness ..... 3-37

3.3 RATIONALE FOR THE SELECTION OF THE STUDY METHOOS ......... 3-37

3.3.1 Methods of Rail-Corridor Characterization ......... 3-40

3.3.1.1 Existing Rai1-System Survey Methods ........ 3-40

3.3.1.2 Methods for Assembly of Repository- 
TABLE OF CONTENTS

(Continued)

Page

3.3.1.3 Identification of Rail-System

Alternative Corridors ................. 3-42

3.3.1.4 Rail-Corridor Environmental

Characterization Methods ................ 3-43

3.3.1.5 Preferred Corridor Data Collection

Methods ........................ 3-43

3.3.2 Methods of Highway-Corridor Characterization ....... 3-43

3.3.2.1 Existing Roadway-System Survey Methods ...... 3-43

3.3.2.2 Methods for Assembly of Repository-Generated

Traffic Data ........................ 3-44

3.3.3 Methods of Alternative Statewide Route

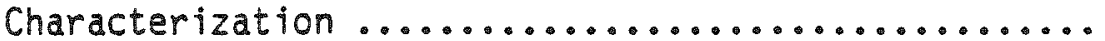

3.3.3.1 Identification of Statewide Multi-Modal

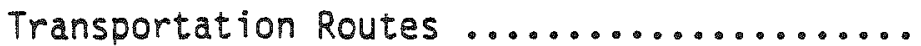

3.3.3.2 Existing Transportation Infrastructure

Survey Methods ...................... 3-45

3.3.3.3 Accident and Incident Survey Methods ........ 3-46

3.3.3.4 Multi-Modal Route Environmental

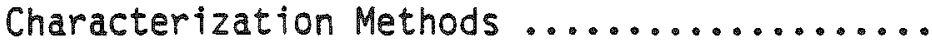

3.3.3.5 Selected Multi-Modal Route Environmental

Data Collection Methods ................ 3-46

3.3.4 Methods of Monitoring Studies ............... 3-47

3.3.4.1 Monitoring of Public Road

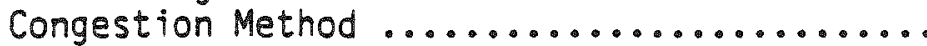

3.3.4.2 Methods for Assembly of Site-

Characterization-Project

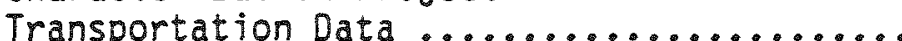

3.3.5 Methods of Aircraft-Overflight, Hazardous-MaterialTransportation, and Emergency-Response Preparedness Characterization Studies ........................

3.3.5.1 Methods for Survey of Aircraft-Overfight

Patterns ........................... 3-49

3.3.5.2 Methods for Survey of Hazardous-Materials-

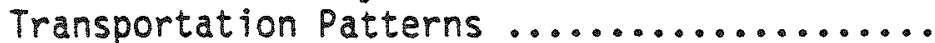

3.3.5.3 Methods for Assembly of Emergency-Response

Data 


\section{TABLE OF CONTENTS}

(Continued)

3.4 DESCRIPTION OF APPLICABLE TECHNICAL PROCEDURES ........... $3-49$

3.4.1 Railroad-Survey Procedures .................... 3-50

3.4.1.1 Statewide Railroad Surveys .............. 3-50

3.4.1.2 Site-Vicinity Railroad Surveys .......... 3-52

3.4 .2 Roadway-Systems Survey Procedures .............. 3-54

3.4.2.1 Statewide Roadway Surveys ............... 3-55

3.4 .2 .2 Site-Vicinity Roadway Surveys ........... 3-56

3.4.3 Port Facility Survey Procedures .............. 3-59

3.4.3.1 Port City Maps ....................... 3-59

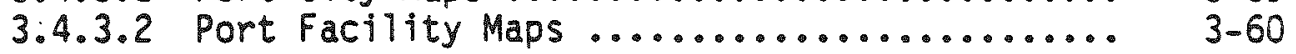

3.4.4 Traffic-Study Procedures ..................... 3-60

3.4.4.1 Initial Traffic Studies at Site Vicinity .... 3-60

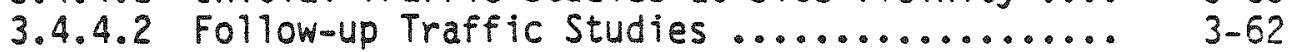

3.4.4.3 Data Collection by others .............. 3-63

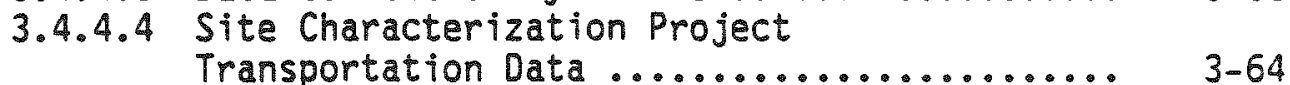

3.4.5 Flight-Path-Assessment Procedures .............. 3-64

3.4.6 Hazardous-Materials-Survey Procedures ............. 3-65

3.4.7 Emergency-Response-Survey Procedures ............ 3-65

3.5 EQUIPMENT AND MATERIALS ........................ 3-65

3.5 .1 Equipment Use ...................................... 3-66

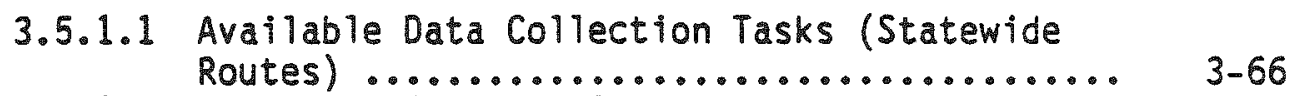

3.5 .1 .2 Site Vicinity Data Generation Tasks ........ $3-66$

3.5.1.3 Feature Maps Compilations .............. 3-68

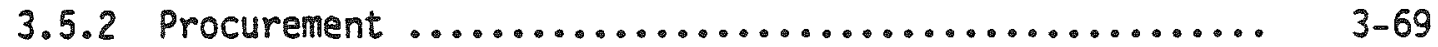

3.5 .3 Logistics ................................ 3-70

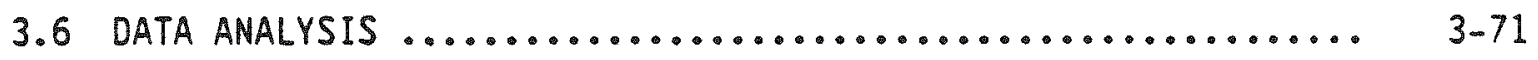

3.6.1 Rail Corridor Characterization Studies ............. 3-71

3.6 .2 Highway-Corridor Characterization Studies ......... 3-... 32

3.6.3 Alternative Statewide Route
Characterization Studies ...................... 3-73 


\title{
TABLE OF CONTENTS
}

(Continued)

\begin{abstract}
3.6.4 Monitoring Studies
3.6.5 Aircraft-Overflight, Hazardous-Material

Transportation, and Emergency-Reponse-

Preparedness Characterization Studies
\end{abstract}

Page

$3-74$

$3-74$

3.7 APPLICATION OF THE RESULTS ...................... 3-75

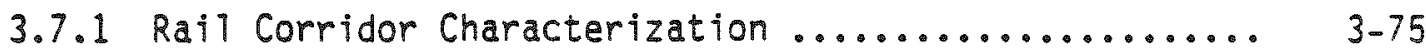

3.7 .2 Highway-Corridor Characterizaiton Studies .......... 3-75

3.7.3 Alternative Statewide Route

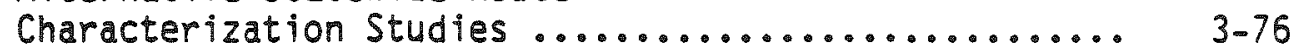

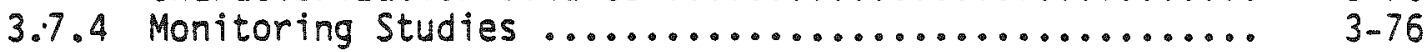

3.7.5 Aircraft-Overfight, Hazardous-Material

Transportation, and Emergency-Response -

Preparedness Characterization Studies

4.0 DATA MANAGEMENT

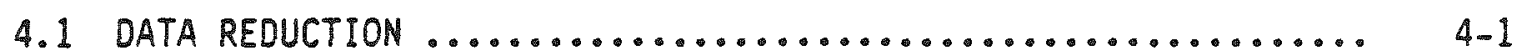

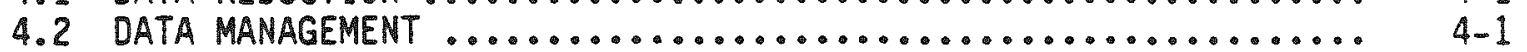

4.3 DATA REPORTING .................................... $4-4$

5.0 SCHEDULE AND MILESTONES ............................. $5-\ldots 1$

5.1 SITE STUDY SCHEDULE ............................. $5-1$

5.1 .1 Site vicinity studies ....................... 5-1

5.1 .1 .1 Rail-Corridor Study ................... 5-1

5.1 .1 .2 Highway-Corridor Study ...................... $5-4$

5.1 .2 Statewide Route Studies ....................... 5-5

5.1.2.1 Identify Alternative Statewide Routes ...... 5-5

5.1.2.2 Survey Statewide Transportation

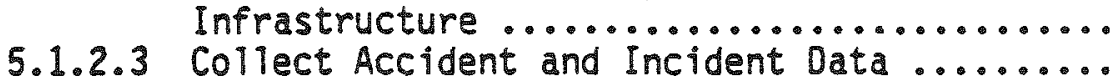

5.1.2.4 Define Required Upgrades and Improvements ...

5.1.2.5 Determine Environmental Conditions Along the Routes ........................................ $5-5$

5.1.2.6 Calculate Radiological Exposure Risks ....... 5-6

5.1 .2 .7 Select Preferred Routes ................. 5-6

5.1 .2 .8 Collect Environmental Data ............. 5-6

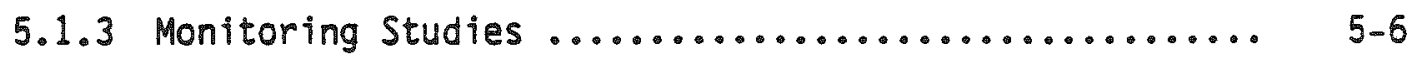

5.1.3.1 Monitor Public Road Congestion ........... 5-7

5.1.3.2 Quantify Site-Characterization Traffic

Activities 
TABLE OF CONTENTS

(Continued)

5.1.4 Overflight, Hazardous-Material, and Emergency-

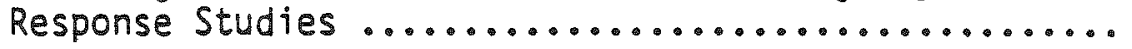

5.1.4.1 Aircraft-Overflight-Pattern Determinations ..

5.1.4.2 Hazardous-Materia1-Transportation

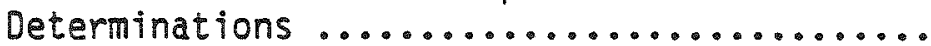

5.1.4.3 Emergency-Response-Preparedness

Determinations

5.2 MILESTONES ...................................... $5-8$

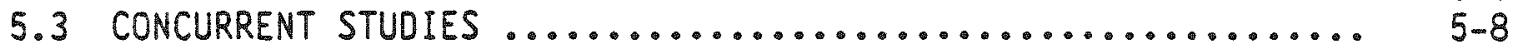

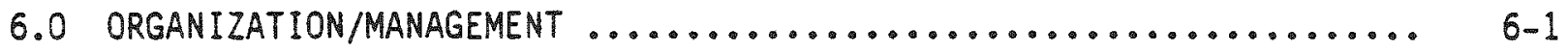

6.1 MANPOWER REQUIREMENTS AND ORGANIZATION ............... 6-1

6.1 .1 Field Staff Requirements ..................... 6-1

6.1 .2 Organization Responsibilities, and
Qualifications of Key Personnel ................. $6-3$

6.2 SAMPLE MANAGEMENT ................................ 6 .4

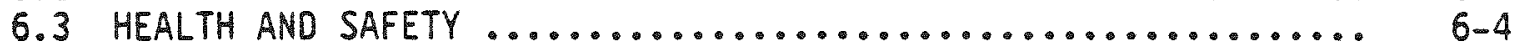

7.0 QUALITY ASSURANCE ............................... $7-1$

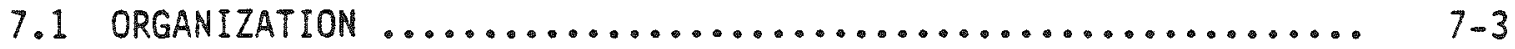

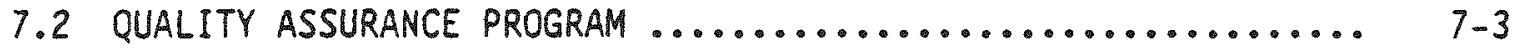

7.3 DESIGN CONTROL .............................. $7-4$

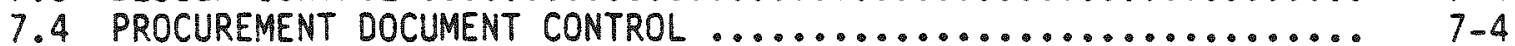

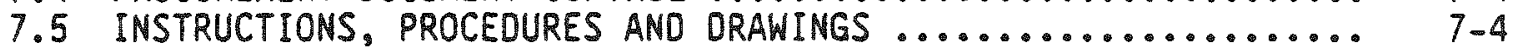

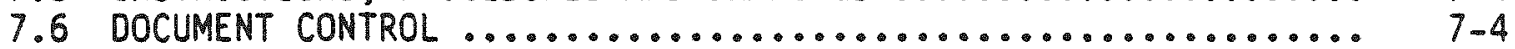

7.7 CONROL OF PURCHASED ITEMS AND SERVICES ................ $7-4$

7.8 IDENTIFICATION AND CONTROL OF ITEMS .................. $7-5$

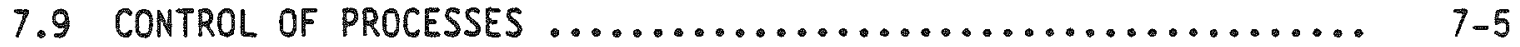

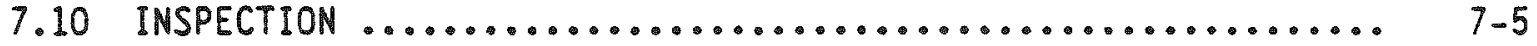

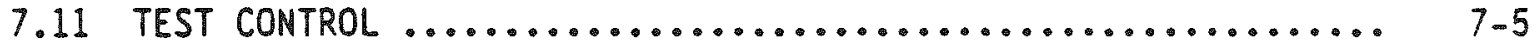

7.12 CONTROL OF MEASURING AND TEST EQUIPMENT ................ $7-5$

7.13 HANDLING, STORAGE, AND SHIPPING ........................... $7-5$

7.14 INSPECTION, TEST, AND OPERATING STATUS ............... $7-6$

7.15 CONTROL OF NONCONFORMING ITEMS ..................... 7-6

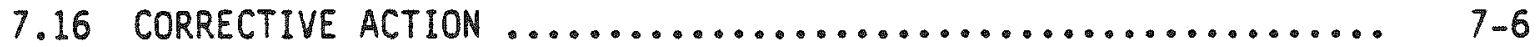

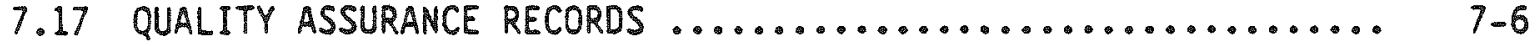

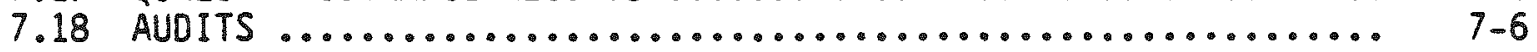

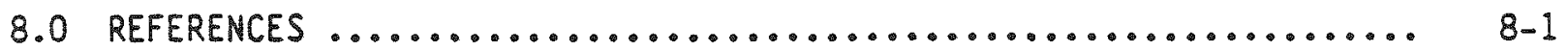

8.1 REFERENCES LISTED BY AUTHOR ...................... 8-1

8.2 FEDERAL AND STATE STATUTES AND REGULATIONS
AND EXECUTIVE ORDERS $\ldots \ldots \ldots \ldots \ldots \ldots \ldots \ldots \ldots \ldots \ldots \ldots \ldots \ldots \ldots \ldots \ldots \ldots$ 


\section{LIST OF TABLES}

Table

Title

Page

2-1. Information to be Collected by the Transportation

Field Program to Satisfy SRP Requirements ................. 2-5

5-1. Concurrent Study Programs That Interact With

Transportation Program

\section{LIST OF FIGURES}

Figure

Title

Page

1-1. Location of the Deaf Smith County Site, Texas .............. 1-3

1-2. Major Highways, Railways, and Seaports Serving Texas .......... 1-4

3-1. Major Road, Rai1, and Air Transportation Systems in the Vicinity of the Deaf Smith County Site ................... 3-2

3-2. Six Potential Rail Access Corridors ....................... 3-4

3-3. Major Airways, Railways, and Seaports Serving Texas ........... 3-14

3-4. Location of Highway Traffic Studies .................... 3-23

4-1. Flow Diagram of Transportation Data ..................... 4-3

5-1. Interrelationship of Environmenta1, Geotechnica1, and ESF Field Activities ............................... $5-2$

5-2. Schedule for Transportation Field Studies ................ 5-3

6-1. Organization of Personnel for Transportation Field Studies ..... 6-2 


\subsection{INTROOUCTION}

The evaluation of environmental issues and concerns and the addressing of statutory requirements are fundamental in the characterization of the site in Deaf Smith County, Texas, for the U.S. Department of Energy's Sait Repository Project (SRP). To ensure that the environmental field program comprehensively addresses the issues and requirements of the project, a site study plan (SSP) has been prepared for each of the following environmental disciplines:
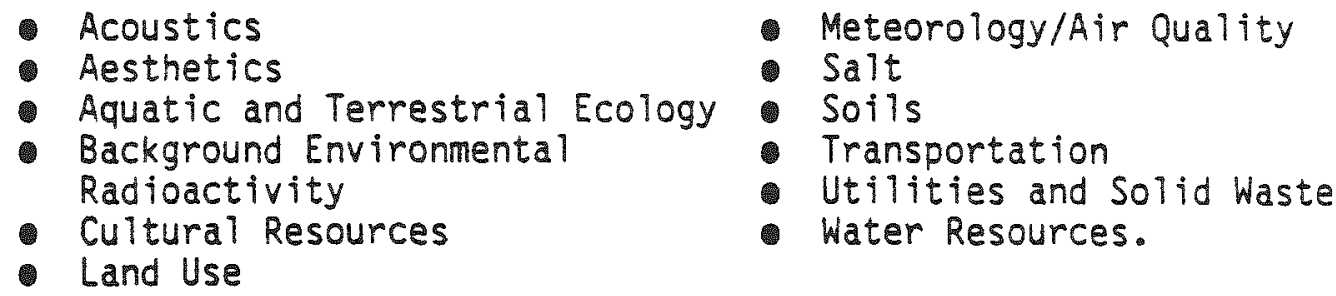

Each SSP presents an overview of the discipline-specific field studies to be conducted during site characterization. The field studies will cover an approximately 7-year period. Technical procedures documents have been developed to implement the field programs described in each SSP.

\subsection{PURPOSE AND SCOPE}

The purpose and scope of the Transportation SSP are to describe the transportation field studies that will be conducted to characterize the environment of the Deaf Smith County site, associated transportation corridors within the site vicinity, and identified transportation routes throughout the state of Texas. The characterizations will be conducted in such a way as to meet Federal, State, and local statutes and regulations as well as SRP directives and requirements. The Transportation SSP requires participation in the field work from the other environmental disciplines listed above to complete the required environmental characterization of the corridors and routes. The nature of this participation is identified in this SSP, but the actual field activities are described in the SSPS prepared for the appropriate disciplines.

The objective of each of the studies described in this SSP is to fulfill data and information needs derived from the requirements in the Requirements Document (SRP-RD) (SRPO, which apply to the environmental program. - As described in the SRP-RD, these data needs can be traced back to the program requirements and directives from which they have been developed. The program requirements and directives that apply to the transportation studies are presented briefly in Chapter 2.

\subsection{DESCRIPTION OF THE SITE}

This section describes the Deaf Smith County site and the local road network. The regional system of major highway and interstate routes and rail lines operating in the area are also discussed. 


\subsubsection{Description of the Deaf Smith County Site}

The proposed site occupies $23.3 \mathrm{~km}^{2}\left(9 \mathrm{mi}^{2}\right)$ in the north-central part of Deaf Smith County in the Southern High Plains of the Texas Panhandle (Figure 1-1) (DOE, 1986). The High Plains are nearly flat, sloping gently to the southeast. The terrain in the area of the site includes small, internally drained lake basins ( $p l a y a s)$ and narrow stream valleys that carry water after rainstorms. The site is in a rural area where the population density averages about 2 persons per $\mathrm{km}^{2}$ ( 4 persons per $\mathrm{mi}^{2}$ ). Most of the population in Deaf Smith County and the surrounding area is concentrated in cities and towns. Amarillo is the regional population center. An east-west Texas farm-to-market (FM) road, FM 2587, passes through the southern part of the site and connects with Interstate $40(I-40)$ via U.S. Route 385 (DOE, 1986).

The local road network in the rural areas is dominated by a gridlike pattern of roads, similar to the pattern of property lines. Overiaid on this local network is a regional system of major highway routes oriented by the location of the population centers that it connects. The rail lines operating in this area tend to parallel the regional highway network.

The two most heavily traveled routes in the vicinity of the site are I-40, approximately $14 \mathrm{~km}(9 \mathrm{mi})$ north of the site, and U.S. Route 60 , approximately $35 \mathrm{~km}$ (22 $\mathrm{mi})$ south of the site. I-40 runs generally east-west; from Amaril10 westward, it connects a series of small population areas, including Bushland, Wildorado, Vega, and Adrian, then continues into New Mexico. A rail line parallels this route from Amarillo to Bushland. From Bushland westward, the tracks have been removed, although the roadbed still exists in some sections.

U.S. Route 60 runs in a southwestern direction connecting the towns of Canyon, Umbarger, Dawn, Hereford, and farther south, Friona and Bovina. The Atchison, Topeka \& Santa Fe Railroad (AT\&SF) operates a line parallel to U.S. Route 60. U.S. Route 385 runs north-south, connecting Vega on I-40 with Hereford on U.S. Route 60 , and passes approximately $6 \mathrm{~km}$ (4 mi) east of the site.

County and farm-to-market (FM) roads traverse the region around the Deaf Smith County study area and most run either north-south or east-west, following the geometric grid pattern of property lines. FM 2587 passes east-west through the southern part of the site, intersecting with U.S. Route 385 and continuing east until it intersects with FM 809, which is a north-south route connecting Wildorado and Dawn.

\subsubsection{Regional Transportation Systems}

For the purposes of this SSP, the "region" is defined as the State of Texas, and does not include areas in adjoining states, the Gulf of Mexico, or the nation of Mexico. Figure 1-2 illustrates the principal transportation systems within the State of Texas.

Amari710, approximately $64 \mathrm{~km}(40 \mathrm{mi})$ from the site, is the largest and closest transportation hub for both rail and highway traffic in the region. 


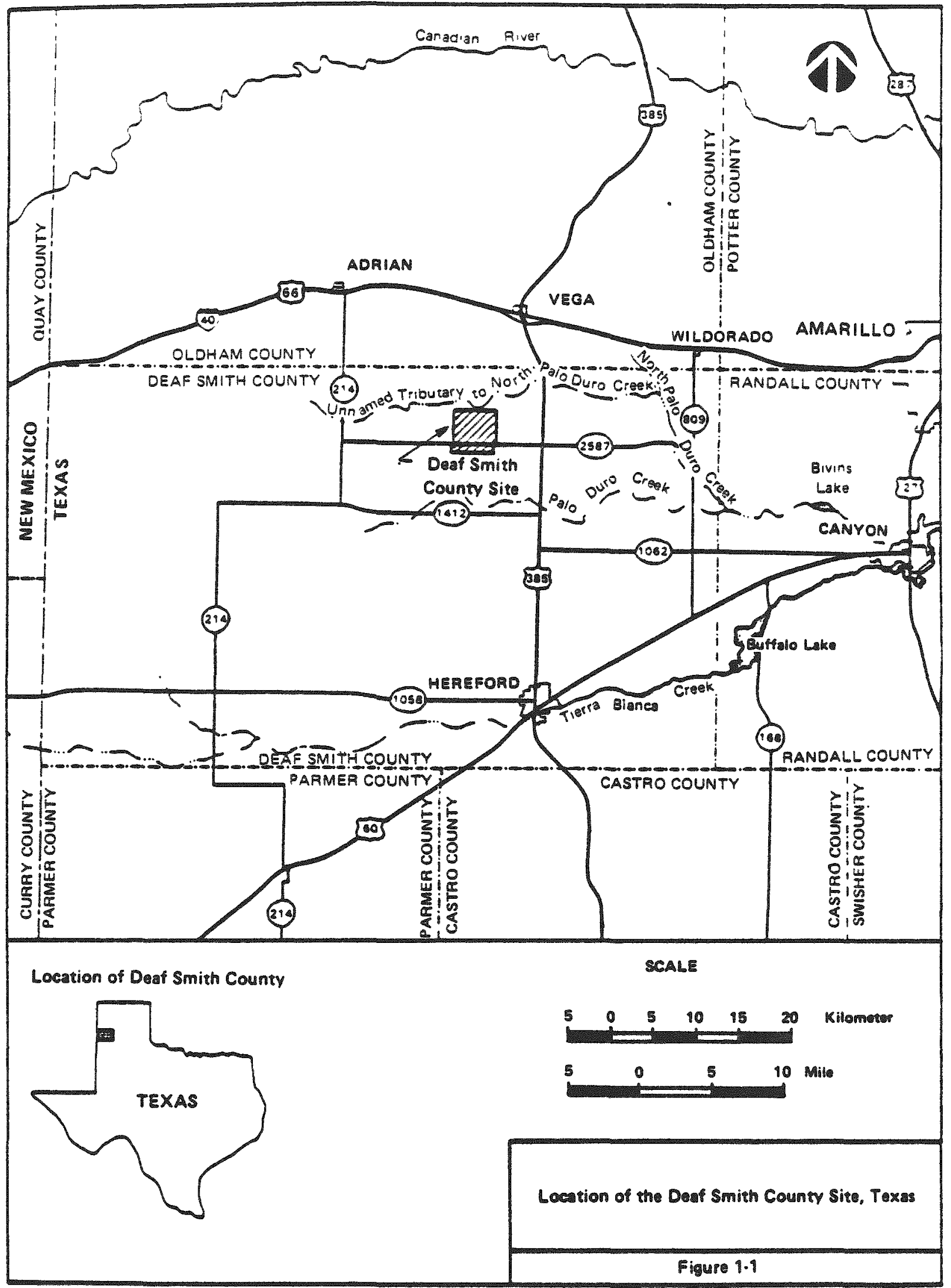




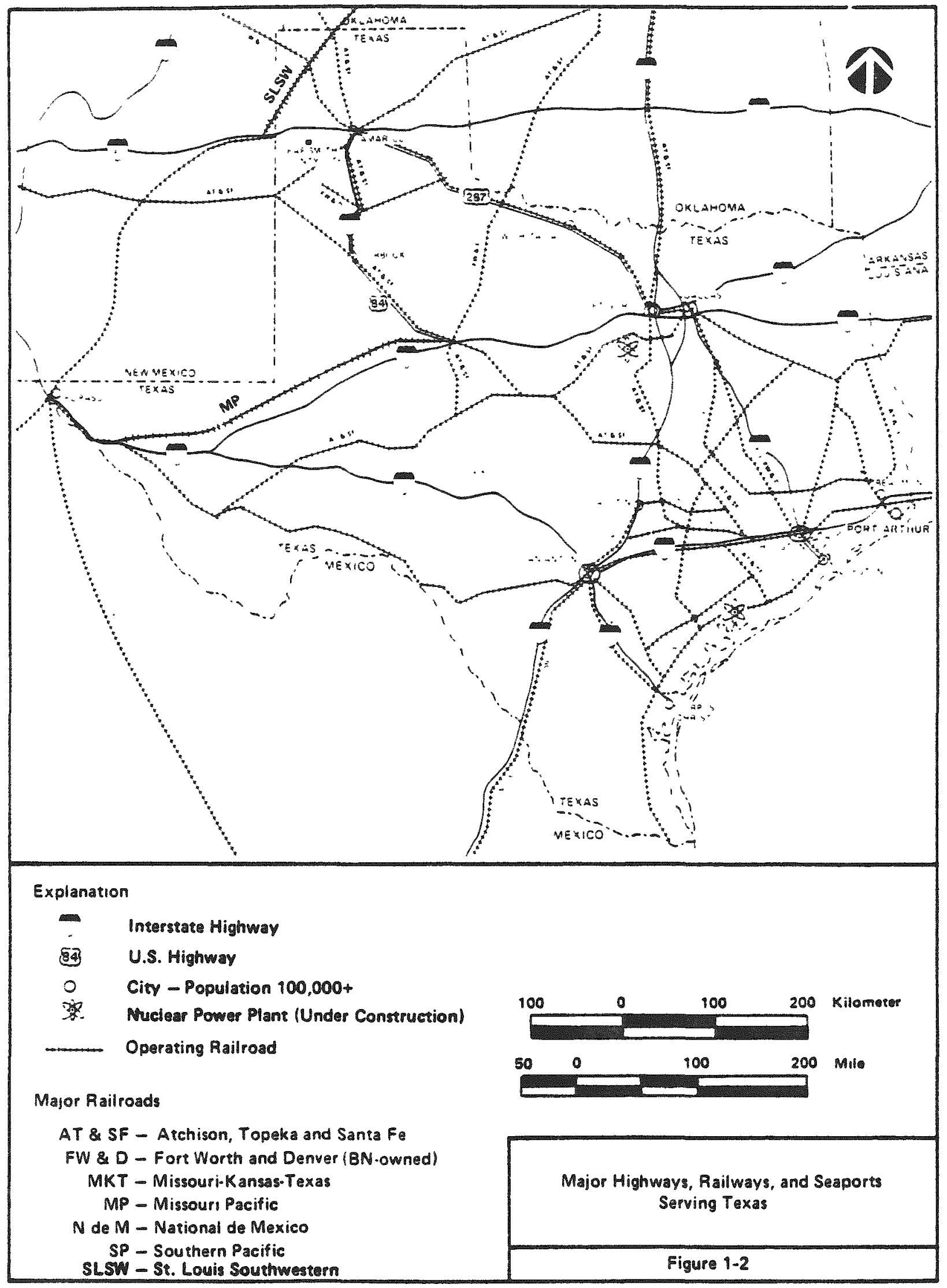


Other significant rail hubs are Lubbock, approximately $192 \mathrm{~km}$ (120 mi) south of the site; Plainview, $134 \mathrm{~km}$ ( $84 \mathrm{mi}$ ) to the south; and Clovis, $96 \mathrm{~km}$ (60 mi) to the southwest in New Mexico.

Part of the national system of interstate highways serve the State of Texas. The U.S. Department of Transportation's routing regulations (49 CFR 177.825) designate interstate highways as the preferred route for transporting spent fuel and other route-controlled quantities of radioactive materials. Route-controlled quantities of radioactive materials are defined in 49 CFR 173.403.

The north-south interstates in Texas are I-27, I-35, I-37, and I-45. The east-west interstates are I-10, I-20, I-30, and I-40. Circumferential highways serving major Texas cities are I-635, Dallas: I-820, Fort Worth; I-610, Houston: and I-410, San Antonio.

According to the Environmental Assessment (EA) (DOE, 1986), the ports of Houston and Galveston could be used for barge transport of repository-related materials. Memphis, Tennessee was also identified in the EA as a potential port for barge transportation of nuclear materials. Houston has a port capable of handing deep-draft barges approximately 7 hours of ship travel time inland from Galveston. The Burlington-Northern Railroad (BN) and the AT\&SF Railroad are two potential access rail routes that could provide service via Amaril10 (BN) and Canyon (AT\&SF) from these port facilities. Travel by highway from Gaiveston or Houston could be on I-45 through the Dallas area, continuing on U.S. Route 287 to I-40 through Amarillo and to the site. The port of Corpus Christi could also provide for barge transport to the site via I-37 and the Missouri Pacific Railroad.

The SRP National Transportation Program (NTP) is evaluating nationwide transportation issues regarding the proposed nuclear repositories, including the Deaf Smith County site (ONWI, 1987b). The NTP will identify transportation routes up to the Texas state borders. This identification will occur in accordance with the schedule of the NTP, and is a constraint on SSP studies of Texas transportation routes. The Southern Pacific (S-P) and the Missouri Pacific (M-P) railroads, in addition to the AT\&SF and BN, may bring shipments destined for the site into the state. Highway routes entering the state could include I-40, I-30, I-20, and I-10 entering the state from the west and/or east, and I-44 and I-35 entering from the north. No interstates enter from the north in the panhandle area, but U.S. Highways $287,87,54,385$, and 83 enter the northern portion of the panhandle. All of these referenced routes could be points of origin for routes to the site within the State of Texas.

There are also two in-state generators of spent nuclear fuel and waste: the South Texas Nuclear Plant of Houston Lighting and Power Company and the Comanche Peak Nuclear Plant of the Texas Utilities Generating Company.

The South Texas Nuclear Plant is south of Houston, $1,386 \mathrm{~km}$ ( $866 \mathrm{mi}$ ) by highway and $1,368 \mathrm{~km}$ ( $855 \mathrm{mi}$ ) by rail from the Deaf Smith County site. Rail and highway access from the reactor to the site could be provided by those routes described previously for the port of Houston. The Comanche Peak Nuclear Plant is in the central part of the state southwest of the Dallas-fort Worth area, $918 \mathrm{~km}$ ( $574 \mathrm{mi})$ by highway and $738 \mathrm{~km}$ (461 $\mathrm{mi}$ ) by rail from the 
site. Rail service to the site from the reactor could be provided by AT\&SF railroad. Highway transportation could initially follow local roads to I-20. From I-20, there are two alternate routes to the site: U.S. 287 from fort Worth to the east, and U.S. 84 through Abilene to the west, then I-27 from Lubbock north to Amarillo and to the site.

The preponderance of reactor sites outside the state are to the northeast and east, and for this reason, most shipments to the site could be expected to be coming from those directions.

\subsection{PREVIOUS STUOIES}

Radiological Impacts of Transporting High-Level Radioactive Waste to Potential Repository Sites in the Palo Duro Basin (NUS Corporation, 1983), assessed the potential transportation impacts associated with a proposed highlevel radioactive waste repository at two hypothetical sites in the Palo Duro Basin in Texas. To assess potential radiation exposure to truck and train crews and the general population, two analyses were performed: one assumed that all waste shipments would be made by truck, and the other assumed all waste shipments would be made by rail to the Deaf Smith County site. The results of these analyses indicated that the potential radiation exposure to truck crews would be many times greater than the potential exposure to the general population during normal truck transport conditions, while during rail transit the crew exposure would be only slightly higher than that of the general population. I-40 from Amarillo to Vega and U.S. Route 385 to the hypothetical site was identified as the highway route with minimum radiological

- exposure potential. The route along the AT\&SF line from Plainview to Canyon to Dawn was identified as the rail route with minimum exposure potential.

Historical accident data for heavy-duty trucks were analyzed for each alternative highway route to the site. The route from Amarilio to Vega on 1-40 was determined to be the route of minimum risk for cargo shipments. Similar data for rail accidents were analyzed and the Amarillo to Canyon to Dawn route proved the safest for cargo shipments.

The radiological impacts of transportation accidents were also addressed. While impacts would be very small from a risk standpoint, routes were compared in terms of the potential consequences of an accident along a given route. Truck accidents along State Route 194 from Plainview to Dimmitt and to the Deaf Smith County site via U.S. Route 385 would result in the fewest consequences. The rail route that would pose minimum risk of radiological impact would be from Plainview to Canyon to Dawn.

Decontamination costs, due to release of radioactive materials in a severe transportation accident, were evaluated by route. The report presented the costs on a per-mile 2 basis for various land uses according to two levels of contamination. Multi-family residential areas were determined to be the most costiy to decontaminate.

NUS Corporation (1986) prepared a report, Rail Transportation Corridor Analys is Report: Deaf Smith County Location in the Palo Duro Basin, Texas. An environmental data base was developed for the preliminary considerations of 
siting potential rail access proposed repository site in divided according to avoidar constraint features were the

Using a computerized Ge was performed applying the $G$ categories to produce a comp statistical analysis using $c$

From eight initial corr posed. The preferred alterr railroad right-of-way direct site, diverging from the ric Vega, the center of populati posed corridor would minimiz lower the probability of rai would occur only along 25.6 (30.5-mi) route. The corric secondary road for most of $t$

Studies specifically ac tion of spent nuclear fuel a are not known to exist. One conduct literature searches

The Department of Eners Deaf Smith County Site, Tex Basin, which is one of five first repository. On the bc DOE found that the Deaf Smit guidelines.

Furthermore, the DOE fC zation because the evidence not be able to meet each of lines. On the basis of thes County site as one of five s

The EA includes a descr site, including roads, railr expected effects of site che describes monitoring and mit the expected effects of the repository, including the ef ments to transportation corr effects on the existing trar region. These consideratior suitability for site charact An appendix, common to 211 if general background informat: provides supplementary refer zorridors between existing rail lines and the zaf Smith County. Environmental conditions were 2 , constraint, and opportunity features. The weighted for environmental impact potential.

Jraphical Information System (GIS), an analysis joverlay process to the various constraint data site constraint map of the study area. A ridor selection guidelines was also conducted.

Jor alternatives, a preferred corridor was proive begins in Bushland, follows the abandoned $y$ west and then south to the Deaf Smith County :-of-way before it reaches Vega. By avoiding 1 and an area of anticipated growth, this prothe number of potential congested areas and coad accidents. Significant land disruption $n(15.9 \mathrm{mi})$ of the corridor's total $49.1-\mathrm{km}$ - would follow a pipeline right-of-way and a a distance.

ressing the topic of the effects of transporta1 high-level waste throughout the State of Texas of the objectives presented in this SSP is to o identify such studies.

(1986) published the Environmental Assessment The Deaf Smith County site is in the Permian istinct geohdyrologic settings considered for the is of the evaluations reported in this EA, the County site is not disqualified under the nd that the site is suitable for site characterioes not support a conclusion that the site will he qualifying conditions specified in the guidefindings, the DOE nominated the Deaf Smith tes suitable for characterization.

ption of the transportation infrastructure at the ads, airports, and waterways. It describes the acterization on transportation systems and gative methods to be adopted. It also describes ransportation activities of the operational ects of nuclear waste transportation, improvedors necessitated by repository operations, and portation infrastructure in the local area and are included in an evaluation of the site for rization, and a comparison of candidate sites. ogram EA's, is also included, that presents $n$ on transportation topics and issues and nces to more-detailed sources of information. 


\subsection{ORGANIZATION OF THE SITE STUDY PLAN}

Chapter 2 identifies the applicable Federa1, State, and local statutes and regulations and the repository program requirements that determine the information needs for of the transportation studies. Chapter 3 presents the technical design and design rationale. It also includes a description of the methods and the rationale for their selection, a description of the technical procedures and equipment, and a discussion of the analysis of the data and application of the results.

Chapters 4 through 8 support the field study design. Chapter 4 discusses the flow of data from the field, its input into a centralized data management system, and access by the technical community and the public. Chapter 5 discusses the SSP schedule and major milestones. Chapter 6 presents the organization of personnel, discussions relating to sample management, and safety considerations. Chapter 7 presents the quality assurance program, and Chapter 8 lists references. 


\subsection{STUOY RATIONALE AND INFORMATION REQUIREMENTS}

This site study plan (SSP) has been designed to collect and analyze sitespecific data to satisfy information requirements derived from statutes, regulations, orders, and other programmatic directives applicable to the Salt Repository Project (SRP). Chapter 2 describes in broad terms the principal requirements, cites the directives from which they have been derived, and defines the process by which the information needs have been identified and will be used to demonstrate compliance with these requirements. Finally, the information to be collected by the field program is summarized relative to requirements and information needs, and the section is identified where studies to collect the information are described.

The timing for the collection of data to satisfy SRP requirements is linked to the project schedule (see Figure 5-1). This study plan will specify in detail data collection to meet early project requirements. This SSP will be revised to address outstanding requirements when they are identified or as project schedule warrants.

The studies described in chapter 3 have been designed to satisfy the information needs of Requirements 1-6 below. An initial evaluation of the site suitability guidelines (Requirement 7) was made in the Final EA for the Deaf Smith County site (DOE, 1986). A more detailed analysis of the guidelines will be conducted prior to the selection of a repository site. Studies may be modified or additional studies included based on guideline evaluation planning and on State Consultation and Cooperation (Requirement 8) described below. And, while it is recognized that requirements for the preparation of an environmental impact statement (EIS) exist now (Requirement 9), the formal process of scoping required by the National Environmental Policy Act of 1969 (NEPA) must occur before a full set of information needs is available. Thus, this SSP will be revised as these additional information needs are defined.

\subsection{FEDERAL, STATE AND LOCAL REQUIREMENTS}

Presented below are the environmental requirements and the statutes, regulations, and programatic directives from which they were derived.

\section{Obtain Applicable Permits and Approvals}

Requirement: Comply with applicable Federal environmental statutes and regulations and applicable State and local laws and regulations: obtain required permits, approvals, or other authorizations; and maintain compliance with these laws.

Directives: EO 12088: 10 CFR 960.5-2-5(b)(1).

2. Monitor and Mitigate Potentially Significant Impacts

Requirement: Monitor and mitigate potentially significant adverse environmental impacts to the extent practicable during site characterization and repository construction, operation, closure, and decommissioning. 
Directives: 10 CFR 960.3-4; EO 11514 as amended by EO 11991.

3. Plan for Decontamination and Decommissioning (Reclamation)

Requirement: Prepare plans for the decontamination and decommissioning of the site if it is determined to be unsuitable for application for a construction authorization; take reasonable steps to mitigate, if necessary, any significant adverse impacts caused by site characterization if such a determination of unsuitability is made; and, if such a determination is made, take necessary and reasonable steps to reclaim the site.

Directives: NWPA $113(\mathrm{~b})(1)(\mathrm{A})$ (iii) and $113(\mathrm{c})(4)$; 10 CFR 960.3-4; EO 11514.

4. Support Engineering Design

Requirement: Provide adequate and timely data about the environmental conditions to support planning and development of the Exploratory Shaft Facility and the Advanced Conceptual and License Application Designs for the repository including inputs to project decision makers about environmental constraints and requirements that affect siting, design, or scheduling and that support cost estimates.

Directives: NWPA 114(a): 10 CFR 960.3-2-4; NEPA 102.

5. Consider Environmental Control Measures. Discussed in the Environmental Assessment

Requirement: Consjider environmental control measures (designed to limit environmental impacts) throughout the site characterization, site selection, and repository development process.

Directives: 10 CFR 960.3-4; EO 11514 as amended by EO 11991.

6. Provide Information for Pre-licensing (SCP) and Licensing

Requirement: Conduct studies during site characterization that support the Site Characterization Plan (SCP) and the repository license application.

Directives: NWPA 113 (b)(1)(A)(iii) and (iv), 113 (c)(4), and 114(b): 10 CFR 60.11 and $60.21 ; 40$ CFR Part 191.

7. Evaluate Site suitability

Requirement: Evaluate the site conditions and projected effects of repository construction, operation, closure, and decommissioning on environmental resources to support a recommendation of a site for the development of a repository using the Siting Guidelines.

Directives: 10 CFR $960.3-1-5 ; 10$ CFR $960.3-2-4 ; 10$ CFR Part 960 App. III. 


\section{Participate in Consultation and Cooperation}

Requirement: Provide information and technical assistance relevant to environmental resources in support of public participation and State Consultation and Cooperation (C\&C) activities with affected States and Indian Tribes.

Directives: NWPA $111(a)(6)$ and $(b)(3), 113(b), 116(c)(2)(A)$, 117 (b): 10 CFR 960.3-3; EO 11514.

9. Evaluate and Mitigate Impacts to Meet NEPA

Requirement: Evaluate the potential direct, indirect, and cumulative environmental impacts of repository construction, operation, closure, and decommissioning and consider appropriate mitigative measures to meet the scope and intention of the National Environmental Policy Act (NEPA).

Directives: NWPA 114(a)(1)(0): NEPA 101, 102; 40 CFR 1502.16, 1502.6, 1508.8; E0 11514; 10 CFR Part 1021.

\subsection{REPOSITORY PROGRAM REQUIREMENTS}

The SSPS are part of a hierarchy of project documents developed to identify and address repository program requirements.

\subsubsection{Purpose and Relationship of Programmatic Requirements}

To assure responsiveness to programmatic requirements, the SRP has specified and is developing a series of documents that present a systematic link between the requirements and the collection of data which will be used to resolve applicable requirements. The following identifies the documents and discusses how each is intended to contribute to the resolution of requirements.

- Systems Engineering Management Plan (SEMP)

The SEMP (SRPO, 1986) is a DOE required plan that uses a systems engineering approach to conducting and managing technical work at the Project office level. This plan describes the strategy for conducting and managing technical work and identifies which component of the project organization is responsible for carrying out the work. Thus, the SEMP is the overall guidance document for the hierarchy of documents that includes the SSPS.

- SRP Requirements Document (SRP-RD)

The SRP-RD (SRPO assembles into a single document the Federal and State directives (statutes and regulations) and identifies repository program functional requirements and performance criteria needed to comply with them. A functional requirement, consists of a statement describing how a particular 
function contributes to achieving a particular project objective. A performance criterion consists of a measure or standard (quantified wherever possible) of performance for the functional

requirement $(s)$.

The development of information needs evolves from a process of identifying the requirements to be addressed. Information needs represent what must be known to implement SRP strategy and conduct assessments using specified methods. Information needs come from several primary sources that can be categorized as follows: (1) environmental compliance information needs, (2) information needs required to prepare the Site Characterization Plan, and (3) information needs to meet repository engineering design requirements. The SSPS are therefore field implementation plans designed to obtain data to satisfy the information needs they have been designed to fulfill.

\subsubsection{Relationship of Programmatic Requirements to the Transportation SSP}

The studies described in Chapter 3 have been designed to provide information to satisfy the requirements identified in this chapter. Table 2-1 summarizes the information needs identified to date (rows). links each information need to a requirement that the information is needed to satisfy (" $x$ " in applicable column), and references (last column) the section where the studies to collect the information are described.

Although multiple requirements may be identified as needing the same piece of information, only one study is planned to obtain the information. The timing of each study described in Chapter 3 and shown in Figure 5-2 is established to meet the requirement having the earliest need for the information. 
Tabie 2-1. Information to be Collected by the Transportation Field Program to Satisfy SRP Requirements

(Page 1 of 3 )

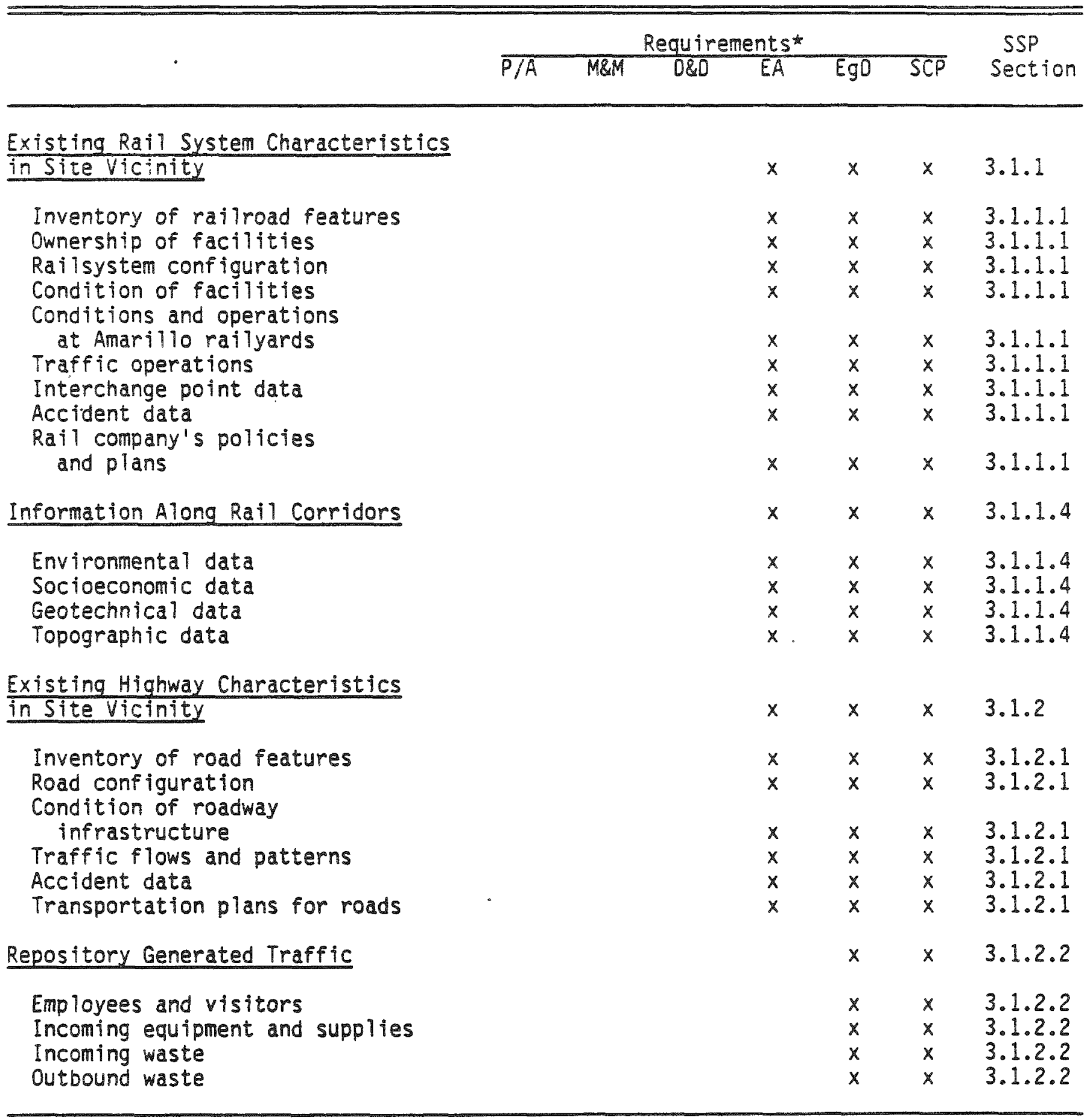


Table 2-1. Information to be Collected by the Transportation Field Program to Satisfy SRP Requirements

(Page 2 of 3 )

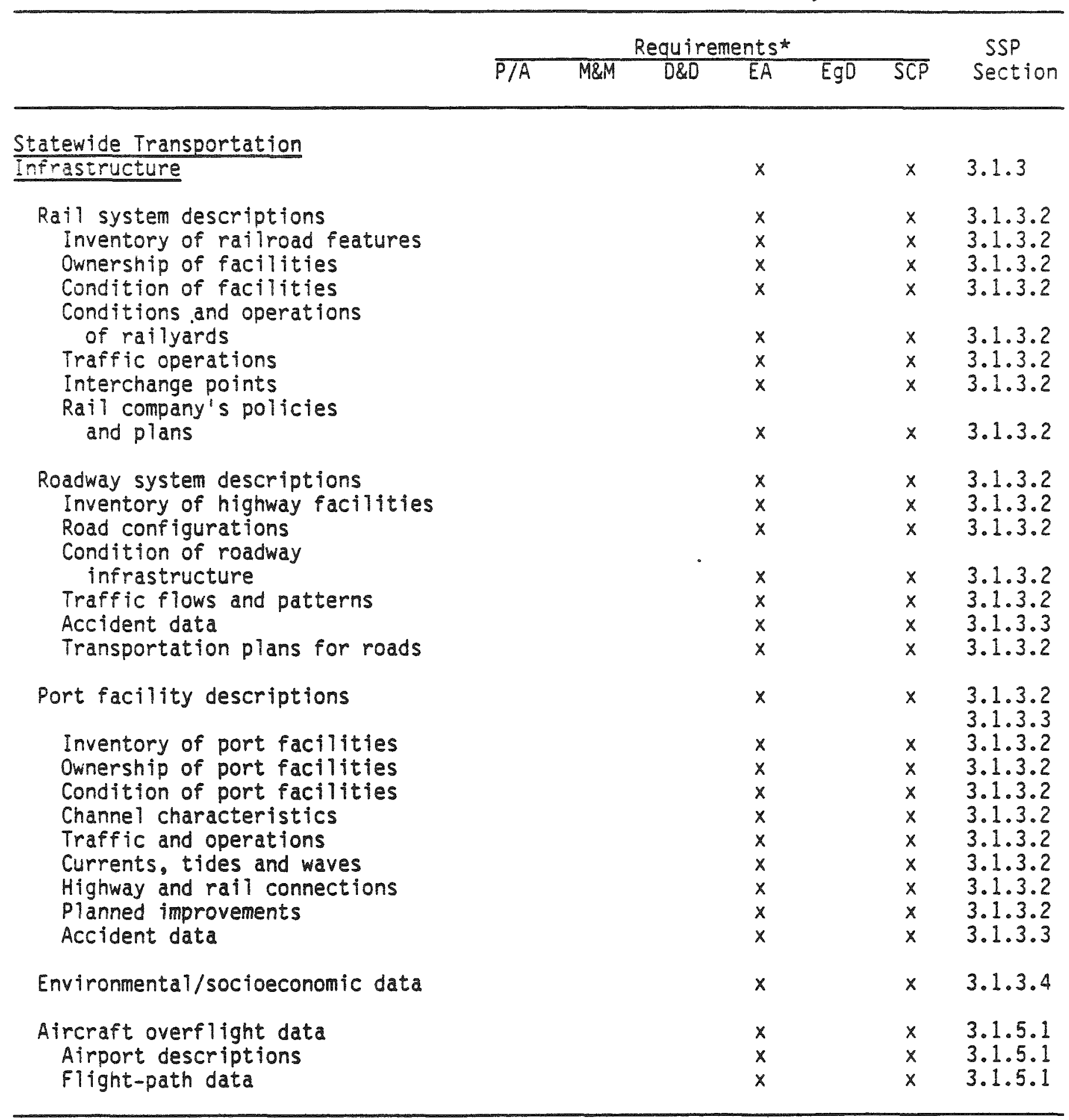


Table 2-1. Information to be Collected by the Transportation Field Program to Satisfy SRP Requirements

(Page 3 of 3 )

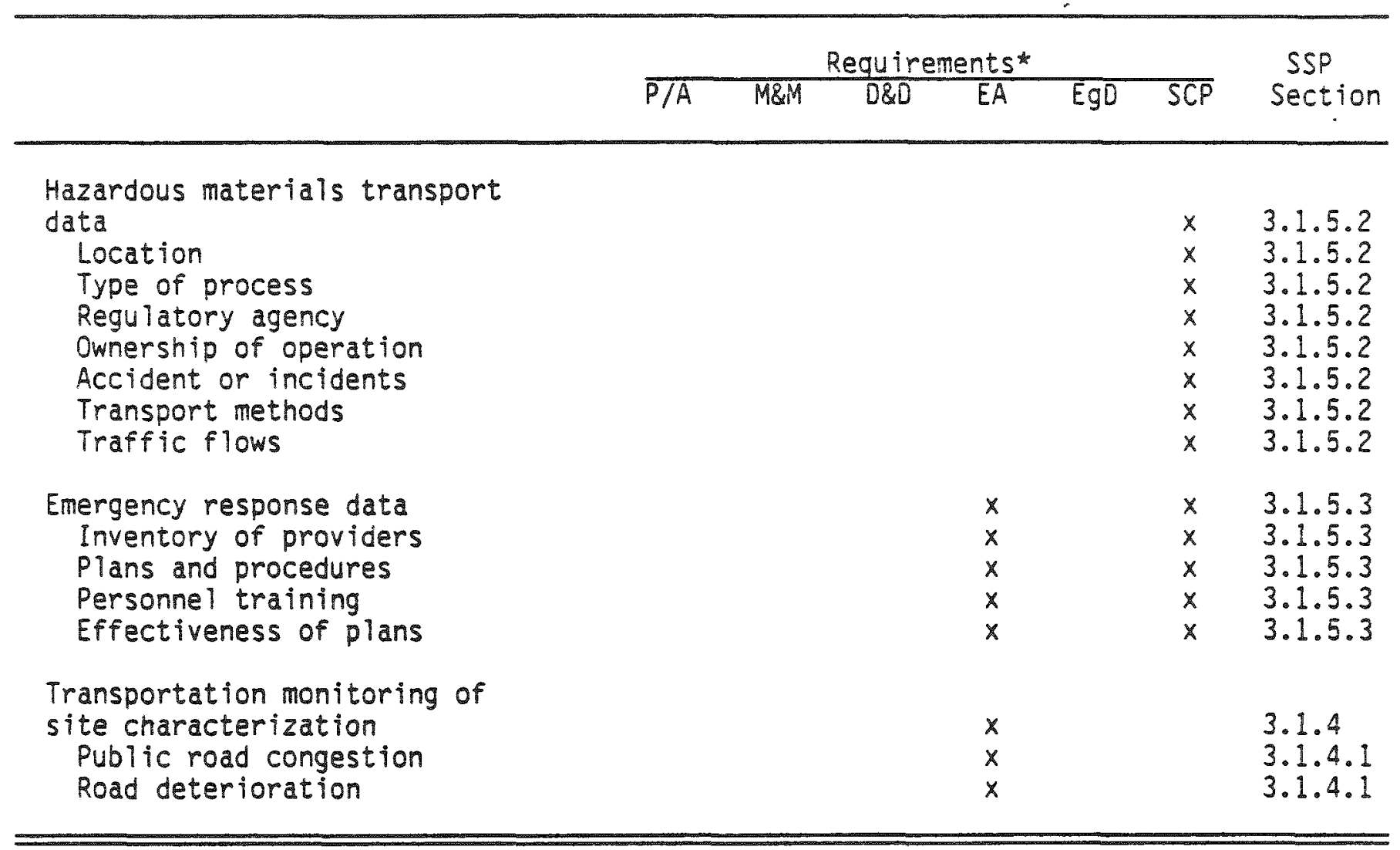

\footnotetext{
*Requirements include: $P / A=$ Permits and Approvals

The studies defined herein under SCP and EgD requirements support site characterization activities undertaken to establish site geologic conditions. Nonsite characterization studies (site investigations) are those predominantly concerned with surface conditions and address the $P / A, M \& M, D \& D$, and EA requirements. Site investigations may be performed before or during site characterization.
} 


\subsection{TECHNICAL DESIGN OF THE STUDY}

This chapter presents the design and rationale along with methods for collecting field data that will support analysis of the transportation characteristics relating to the Deaf Smith County site. The transportation characteristics include highway and rail transportation considerations in the vicinity of the site and extending outward to the borders of the state. Also included are Gulf Coast ports for receipt of water-borne barge transportation. The scope of activities included in this study has been restricted to considerations within the State of Texas. Considerations external to Texas will be the responsibility of the Civilian Radioactive Waste Management (CRWM) National Transportation Program (NTP).

Transportation, as a descriptive term, includes the movement of all personnel, materials, and supplies to and from the site, including high-level nuclear waste being transported to the site and excess mined salt being transported away from the site.

Chapter 3 is divided into seven sections. Section 3.1 describes the study design, addressing the transportation-related field programs, their location, and the data they will produce. Section 3.2 explains the technical rationale behind the transportation field program. Section 3.3 explains how the field program data will be collected, giving information on equipment and methods, and rationale for their selection. Section 3.4 lists and briefly describes the applicable technical procedures to carry out data collection using the methods described in Section 3.3. Section 3.5 1ists and discusses the equipment and materials required by the technical procedures. Section 3.6, explains how the field data will be analyzed, where analysis is required. The last section, Section 3.7 , explains how information from the data analyses will be applied.

\subsection{DESCRIPTION OF THE STUDY DESIGN}

Studies for the transportation programs are organized into rail-corridor characterization: highway-corridor characterization; alternative-statewideroute characterization: monitoring studies: and aircraft-overfight, hazardous-materials transportation, and emergency-response-preparedness characterization. The site study plan (SSP) also evaluates salt-repositorytransportation effects, radiological-exposure risk due to transportation, and required upgrades and improvements to statewide routes to accommodate site transportation needs. Because these evaluations involve analysis of collected data, they are discussed in Sections 3.6 and 3.7. Data Analys is and Application of Results, respectively.

The study design is concerned with two basic geographical subdivisions. The first one is the vicinity of the site, which refers to an area within a roughly $80-\mathrm{km}$ (50-mile) radius surrounding the site boundary (see figure $3-1$ ). This area includes the communities in the vicinity which will be of primary concern, including the city of Amaril10, without including any area outside of the state boundaries. The other subdivision is the region, which in the case of the SSP refers to the State of Texas, but not to areas in adjoining states, or Mexico. Where the term "corridor" is used, it will mean a transportation 


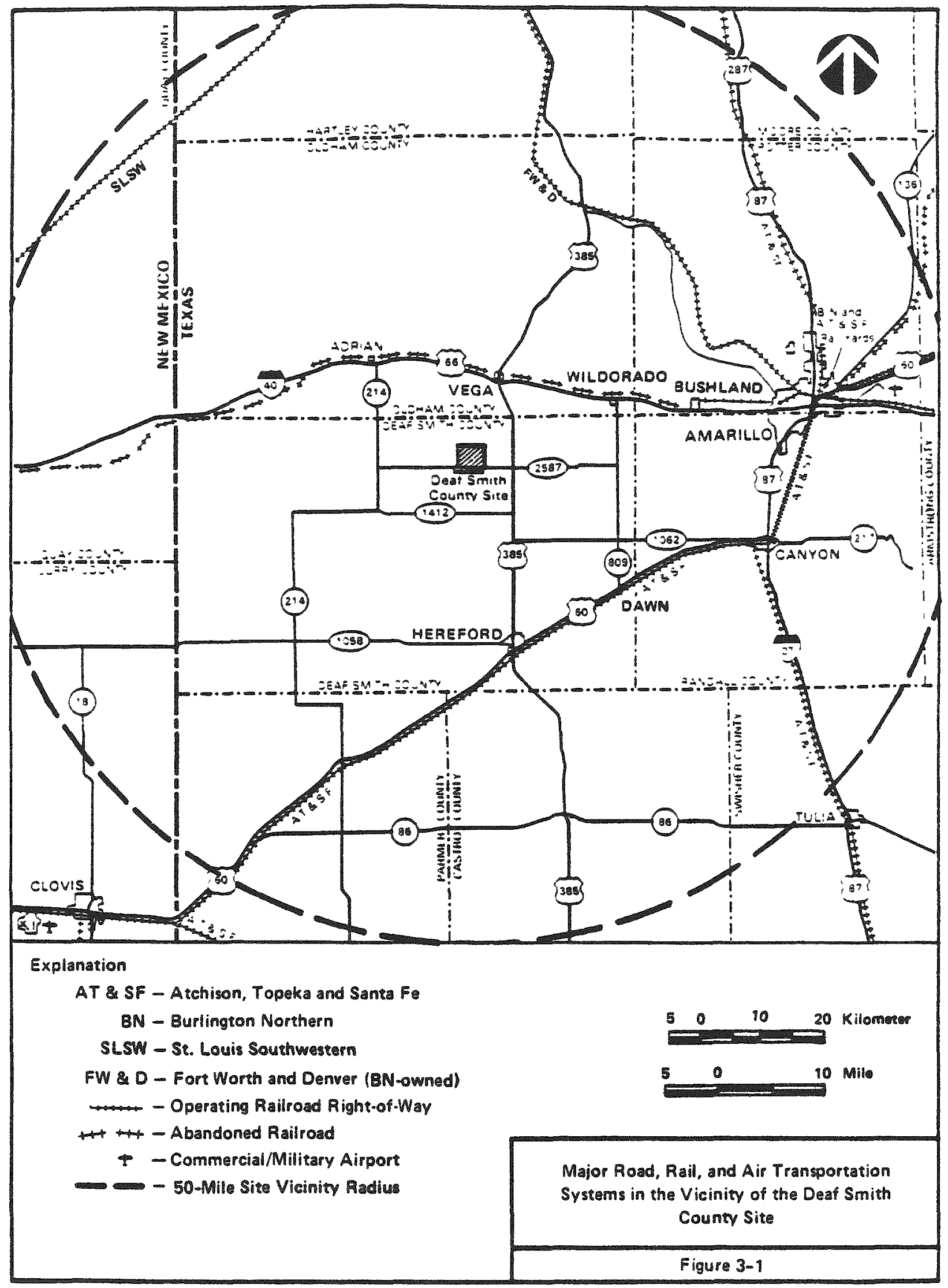


zone within the site vicinity where transportation-related data will be intensively developed and where new construction of transportation facilities, such as a railroad spur, may be required. Where "route" is used, it will mean a transportation path that could feature more than one transportation mode (e.g., barge offloading to rail) utilizing both existing infrastructure and newly-constructed facilities. A route, which could transit the entire state of Texas, would link to a corridor or corridors within the site vicinity, and would thus connect to the site.

A complete route, therefore, would extend either from an origindestination point within Texas, or a point on the Texas State border defined by the National Transportation Program (NTP), to the Deaf Smith County site boundary. Transportation facilities and data within the site boundaries or outside the state of Texas are not included in the scope of this SSP.

\subsubsection{Design of Rail-Corridor-Characterization Studies}

The site is presently not accessible by rail. Therefore, rail-corridorcharacterization data must be obtained, including field data adequate to characterize the construction of a new rail spur to the site.

The rail-corridor-characterization studies will be confined to the vicinity of the site, and will interface with regional (statewide) railtransportation-data-collection activities described in Section 3.1.3, Design of Alternative-Statewide-Route-Characterization Studies.

A number of alternative access corridors have already been investigated to determine the effects that would result from the construction and operation of a rail access line (NUS Corporation, 1986). One or more preferred cor-

- ridors will be chosen for more detailed study, according to the Environmental Assessment (DOE, 1986). Six potential corridors are discussed in the Environmental Assessment and are depicted in Figure 3-2.

Rail-corridor characterization will be accomplished through collecting information on

- Existing rail systems in project vicinity

- Projections of repository generated traffic

- Alternative-rail-corridor environmental conditions

- Preferred-rail-corridor environmental conditions.

The programs for collecting this information are described in the following sections.

\subsubsection{Survey Existing Rail Systems \\ in the Project Vicinity}

Existing rail-system characteristics that are important in influencing rail transportation in the site vicinity will be surveyed. This survey will include conducting a field reconnaissance, confirming rail configurations with aerial photography, reviewing previous rail-corridor studies, ascertaining the 


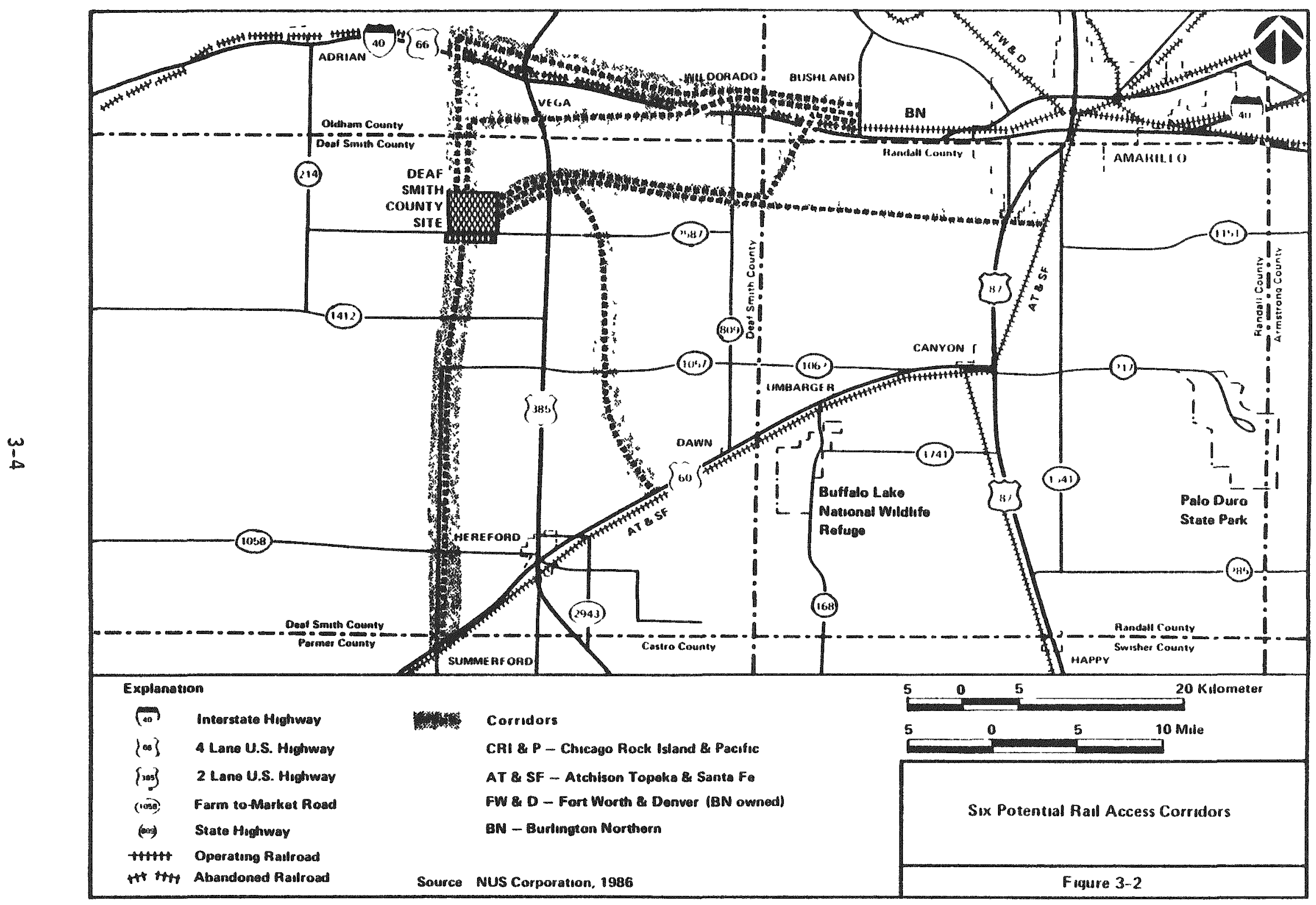


condition of existing rail facilities, characterizing conditions and operations at Amarillo railyards, and interviewing appropriate rail companies, agencies, and associations to obtain railroad technical and operating data. Appropriate procedures will be followed to ensure that advance arrangements are made and permission received before investigators conduct data-gathering activities on railroad property.

Conduct field Reconnaissance. A field reconnaissance will be conducted in the site vicinity by transportation engineers. The following data will be obtained by touring the vicinity, contacting key authorities and organizations and visiting transportation facility installations:

- State, county, municipality, and commercial maps showing railroad facilities in the vicinity

- Photographs of principal railroad features, such as terminuses, junctions, major bridges, railyards, utilities, and crossings

- Identification, addresses, and telephone numbers of key local government and industry officials with responsibility for railroad construction, operations, maintenance, and regulation

- Verification of ownership of existing rail facilities.

Confirm Rail Configuration. Aerial photographs of the vicinity will be obtained and compared to maps of the rail system to confirm the rail system configuration in the vicinity. The following data will be obtained:

- Aerial photograph mosaics at an appropriate scale to conform to available mapping of the vicinity

- Up-to-date map(s) of all railroad facilities in the vicinity, at an appropriate scale. These maps will be produced as part of this SSP activity.

Review Previous Rail-Corridor Studies. A literature search will be conducted, and previous rail-corridor studies of the vicinity will be obtained and reviewed.

Obtain Existing Infrastructure, Traffic, Accident and Institutional Data. Infrastructure and traffic data will be obtained from published data and interviews with government-agency personne 1, transport companies, and trade associations. These information resources will include the Railroad Commission of Texas, the BN, the AT\&SF, and the Association of American Railroads. Published data and company and agency records will be obtained, yielding the following information:

- Track, roadway, and route characteristics and condition data

- General alignment and profile

- Type of tracks - single or multiple

- Type of signaling

- Weight of rail - welded or jointed

- Ballast, subballast, tie, and rail condition 
- Major structures (bridges and tunnels) and condition

- Four-axle and six-axle load limits

- Impaired clearances - clearance diagrams

- Road crossings - number and type of protection.

- Right-of-way width

- Line capacity

- Planned changes or improvements

- Traffic-operations data

- Freight volumes (trains, carloads, and tons)

- Major commodities (including hazardous materials)

- Passenger trains

- Locomotive, crew, and interchange locations

- Track-maintenance levels (Federal Railroad Administration class of track)

- Traffic control

- Interchange-point data

- Location

- Operation

- Proximity to population

- Type of interchange (switching yard or crew-change point)

- Accident data

- Location and direction

- Cause

- Damage, injuries and fatalities

- Date and time

- Hazardous material involvement

- Rail company policies, programs, and plans

- Hazardous-materials-traffic policies

- Safety programs, including emergency-response capabilities and plans

- Any planned mergers, sellouts, or line abandonments in the vicinity.

Ascertain Condition of Existing Rail Facilities. After reviewing the data collected above, field inspections will be conducted to ascertain conditions of existing rail facilities to the extent deemed advisable. visual inspections supplemented by field notes and photographs will document the extent of visible deterioration or loss of serviceability of the following:

- Rails, joints, and other hardware

- Ties, spikes, and spreader bars

- Ballast, embankments, and excavations

- Signal systems

- Grade crossings and crossing protection systems

- Fencing, cattle guards, and gates

- Bridges, piers, and abutments

- Access and service roads. 
Characterize Conditions and Operations at Amarillo Railyards. The Atchison, Topeka, and Santa Fe (AT\&SF) railroad and the Burlington Northern (BN) railroad operate railyards in Amari110. Most rail shipments destined for the site or originating from the site, will pass through these railyards. The railyards will be visited and inspected, and appropriate individuals who can provide railyard technical and operational data will be identified and interviewed. The following railyard data will be gathered:

- Average stop times for hazardous and nonhazardous freight cars

- Origin-destination characteristics for freight traffic

- Interline transfer procedures and characteristics

- Permanent and transient railyard-worker populations and their residence locations

- Physical track layout, including maps

- Track and switch characteristics

- Lighting, communication, and control-system characteristics

- Railyard capacity determinations

- Future expansion and modification plans

- Other data that may be identified.

\subsubsection{Assembly of Repository-Generated Traffic Data} traffic:

There are at least two sources for projections of repository-generated

- Repository Standard Review Plan

- Environmental Assessment Data Base.

These sources will be evaluated and data will be obtained to determine the expected increase in traffic due to repository activities. Documented program changes will also be considered. Repository-generated traffic will relate to construction and operations. The number of employees and visitors: the amount of incoming materials, supplies, equipment, and radioactive wastes; and the amount of outbound salt and other wastes will be considered. This data will be put into the same format as the remainder of data collected for this SSP.

\subsubsection{Identification of Rail-System \\ Alternative Corridors}

The identification of alternative rail-system corridors is not a specified SSP activity. Corridor selection will be performed by other CRWM 
Program activities. Engineering considerations, as well as environmental factors, will apply in alternative rail corridor identification. It is necessary that this identification be accomplished prior to performing the subsequent SSP data-gathering activities described in Section 3.1.1.4. Figure 3-2 shows rail corridors identified in the EA.

\subsubsection{Determination of Alternative Rail- Corridor Environmental Conditions}

Once the alternative rail corridors have been identified, an interdisciplinary study will be conducted to determine the environmental elements that could be potentially affected by access-route development. These elements to be studied will include

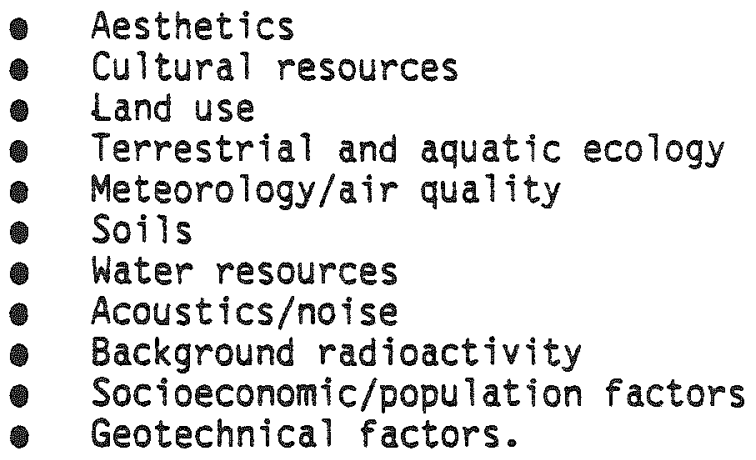

Data will be collected to enable comparisons to be. made among the proposed alternative corridors.

Specialists from appropriate nontransportation disciplines will collect applicable data along each corridor in a manner consistent with subsequent SSP drafts defining their activities during site characterization. These activities will be coordinated by Transportation SSP personnel to facilitate data collection. The alternative rail-corridor environmental characterization will be conducted as an integral part of concurrent evaluations of the adjoining repository site.

\subsubsection{Collection of Data to Confirm Preferred Rail Corridor}

It will be necessary to reduce the number of alternative rail corridors to one preferred corridor within which the site rail-access spur will be constructed. The selection of a preferred rail-spur corridor is not a specified SSP activity: however, this SSP will provide environmental data to support the route selection. This selection will be accomplished by other CRWM Program activities. Engineering considerations, as well as environmental factors, will apply in rail corridor selection. Once a preferred corridor has been selected for the environmental contractors, an interdisciplinary study similar to that described in Section 3.1.1.4 will be conducted in greater detail to confirm environmental conditions. 
In addition to the environmental data gathered by the interdisciplinary study, topographical surveying and mapping of the preferred rail corridor will be obtained.

Nontransportation specialists from other project disciplines will collect the applicable data with the exception of topographical surveying and mapping, for which the transportation discipline will assume responsibility. The entire preferred corridor will be mapped (to a scale to be determined) to support further project-related activities within the corridor, including rail-spur design engineering and construction. Appropriate map control points will be established by survey, tied in to the survey-control grid system in use in the vicinity, and monumented.

Nontransportation data-gathering activities within the preferred rail corridor wil1 be coordinated by Transportation SSP personnel.

\subsubsection{Design of Highway-Corridor- Characterization Studies}

Highways in the site vicinity may be used to transport radioactive and nonradioactive wastes, construction materials, operating supplies and personnel. Therefore, highway-corridor-characterization data must be obtained to provide a basis to adequately assess the transportation effects on roads and highways in the site vicinity.

Highway-corridor-characterization studies described in this section of the SSP will be restricted to the vicinity of the site, and will be interfaced with regional (statewide) multi-modal-transportation-data-collection activities described in Section 3.1.3. Design of Alternative Statewide-RouteCharacterization Studies.

Highway-corridor characterization will be accomplished through collecting information on

- Existing and future roadway systems in the project vicinity

- Projections of repository-generated traffic.

The programs for collecting this information are described in the following sections.

\subsubsection{Survey of Existing Roadway Systems in the Project Vicinity.}

Existing roadway characteristics that are important in influencing transportation in the site vicinity will be surveyed. This survey will include conducting a field reconnaissance, confirming roadway configuration with aerial photos, ascertaining the condition of existing roadway infrastructure, and interviewing appropriate agencies and associations to obtain highway technical and use data.

Conduct field Reconnaissance. A field reconnaissance will be conducted in the site vicinity by transportation engineers. The following data will be 
obtained by touring the vicinity, contacting key authorities and organizations, and visiting transportation facility installations:

- State, county, municipality, and commercial maps showing roads and highways in the vicinity

- Photographs of principal features, such as major intersections, bridges, and crossings for railroads, utilities, etc.

- Identification, addresses, and telephone numbers of key local government and industry officials with responsibility for roadway construction, operations, maintenance, and regulations.

Roadway Configuration Confirmation. Aerial photographs of the vicinity will be obtained and compared to existing maps of the road and highway system to confirm system configuration in the vicinity. The following data will be developed:

- Aerial photograph mosaics at a scale to be determined to conform to available mapping of the vicinity

- Up-to-date map(s) of all roads in the vicinity, scale to be determined. These maps will be produced as part of the SSP activity. The road maps and the railroad maps discussed in Section 3.1.1.1 may be combined into one set of vicinitytransportation-infrastructure maps.

Obtain Existing Infrastructure, Traffic, Accident, and Institutional Data. Infrastructure and traffic data will be obtained from published data and interviews with government agency personnel, transport companies, and trade associations. These information resources will include the Texas Department of Highways and Public Transportation, the Texas Department of Public Safety, the Panhandle Regional Planning Commission, and the North Central Texas Council of Governments. Published data and company and agency records will be obtained, yielding the following information for the road segments identified above:

- Federal Highway Administration classification and lengths for each roadway segment

- Driving times

- Roadway descriptions

- Horizontal alignment and profile

- Number of lanes

- Lane widths

- Type and thickness of roadway surfacing

- Divided or undivided

- Median description

- Turning lanes and locations

- Shoulder widths

- Shoulder surfacing

- Access controls

- Right-of-way widths and type of fencing 
- Major structures - number, type, location, and length

- Design speed and posted speeds

- Weight or clearance restrictions

- Major intersections and congested areas

- Railroad crossings and type of protection

- Population density along routes

- Number and location of adjacent schools and hospitals

- Types of development through which routes pass

- Roadway capacities and level of service

- Roadway and structure conditions

- Maintenance levels or deficiencies

- Planned improvements and timing

- Adjacent complexes involving major military and industrial operations likely to involve hazardous materials

- Traffic controls (signs, signals, pavement markings)

- Traffic

- Average annual daily traffic

- Peak hour traffic

- Auto to truck ratios

- Seasonal nature

- Speeds and speed limits

- Accident data

- Location and direction

- Cause

- Damage, injuries, and fatalities

- Date and time

- Hazardous material involvement

- Vehicle type (single vehicle, cycle, pedestrian, etc.)

- Other transportation considerations

- Local motor carriers in area

- Services provided - bulk, liquid, truckload, and less-thantruckload

- Public-passenger services available - type, routes, and frequencies

- Truck travel restrictions.

Ascertain Condition of Existing Roadway Infrastructure. After reviewing the data collected above, field inspections will be conducted to ascertain conditions of existing roadway infrastructure to the extent deemed advisable. Visual inspections supplemented by field notes and photographs will establish the extent of visible deterioration or loss of serviceability of the following:

- Pavements, shoulders, and medians

- Curbs, gutters, and sidewalks (where existing)

- Drainage cuiverts and ditches

- Bridges and structures

- Embankments, cut slopes, and guardrails

- Signs, traffic signals, and lighting. 
The field inspection will be limited to the following:

- I-40 between Amaril10 and the New Mexico State line

- US 385 between Vega and Hereford

- I-27/US 87 between Amarillo and Canyon

- US 60 between Canyon and Hereford

- State Route 809 between Dawn and Wildorado

- FM Road 1062 between Canyon and US 385

- FM Road 2587 between State Route 809 and the site.

\subsubsection{Assembly of Repository-Generated Traffic Data} traffic:

There are at least two sources for projections of repository-generated

- Repository Standard Review Plan

- Environmental Assessment Data Base.

These sources will be evaluated and data will be obtained to determine the expected increase in traffic due to repository activities. Documented program changes will also be considered. Repository-generated traffic will relate to construction and operations. The number of employees and visitors; the amount of incoming materials, supplies, equipment, and radioactive wastes; and the amount of outbound salt and other wastes will be considered. This data will be put into the same format as the remainder of data collected for this SSP.

\subsubsection{Design of Alternative Statewide} Route Characterization Studies

Statewide-multi-modal-transportation-route characterization will be accomplished through collecting information for the selected routes on

- Existing statewide transportation infrastructure

- Statewide accident and incident data

- Alternative route environmental conditions

- Preferred route environmental conditions.

The identification of routes for these data-gathering investigations will not be determined as part of this SSP.

The programs for collecting this information are described in the following sections.

\subsubsection{Identification of Statewide Multi-Modal- Transportation Routes}

It is necessary for alternative routes to be identified and selected, prior to proceeding with SSP data-gathering activities described in the following sections. The identification of alternative statewide multi-modal 
routes is not an SSP function. This will be accomplished by other CRWM Program activities and the State of Texas. Engineering considerations, as well as environmental factors, will apply in statewide route identification.

\subsubsection{Survey of Existing Statewide Transportation Infrastructure}

Figure 3-3 illustrates the major highways, railways, and seaports serving the state. It is expected that alternative multi-modal routes to the site vicinity will be selected from those illustrated on Figure 3-3. With alternative routes identified, the affected transportation infrastructure will be surveyed and data gathered to define rail systems, roadway systems, and port facilities.

Rail System Descriptions. The rail systems to be incorporated into the alternative statewide-multi-modal routes will be surveyed in a manner similar to that described in Section 3.1.1.1 for the rail corridors in the site vicinity. Field reconnaissance activities will be performed along each rail alignment; aerial photographs will be taken of each alignment; rail companies, agencies, and associations knowledgeable in the condition of the identified rail routes will be interviewed to obtain technical and operating data: conditions of the rail facilities will be ascertained at selected locations identified as a result of the previous activities; and railyards located along the alignments will be characterized.

The following data will be obtained for the identified rail alignments on a statewide basis:

- Field reconnaissance data

- State, county, municipality, and commercial maps showing railroad facilities along identified routes

- Photographs of principal railroad features, such as terminuses, junctions, major bridges, raliyards, and crossings

- Identification, addresses, and telephone numbers of key local government and industry officials with responsibility for railroad construction, operations, maintenance, and regulation

Aerial photography data

- Aerial photograph mosaics at a scale to be determined to conform to available mapping of the alignments

- Up-to-date maps of all railroad facilities along with routes, scale to be determined. These maps will be produced as part of this SSP activity.

- Characterization of railyards data

- Average stop times for hazardous and nonhazardous freight cars

- Origin-destination characteristics for freight traffic

- Interline transfer procedures and characteristics

- Permanent and transient railyard worker populations and residence locations

- Physical track layout, including maps

- Track and switch characteristics

- Lighting, communication, and control system characteristics. 


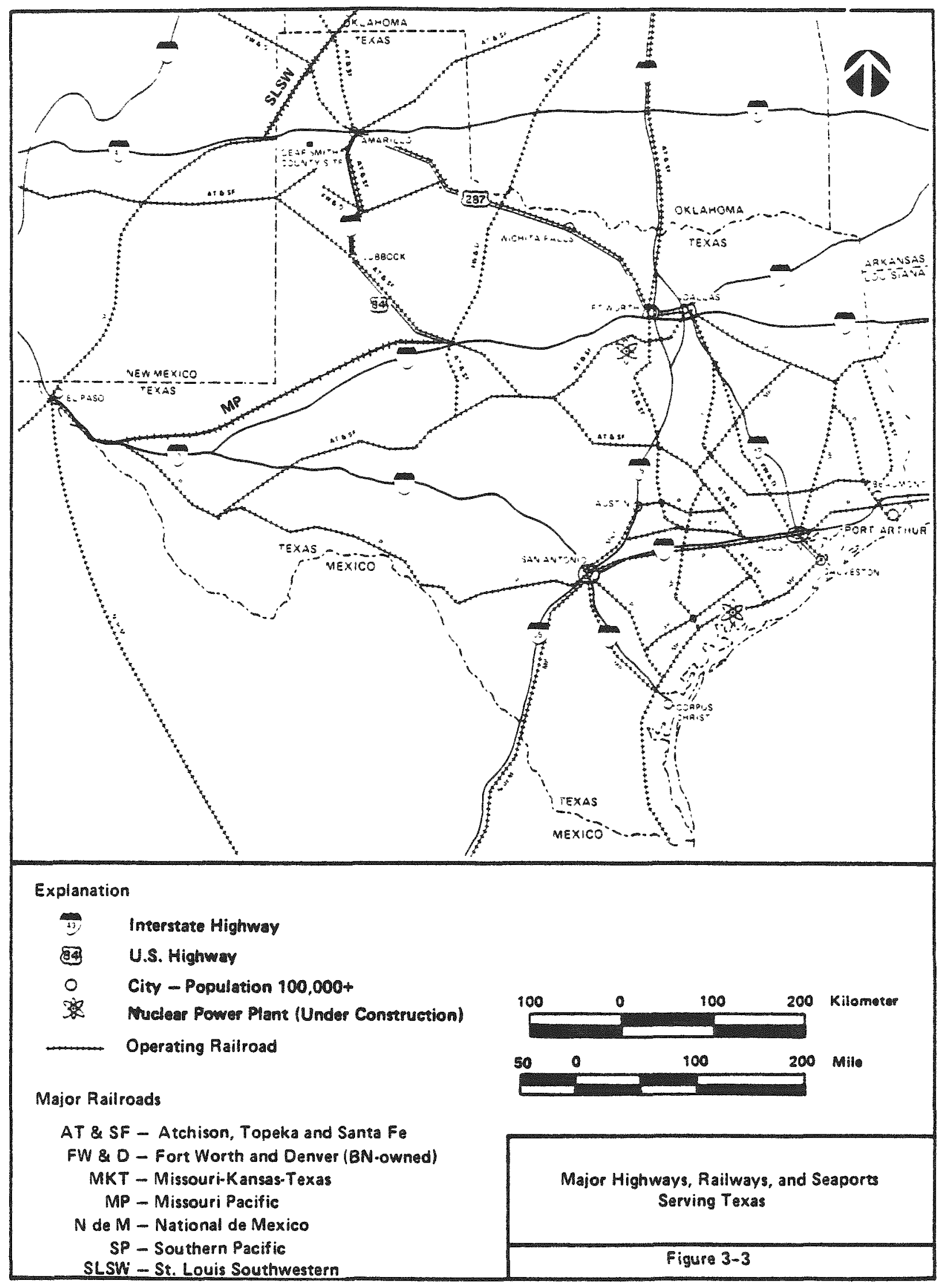


- Railyard capacity determinations

- Future expansion/modification plans

- Other data that may be identified

- Data to be obtained from contacts with cognizant pail companies, agencies, and associations identified during field reconnaissance, or from literature research

- Track, roadway, and route condition data

a) Horizontal alignment and profile

b) Single/multiple tracks

c) Type of signaling

d) Weight of rail - welded/jointed

e) Ballast, subballast, tie, and rail condition

f) Major structures (bridges and tunnels) and condition

g) Four-axle and six-axle load limits

h) Impaired clearances - clearance diagram

i) Road crossing - number and type of protection

j) Right-of-way width

k) Line capacity

1) Planned changes or improvements

- Traffic operations data

a) Freight volumes (trains, carloads, tons)

b) Major commodities (including hazardous materials)

c) Passenger trains

d) Locomotive, crew, and interchange locations

e) Track maintenance levels (Federal Railroad Administration class of track)

f) Traffic control

g) Local service

- Interchange points
a) Location
b) Operation
c) Proximity to population
d) Type of switching yard or crew change point

- Each rail company's policies, programs, and plans

a) Hazardous material traffic policies

b) Safety programs including emergency response capabilities and plans

c) Any planned mergers, line abandonments in the vicinity, or sale of the company

- Existing condition data to be obtained at locations identified during field reconnaissance and by evaluation of data collected from agency contacts and other research. Visual inspections supplemented by field notes and photographs will establish the extent of visible deterioration or loss of serviceability of the following:

- Rails, joints, other hardware

- Ties, spikes, spreader bars

- Ballast, embankments, excavations

- Signa 1 systems

- Grade crossings, crossing protection systems

- Fencing, cattle guards, gates

- Bridges, piers, abutments

- Access and service roads 
Roadway System Descriptions. The roadway systems to be incorporated into the alternative statewide-multi-modal routes will be surveyed in a manner similar to that described in Section 3.1.2.1 for highway transportation corridors in the site vicinity. Field reconnaissance activities will be performed along each roadway alignment; agencies and associations-knowledgeable in the condition of the identified highway routes will be interviewed to obtain technical and operating data; and conditions of the roadway infrastructure will be ascertained at selected locations identified as a result of the previous activities.

The following data will be obtained for the identified highway alignments on a statewide basis:

- Field reconnaissance data

- State, county, municipality, and commercial maps showing roads and highways along identified routes

- Photographs of principal highway features, such as principal intersections, major bridges, and crossing for railroads, major utilities, etc.

- Identification, addresses, and telephone numbers of key local government and industry officials with responsibility for roadway construction, operations, maintenance, and regulation along the identified routes

- Aerial photography data

- Aerial photograph mosaics at a scale to be determined to conform to avallable mapping of the alignments

- Up-to-date maps of a 11 roads along the routes, scale to be determined. These maps will be produced as part of this SSP activity.

- Data to be obtained from contacts with cognizant agencies and associations identified during field reconnaissance or from literature research.

- Federal Highway Administration classification and lengths for each roadway segment

- Driving times

- Roadway descriptions

a) General alignment and profile

b) Number of lanes

c) Lane widths

d) Type and thickness of roadway surfacing

e) Divided/undivided

f) Median description

g) Turning lanes - locations

h) Shoulder widths

i) Shoulder surfacing

j) Access controls

k) Right-of-way width

1) Major structures - number, type, location, length

m) Design and posted speeds

n) Weight or clearance restrictions

o) Major intersections, congested areas 


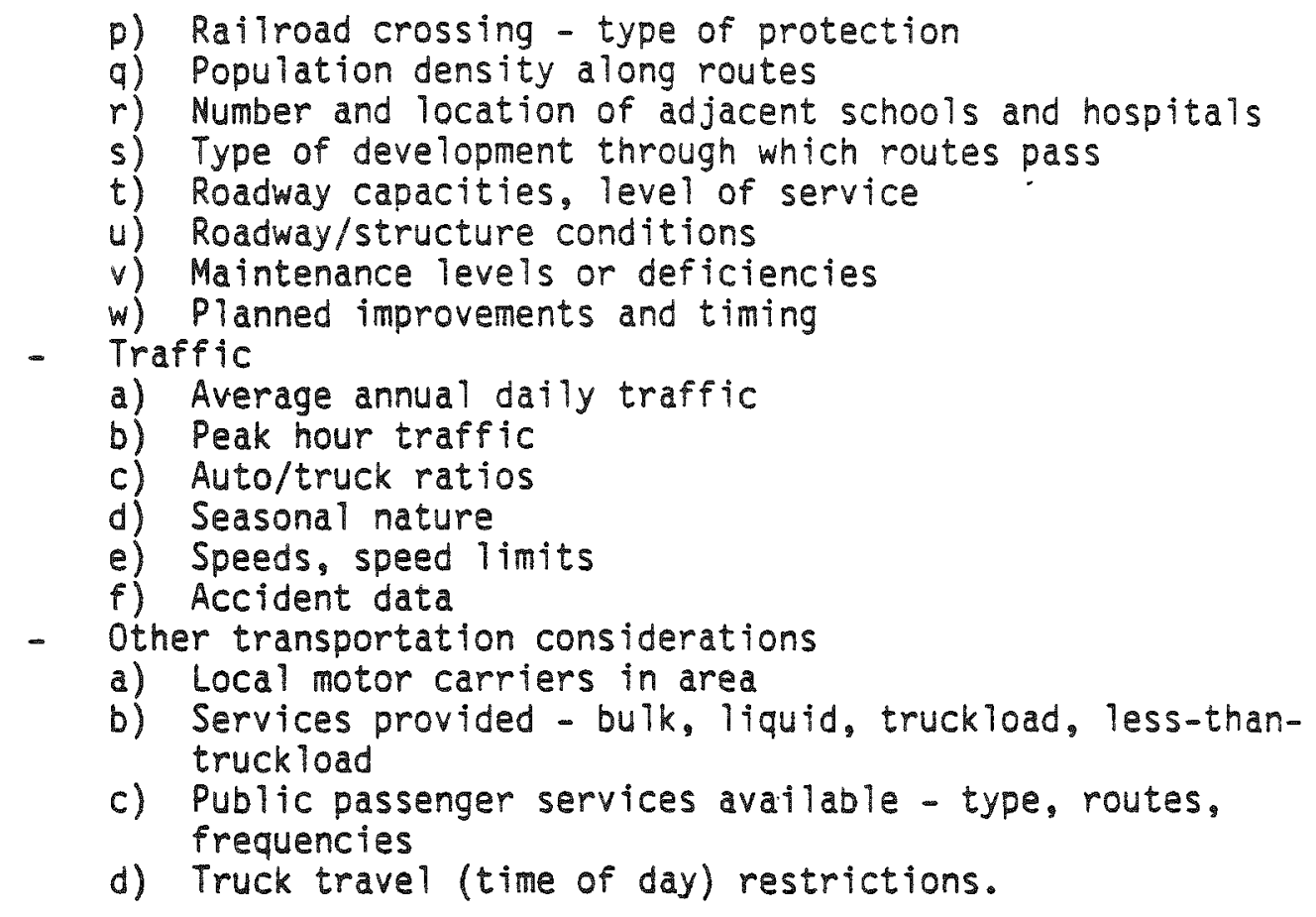

- Existing condition data to be obtained at locations identified during field reconnaissance and by evaluation of data collected from agency contacts. Visual inspections supplemented by field notes and photographs will establish the extent of visible deterioration or loss of serviceability. of the following:

- Pavements, shoulders, medians

- Curbs, gutters, sidewalks (where existing)

- Drainage culverts, ditches

- Bridges and structures

- Embankments, cut slopes and guard rails

- Signs, traffic signal, lighting

Port Facility Descriptions. The Gulf Coast ports identified as alternative entry locations for the statewide multi-modal routes featuring barge transportation will be surveyed and characterized. This characterization will occur in accordance with the NTP's schedule, and is a constraint on SSP studies of Texas transportation routes. The ports to be characterized include facilities at the port cities of Corpus Christi. Houston. Galveston, and Port Arthur. Characterization activities within the scope of this SSP will consist of data gathering by means of a field reconnaissance of each port, aerial photography, and contacts with the U.S. Army Corps of Engineers, the U.S. Coast Guard, and public and private port and maritime authorities. Published reports, records, and interviews will yield information to establish the capability of the various port installations to handle barge transport of spent fuel and high-level radioactive waste. 
The following data will be obtained for the specified ports:

- Field reconnaissance data

- Identity and ownership of individual port installations at each port city

- Photographs of principal features such as docks, wharves, cranes, laydown areas, access routes for road and rail transportation, channels, berthing areas and turning basins, etc

- Available mapping of port facilities, land transport links and marine channels, basins, etc

- Identification, addresses, and telephone numbers of key local government and industry officials with responsibility for port supervision

- Aerial photography data

- Aerial photograph mosaics at appropriate scale to conform to available maps

- Up-to-date maps of each port which will be produced as part of this SSP activity

- Contacts with port and maritime agencies and officials

- Location of port facilities

- General description

- Distance from site

- Authorized and maintained channel depths and widths

- Docks and wharves

- Lock locations, size, and locking times (if any)

- Highway and rail connections

- Planned improvements

- Traffic and operations

- Volumes - tons, docking, and number of tons per period

- Maximum tow or ship sizes

- Currents, tides, and waves

- Maintenance dredging requirements

- Clearances

- History of weather disruptions

- Existing condition data at each port. Visual inspections supplemented by field notes and photographs will establish the extent of visible deterioration or loss of serviceability of the following:

- Wharves and docks

- Cranes

- Laydown areas

- Landside transport links

- Marine works. 


\subsubsection{Survey of Accident and Incident Data}

Available accident and incident data will be collected from Federal, State, local, and carrier sources for port, railroad, and highway transportation. Data obtained will include vessel or vehicle type; accident time and season; injuries, fatalities, and property damage sustained; relation to weather conditions: causative factors; and cargo involved. Special note will be made of accidents or incidents involving radioactive and hazardousmaterials cargoes. These data may be collected during the data collection activities for railroads, highways, and ports described in Section 3.1.3.2. All accidents and incidents for which data are gathered will be identified by location and referenced appropriately to aerial photography activities. Accident and incident data will be collected for a timeframe not to exceed the most recent 5 preceeding years for which data are available. Data collection will be restricted to the identified statewide-multi-modal routes.

\subsubsection{Determination of Alternative Multi-Modal Route Environmental Conditions}

Once the alternative statewide-multi-modal routes have been identified, an interdisciplinary study, similar to that outlined in Section 3.1.1.3, but to a less-intensive level of detail appropriate to the large scope of the areas requiring investigation, will be conducted to determine the environmental elements that could be potentially affected by transportation. The aspects to be studied will include:

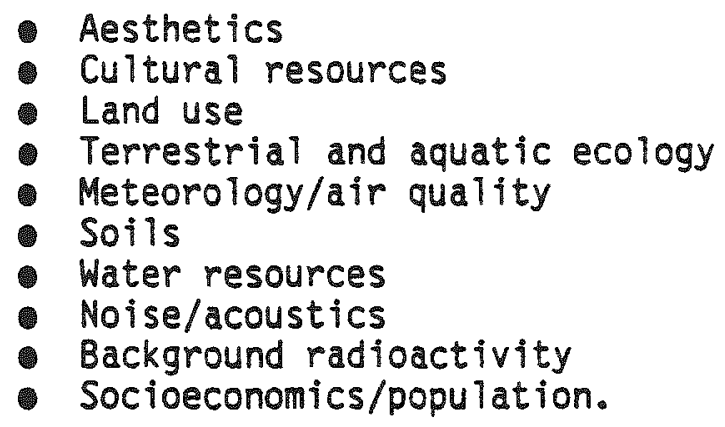

Data will be collected for all the above categories to enable comparisons to be made among the proposed alternative routes, but greater emphas is will be placed on land use and socioeconomics than on the other disciplines. The data collected will also permit the determination of constraints for shipments and radioactive risk. Data such as weather conditions, proximity to sensitive environmental areas, and water-way environmental characteristics will be used to determine if constraints exist along the routes. Land use data, such as proximity to schools, hospitals, and adjacent industries involving hazardous materials and land use plans will similarly provide information on potential constraints to shipping radioactive waste. Population and employment data will be collected along the potential routes using U.S. Census Bureau reports and information available from State and regional planning agencies. Where the alternative statewide routes approach the site via rail corridors in the site vicinity, environmental data collected for rail corridors within the vicinity as described in Section 3.1.1.3 will be incorporated as appropriate. 
Where the alternative routes approach the site via roadways in the site vicinity, the data will be collected along the specified route(s) up to the site boundary, since data gathering for roadway corridors is not included in the site vicinity design.

Specialists from appropriate nontransportation disciplines will collect applicable data within a corridor along each route in a manner consistent with subsequent drafts of the SSPS defining their activities at the site during site characterization. A corridor extending one-haif mile on either side of each aiternative route will be studied. This width is consistent with the corridor widths established in the EA (See Section 5.1.2.2). These activities will be coordinated by Transportation SSP personnel to facilitate data collection. The alternative-corridor environmental assessments may be conducted concurrently with evaluations of the repository site vicinity and adjoining transportation corridors, or may be conducted separately due to the extensive areas covered by the statewide corridors.

\subsubsection{Collection of Data to Confirm Preferred Statewide Multi-Modal Routes}

It will be necessary to reduce the number of alternative statewide routes to one or more preferred routes to the site from each of the principal points of entry into the state and from the in-state generator locations. The selection of preferred routes is not an SSP activity. This will be accomplished by other program activities and the State of Texas. Engineering considerations, as well as environmental factors, will apply in preferred route selection. Once the preferred routes have been selected, an interdisciplinary approach similar to that described in Section 3.1.3.4 above will be conducted in greater detail to confirm environmental conditions, for subsequent impactassessment determinations.

\subsubsection{Design of Monitoring Studies}

To provide the data necessary to support the evaluation of transportation effects in the site vicinity, the traffic effects of site characterization activities will be monitored. Repository-site-characterization-transportation effects will be determined by collecting information on public road congestion in the project vicinity and traffic specifically related to site-characterization activities, as discussed in the following sections.

\subsubsection{Monitor Public Road Congestion in the Project Vicinity}

During site characterization, a substantial increase in public road congestion in the project vicinity is expected. Monitoring this increase and correlating the increase to site-characterization activities will yield valuable data for projecting effects and determining mitigation needs that will arise from site-repository construction and operation. 
Monitoring of public road congestion in the project vicinity will be accomplished by determining pre-site-characterization trends in traffic congestion and accident rates, obtaining traffic counts and congestion measurements at selected locations in the project vicinity during site characterization, and assembling accident reports in the project vicinity during site characterization.

Determine Pre-site-Characterization Trends. Data will be collected from State, Federa T, and local government agencies and principal carriers using the public roads regarding pre-site-characterization trends in traffic congestion and accidents. Data will be collected for a timeframe not to exceed the most recent 5 preceding years for which data are available. Data collection will be restricted to the identified roads and road segments listed in Section 3.1.2.1. Survey of Existing Roadway Systems in the Project Vicinity.

Data to be obtained will include (as available)

- Daily average traffic levels in vehicles per hour, classified by trucks and autos

- Daily peak traffic levels, for trucks and autos

- Average travel times for selected times of day

- Accidents

- fatal and nonfatal

- type

- involving hazardous materials

- Seasonal effects of weather and agricultural activity.

Records will be assembled in computerized format for ease of reporting, summarization, and retrievability.

Traffic Counts and Congestion Monitoring. Before major site characterization field work begins, to establish conditions prior to site characterization field studies, traffic volumes on public roads in the vicinity of the site will be manually counted on random days during morning and afternoon peak periods to establish a baseline for determining at later times whether traffic related to characterization is significantly exceeding anticipated levels. Traffic counts will also be taken by automatic equipment.

Monitoring for congestion and traffic problems will also be conducted after the beginning of major site characterization field work to ascertain increases in accident rates at peaks in site characterization activities. other indicators of congestion that will be investigated on random days during site characterization include intersection delays, vehicle-turning movements, and travel times. Traffic counting and congestion measuring will continue during site characterization. 
Figure 3-4 illustrates the locations for traffic count and congestion measuring activities. The data to be obtained will include

- Traffic counts (manual)

- At least 9-hour counts (to include both peaks) classified by heavy trucks, busses, large RV's, small pickups and automobiles

- If substantial incentives are found to exist, consideration will be given to omitting all manual counting in favor of automatic

- Traffic counts (automatic)

- 24-hour counts to be recorded in 15-minute increments with hourly subtotals

- The use of buried sensors and impulse transmission to remotelylocated counters will be considered if vandalism appears to be a problem or if roadway uses such as snowplowing seem to require the ir use

- Congestion measuring (manual)

- Observed accidents and incidents

- Intersection stop delays

- Vehicle-turning movements

- Speed and delay studies for travel times

- Speed and delay studies, conducted by driving the routes shown on Figure $3-4$.

Records will be kept in computerized format for ease of reporting, summarization, and retrievability.

Accident Reports. By contacts with law enforcement agencies and review of local publications, data will be assembled on all reported accidents occurring on public roads in the site vicinity during site characterization. Data to be collected, as available, will include the following:

- Fatal or nonfatal

- Type of vehicles involved

- Type of accident, time of day, circumstances of weather, etc.

- Involvement of site characterization personnel

- Involvement of hazardous materials

- Nature of response.

Records will be kept in computerized format for ease of reporting, summarization, and retrievability.

\subsubsection{Assembly of Site Characterization Project \\ Transportation Data}

During site characterization, the following transportation data will be gathered:

- Number of personnel and shifts required to perform the field studies 


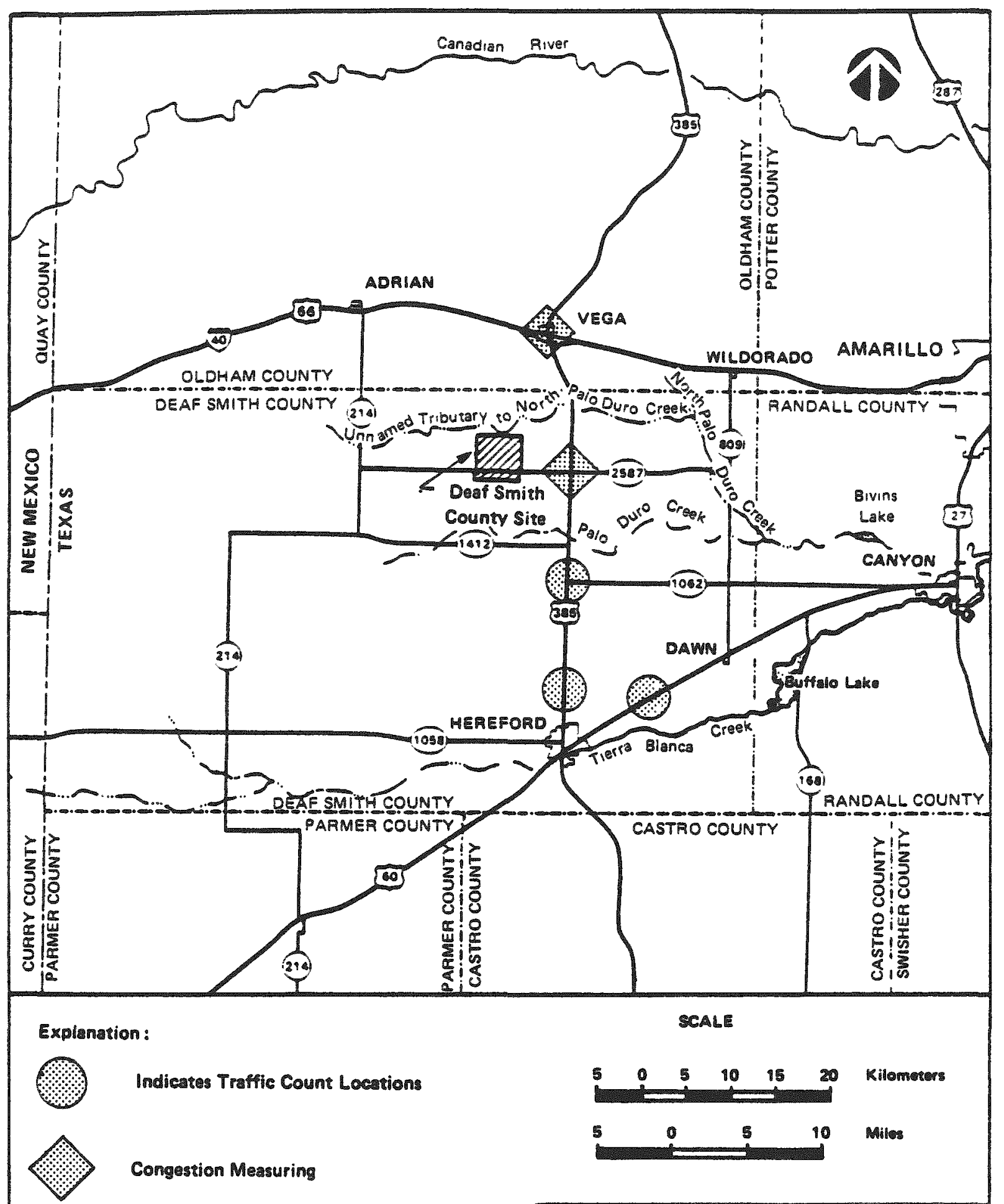

Location of the Deaf Smith County Site, Texas

Figure 3.4 
- Residence of workers

- Number and type of vehicles required to transport both personnel and supplies

- Number, length, and location of additional access roads to specific project areas.

These data will be obtained from the responsible managers and administrators of the site characterization field activities by the Socioeconomic discipline acting under the direction of the Transportation discipline.

\subsubsection{Design of Aircraft-Overflight, Hazardous- Material-Transportation, and Emergency- Response-Preparedness Characterization Studies}

The studies described in this section all relate to concerns regarding hazards and emergency response. Aircraft-overflight patterns, particularly airport landing and takeoff approaches, are of concern to the location of the transportation corridors for establishing the probability of aircraft crashes affecting the route. Aircraft-overflight patterns will require data gathering for the site vicinity. Aircraft overfight may be a constraint to the selection of transportation corridors.

Hazardous-material transportation is of concern for the risk posed to the transportation routes in the event of hazardous-material accidents. Hazardous-material transportation is a constraint to the selection of transportation routes to and from the site. The study of hazardous material transportation as described in this section is a statewide data-gathering activity.

Emergency-response preparedness may be a constraint to the selection of statewide routes. As described in this section, emergency-response preparedness involves a statewide data-gathering activity.

The identification of alternative statewide routes, which are the subject of the foregoing studies, is not an SSP activity.

The programs for collecting data on aircraft-overflight patterns, hazardous-material-transportation patterns, and emergency-response preparedness are described in the following sections.

\subsubsection{Survey Aircraft-Overfight Patterns}

It is recognized that aircraft hazards are likely to be low. However, such concerns may be significant in selecting between potential rail corridors. Accordingly, data that are required to establish aircraft-overflight patterns in the vicinity of the transportation routes will be obtained. Activities required to obtain the necessary data include determining airport and airstrip locations from which approach paths and low-level flights such as crop dusting could overcross the routes, preparing descriptions of these airports, and assembling flight-path data. These activities are described in the following paragraphs. 
Airport/Airstrip Location Determinations. A review of published data, contacts with the Federal Aviation Administration (FAA), and contacts with other Federal, State, and local officials will establish the identity and locations of all private, commercial, and military airports or airstrips in the vicinity of the corridors or in outside areas where air travel could be expected to involve flight patterns crossing the route vicinities.

Aerial photographs of the route vicinities will be obtained and studied to determine the presence of inactive or abandoned commercial, military, or private air strips. In addition, the following data will be collected for the site vicinity:

- U.S. Coast and Geodetic Survey (CGS) aeronautical maps

- U.S. CGS instrument flight rule (IFR) charts and visual omni range (VOR) station maps

- U.S. Air Force navigation maps.

A site vicinity map or maps will be prepared as part of this SSP showing all known airport and airstrip locations identified by the foregoing data.

Airport/Airstrip Descriptions. For all private and commercial airports identified through the foregoing data-collection activity, the following information will be gathered by visiting the airports and interviewing appropriate personnel:

- FAA classification

- Runways

- Number

- Length

- Width

- Orientation

- Type of surfacing

- Lighting and navigational aids

- Hangar and tie-down space

- Terminal facilities and number of gates

- Parking

- Planned improvements

- Services

- Regional and national airline service

- Computer, charter, and air-taxi service

- Air-ambulance service

- Fuel and repair service

- Flight training

- Traffic and operations

- Number of aircraft based

- Maximum aircraft size accommodated

- Approach patterns and obstructions

- Daily airline schedules

- Total annual landings and takeoffs

- Hours of operation per day (attended) 
- Weather disruptions - frequency and history

- Projected changes in traffic

- Maps, plot plans, and other descriptive drawings of the airports as may be available.

The above data will be collected for the most recent 5 years for which data are available.

For military airports identified in the foregoing data-collection activity, the same data as listed above for commercial airports will be obtained to the extent available.

For abandoned airports or airstrips, and private airstrips, efforts will be made to visit each site, and descriptive data will be collected to the extent availiable.

Flight-Path Data. Discussions with airport officials and other Federal, State, and local officials identified during the airport location and description data collection activities will be undertaken to define the low-level flight paths and the landing and takeoff approaches associated with the airports or airstrips in the vicinity of the corridors. These flight paths will be presented on maps at an appropriate scale. Additionally, the frequency of aircraft by type using each fight path will be established to the extent possible. Data will be obtained for the most recent 5 years for which data are available.

\subsubsection{Survey Hazardous-Materials Transport Patterns}

The use, manufacture, processing, storage, and transport of hazardous materials within the 20 hazard classes defined in 49 CFR 172.102 in the vicinity of the routes will be identified. Industrial and military facilities and transportation routes, including air, rail, highway, water, and pipeline, are to be considered in terms of the magnitude and significance of risk that they pose to the transportation routes under consideration.

The collection of hazardous-material-transportation data will be obtained by establishing a definition of what constitutes a hazardous material, identifying locations of hazardous materials in the route vicinities, and interviewing appropriate agencies and carriers regarding hazardous material transportation. These activities are described in the following paragraphs.

Define Hazardous Material. Reference will be made to appropriate published material and government regulations, particularly 49 CFR 172.102 for definition of what constitutes a hazardous material. A listing will be developed of the materials classified as hazardous.

Identify Locations and Users of Hazardous Materials. The location of users of hazardous materials in the vicinity of the routes will be obtained from Texas agencies such as the Department of Health, the Texas Water Commission, local planning and regional agencies, and Chambers of Commerce. 
The data to be gathered will include

- Location, address, and telephone number of user or hazardous material site

- Nature of process or use

- Nature and quantity of hazardous material(s) at that site

- Method of storage

- Method of receipt

- Method of disposal or other description of ultimate destiny of hazardous material

- Identity of regulatory or supervisory government agencies

- Identity of ownership of operation

- Description of hours per day and days per week of operation (or other appropriate schedule definition)

- Description of workforce on site including size, training, stability, and other appropriate factors

- History of accidents or incidents at the site.

Conduct Interviews Regarding Hazardous-Material Transportation. Information regarding hazardous-materials transportation by rait will be obtained from the Federal Railroad Administration (FRA) and from rail companies operating in the route vicinities. Detalled information on hazardous-material shipments is broken down according to Standard Transportation Commodity Code. The FRA can supply maps, the number of hazardous-materials cars, and accident data for each railroad system.

Pipelines are used to transport natural gas, liquid petroleum, and other hazardous materials. The Texas Railroad Commission regulates the iiquifiedpetroleum gas industry including the transport of gas by pipeline. The U.S. Department of Transportation's Office of Pipeline Safety Regulations oversees interstate pipeline safety.

The Texas Railroad Commission also regulates the movement of intrastate motor carriers. An inventory of hazardous-materials haulers can be made through their permit information. The Texas Department of Public Safety supervises the commercial motor vehicles operating in the state to ensure their compliance with transportation regulations. This agency would aiso have data on compliance with hazardous-materials regulations. The Division of Emergency Management is responsible for responding to hazardous materials emergencies and would have data on the number and type of vehicle-related accidents. Limited roadside counts of placarded trucks can supplement the existing data regarding hazardous-waste-transportation frequency. 
These agencies plus the users and suppliers themselves, identified in the data collection activity described previously, will be interviewed for information regarding hazardous-materials transportation. The following data will be gathered for each type of hazardous material:

- Method(s) and vehicles used in transporting the material

- Origins and destinations

- Routes followed

- Consignment size(s)

- Safety precautions taken during transportation

- Recommended procedures in the event of accident or incident

- History of accidents or incidents during transportation

- Identity of principal transporter

- Identity of reguiatory or supervisory government agencies

- Description of transportation workforce, including size, training, stability, and other pertinent factors

- Placarding procedures and appropriate shipping documents.

\subsubsection{Assemble Emergency-Response Data}

Along Statewide Multi-Modal Routes

Data will be collected to enable a determination of to be made emergency response capabilities along statewide transportation routes to be made. This will include the site vicinity.

Emergency-response data will be assembled by identifying and interviewing representatives of regional and local emergency-response jurisdictions and private organizations providing emergency services: by collecting data on disruptive meteorological and other natural conditions; and by collecting data on other sources of potential disruptions or hazards along the routes. These activities are described in the following paragraphs.

Identify Providers of Emergency Services. During the survey of accident and incident data along the statewide multi-modal routes, as defined in Section 3.1.3.3, the responding emergency service agencies will be identified. These data will be computerized and appropriate printouts listing the emergency respondents will be generated. Telephone and letter inquiries to these entities will be used to identify additional providers of emergency services. The Texas State Emergency Plan will be obtained, reviewed, and incorporated into the data identifying emergency services providers. A comprehensive list of a 11 known providers of emergency services along the routes will then be compiled. 
Interview Providers of Emergency Services. Representatives of the organizations identified through the activity described above, including police, fire, and emergency-medical services; the State of Texas: Federal agencies: transport companies; and industry groups, will be interviewed about their capabilities to respond to transport accidents, including hazardousmaterial accidents. The emergency services available at the Deaf Smith County site will be included in the collected data.

Data to be collected will include

- Plans and procedures

- Equipment

- Personnel

- Training programs and requirements

- Funding levels and sources

- Organizational effectiveness

- Types of emergency-response experience

- Statistics on responses by type for most recent 5-year period for which data are available.

Collect Data on Disruptive Weather and Other Natural Conditions. During the interviews with providers of emergency services, data will be requested regarding disruptive weather and other natural conditions that contribute to transportation emergencies. Additionally, Federa1, State, and local weather agencies and bureaus will be contacted, and published literature will be studied, to establish weather patterns that may disrupt transportation along the identified statewide routes. Data to be collected will include

- Records from transporters regarding the frequency and duration of delays caused by weather

- Days per year of subfreezing weather

- Precipitation and wind patterns

- Flooding patterns

- Thunderstorm and lightning strike patterns

- Tornado occurrences

- Hurricane patterns

- Earthquake occurrences.

Collect Data on Other Sources of Potential Disruptions or Hazards. Also during the interviews with providers of emergency services, data will be requested regarding other potential disruptions or hazards along the transportation routes. These would probably be largely human-induced problems. These concerns will be defined as completely as possible. 


\subsection{RATIONALE FOR THE STUDY DESIGN}

The transportation field program is designed to fulfill the data requirements presented in Section 2.2. These data are necessary to identify and assess potential project impacts to transportation infrastructure and traffic in the site vicinity, as well as to statewide transportation routes. These routes will be used for the movement of personnel, supplies, high-level radioactive waste, excess mined salt, and other materials to be transported to and from the site during construction and operations.

The rationale for the design of the transportation field program, as detailed in Section 3.1, is discussed in the following sections. These sections represent the five principal subdivisions of the Transportation SSP:

- Rail corridor characterization

- Highway corridor characterization

- Alternative statewide route characterization

- Repository characterization impact studies

- Aircraft-overflight, hazardous-material transportation, and emergency-response-preparedness characterization.

\subsubsection{Rationale for Rail-Corridor-Characterization Study Design}

The potential for transporting high-level nuclear waste, construction materials, and operating supplies to the site as well as transporting excess salt and nonsalt waste products from the site, exists for rail transportation. The site is presently not accessible by rail. Therefore, rail-corridorcharacterization data must be obtained, including field data adequate to characterize the construction of a new rail spur to the site, and data to adequately assess the transportation effect on existing rail systems in the site vicinity.

The rail-corridor characterization study will be conducted within the site vicinity. The principal activities to be carried out are

- Surveying existing rail systems

- Assembling of repository-generated traffic data

- Identifying alternative corridors

- Assessing corridor environmental conditions

- Confirming preferred corridor selection.

\subsubsection{Survey Existing Rail Systems}

An evaluation of the existing condition of $10 \mathrm{cal}$ rail infrastructure is fundamental to site characterization. A field reconnaissance of the site 
vicinity will serve to familiarize the investigators with the general characteristics of the railroad system in the vicinity. Review of existing documentation (e.g., aerial photos, previous studies) will create an up-to-date awareness of project concerns. Aerial photographs will serve to confirm the rail system configuration. Ascertaining the conditions of local rail facilities and the Amarillo railyards will require considerable interaction with responsible railroad, community, and government officials. This interaction should not be undertaken until a thorough understanding of work performed previously, and project issues in general, has been established. A special effort to define existing conditions in the Amarillo railyards is necessary because most rail traffic to the site, with few exceptions, must pass through these yards.

\subsubsection{Assemble Repository-Generated Traffic Data}

This approach requires repository-generated traffic estimates to be obtained from existing sources, rather than independentiy estimated. This will increase study compatibility with other project activities. A major objective of this activity is to get repository traffic predictions in the same format as information from other study activities.

\subsubsection{Identify Alternative Corridors}

With a potential for a large number of possible rail corridors, it will be necessary to reduce the study to a reasonable level by selecting the most attractive candidates for corridor identification. Sections 4.1.3.1.10 and 5.1.2.2 of the Environmental Assessment (DOE, 1986) require that alternative corridors be identified during the site characterization activities as a prelude to later selection of preferred transportation routes. Since the SSP is devoted to the collection of data, the identification of alternative corridors is not considered to be an SSP activity but will be carried out by other CRWM Program activities. Engineering considerations, as well as environmental factors, will apply in identifying alternative corridors.

\subsubsection{Determine Corridor Environmental Conditions}

Assigning the environmental characterization of the rail transportation corridors to the appropriate nontransportation professionals in the project organization will ensure consistency of methods and results with the site evaluation itself, and will ensure the highest quality of work.

\subsubsection{Confirm Preferred Corridor Selection}

A new rail spur into the site will be necessary, since none presently exist. It will be necessary to reduce the number of alternative rail corridors to one preferred corridor within which the site rail-access spur will be constructed. The selection of a preferred rail-spur corridor is not a specified SSP activity. The rail corridor selection will be made on the basis of logistics, length, number of at-grade crossings, engineering design, cost, and 
environmental conditions. The selection will be made by other CRWM Program activities. Engineering considerations, as well as environmental factors, will apply in the railroad corridor selection.

\subsubsection{Rationale for Highway-Corridor- Characterization Study Design}

High-level waste, construction materials, and operating supplies all may arrive at the site on highway routes. Additionally, all personnel visiting or working at the site can be expected to travel to and from the site in trucks or cars. Nonsalt waste products will probably leave the site by truck. Therefore, highway-corridor-characterization data must be obtained to provide a basis to adequately assess the transportation effects on roads and highways in the site vicinity.

The highway-corridor characterization study will include a survey of the existing roadway infrastructure and an assembly of projections of repositorygenerated traffic within the site vicinity.

Environmental data-gathering is not included in the study design for highway corridor characterization, since no new offsite roadways will be constructed in the vicinity for site transportation purposes.

\subsubsection{Survey Existing Roadway Infrastructure}

A field reconnaissance of the site vicinity will serve to familiarize the investigators with the general characteristics of the roadway system in the vicinity. The local infrastructure for highway traffic must be characterized for overall site characterization. In addition, a basis must be created for assessing repository-generated traffic impacts on the local road network. Ascertaining the conditions of the local roadway facilities will require considerable interaction with responsible officials and users. The approach emphasizes obtaining data from appropriate agencies and major trucking firms. Aerial photographs will serve to confirm the roadway system configuration.

\subsubsection{Assemb Te Repository-Generated Traffic Data}

This approach requires repository-generated traffic estimates to be obtained from existing sources, rather than independently estimated. This will increase study compatibility with other project activities. A major objective of this activity is to get repository traffic predictions in the same format as information from other study activities.

\subsubsection{Rationale for Design of Alternative Statewide Route Characterization Studies}

A necessary task of the CRWM Program is to identify the route or routes most likely to be selected by State officials, including alternatives to Interstate highways, for the movement of radioactive materials to the site. This will require identification of alternative routes and the selection of preferred route(s) from among the alternatives. 
The alternative statewide route characterization studies will be conducted within the confines of the State of Texas, and will interface with the site vicinity corridor studies for connection to the site itself. For connection to high-level radioactive waste sources outside of Texas, and for disposal of excess mined salt beyond the state borders, the alternative statewide route characterization studies will interface with the National Transportation Program. The following principal activities will be carried out during the alternative statewide route characterization studies:

- Identify alternative statewide routes

- Survey existing transportation infrastructure for aiternative statewide routes

- Determine environmental conditions along aiternative statewide routes

- Select preferred statewide routes

- Collect environmental data for preferred statewide routes.

\subsubsection{Identify Alternative Statewide Routes}

With a potential for a very large number of statewide routes, if all existing roads and railways are considered, it will be necessary to reduce the study to a reasonable level by selecting the most logical candidates for statewide route identification.

Section 4.1.3.1.10 of the EA (DOE, 1986) discusses the requirement that regional and national transportation issues be addressed. This non-SSP activity will result in the identification of points of entry and exit for highlevel radioactive waste and mined salt transportation at the Texas state border. The location of these points of entry and exit will impose one constraint on possible alternative routes to the site. This constraint will result in a relatively limited number of alternative statewide routes being identified for data gathering and characterization activities.

The alternative statewide routes will be identified by non-SSP CRWM activities and by the State of Texas. Engineering considerations as well as environmental factors will apply in making this identification.

\subsubsection{Survey Existing Transportation Infrastructure for Alternative Statewide Routes}

To develop a database for selection of preferred statewide transportation routes, a thorough characterization of the existing transportation infrastructure is required. Figure 3-3 iliustrates the major highways, railways, and seaports serving the state. It is expected that the statewide routes to be studied will be selected from these major transportation facilities. 
An evaluation of the existing conditions of highway, port, and rail infrastructure is fundamental to characterization. A statewide reconnaissance of the routes will serve to orient the investigators, after which review of existing documentation (e.g., aerial photos, previous studies) will create an up-to-date awareness of project concerns. Ascertaining the conditions of transportation facilities and ports will require considerable interaction with responsible private, company, community, and government officials. This interaction should not be undertaken until a thorough understanding of work performed previously, and project issues in general, have been established.

\subsubsection{Collect Accident and Incident Data Along Alternative Statewide Routes}

A database of accident-related information is necessary for a characterization of the transportation aspects of the state. Obtaining this data from appropriate agencies and principal carriers will ensure that the data are consistent with those used by the reviewing agencies. Furthermore, undertaking an independent survey of accidents and incidents throughout the state would be impractical.

\subsubsection{Determine Environmental Conditions Along Alternative Statewide Routes}

Assigning the environmental characterization of the transportation corridors to the appropriate nontransportation professionals will ensure consistency of method and results with the site evaluation itself and will ensure the highest quality of work.

While all environmental disciplines will participate in this statewide data-gathering activities, the socioeconomic and land-use disciplines will be emphasized. The socioeconomic and radiological risks from transportation to and from the site must be quantified for a complete environmental characterization. Therefore, collection of population and land-use information for this purpose is especially required.

\subsubsection{Select Preferred Statewide Routes}

The SRP Transportation Program Plan (ONWI, 1987b) and CRWM national transportation program objectives require the selection of preferred routes, including routes within the State of Texas. This will be accomplished by nonSSP CRWM activities and by the State of Texas. Engineering considerations, as well as environmental factors, will apply in making this selection. Utilizing the data obtained in the foregoing activities will serve to define the key transportation needs of routes that are adequate to handie radioactive and nonradioactive waste shipments and movements of supplies and workforce for repository construction and operation: determination of preferred routes with respect to technical, socioeconomic, environmental, safety, conflicting land use, local compatibility, and programmatic considerations: and determination of any needed improvements or upgrades to the transportation infrastructure to make it suitable for project use. 


\subsubsection{Collect Environmental Data for Preferred Statewide Routes}

The establishment of environmental data from which to measure the impacts of the preferred statewide transportation routes is required for the array of environmental disciplines involved in the project.

Assigning the environmental characterizatjon of the preferred statewide transportation routes to the appropriate nontransportation professionals within the project organization will ensure consistency of methods and resuits with the site evaluation itself.

\subsubsection{Rationale for Design of Repository-Characterization Transportation-Impact Studies}

The Environmental Assessment (DOE, 1986) requires that monitoring for congestion, traffic problems, and road deterioration caused by site characterization be performed (EA Section 4.1.3.1.10), and that mitigation measures be investigated and proposed to the DOE as may become evident during site characterization (EA Section 4.2.1.10.5). Additionally, the Nuclear waste Policy Act of 1982 (NWPA) Section $113(\mathrm{a})$ requires site characterization environmental impact minimization. The transportation effects to the site during characterization will be essentially roadway oriented. The study design proposed in Section 3.1.4 is consistent with accepted traffic-engineering practices and procedures (Box and Oppenlander, 1976).

In addition, the collection of data defining the transportation impacts of site characterization will be invaluable in projecting the transportation effects of the repository itself.

\subsubsection{Rationale for Monitoring of Public Road Congestion in the Project Vicinity}

During site characterization, a substantial increase in public road congestion in the project vicinity is expected. Monitoring this increase and correlating the increase to site-characterization activities will yield valuable data for projecting transportation effects and determining mitigation needs that will arise from site-repository construction and operation.

It is anticipated that most traffic will approach the site by means of three principal routes:

- West from Amarillo along I-40 to Vega, then south via US 385 to FM 2587, and then west to the site

- West from Canyon along FM 1062 to US 385, then north on US 385 to FM 2587, and then west to the site

- West from Canyon along US 60 to Hereford, then north on US 385 to FM 2587, then west to the site.

As can be seen, most of the site traffic can be expected to converge onto U.S. Route 385 and turn onto FM 2587, resulting in congestion problems at the 
US 385 and FM 2587 intersection. To mitigate this potential probiem, the Environmental Assessment recommends the construction of a clover leaf (gradeseparated) interchange at this intersection during the first year of site characterization if monitoring results warrant. Installation of traffic controls such as intersection improvements and turn signals are also slated for peak-hour congestion periods in other locations, such as north of Hereford along U.S. Route 385 , if monitoring results warrant.

As further indicated in the EA, these mitigations will not be provided unless monitoring indicates a need.

Before major site characterization begins, to establish conditions prior to site characterization field studies, traffic volumes on public roads in the vicinity of the site will be manually (and automatically) counted on random days during morning and afternoon peak periods to determine whether traffic related to characterization is significantly exceeding anticipated levels. Counting will continue at intervais to be determined, throughout the duration of site characterization activities, to provide a continuing monitoring service for assessing the effect of characterization activities on the site vicinity transportation infrastructure. Monitoring for congestion and traffic problems will be conducted to ascertain increases in accident rates at peaks in site characterization activities.

Manual counting (as well as automatic counting) is included in the SSP to ensure that subjective and judgmental aspects of traffic monitoring are fully included in the data base gathered during the congestion monitoring program. Manual counting can be omitted in favor of a 11 -automatic counting if significant programmatic or budgetary incentives are found to exist.

\subsubsection{Rationale for Assembly of Site Characterization Project Transportation Data}

The extent of the overall projects effect on the transportation network in the site vicinity will be determined by gathering data regarding site characterization program transportation characteristics. These data will be gathered from project management sources, not individual employees. The datagathering will be accomplished by the socioeconomics discipline, under the direction of the Transportation discipline.

\subsubsection{Rationale for the Design of Aircraft- Overflight, Hazardous-Material-Transportation, and Emergency-Response-Preparedness Characterization Studies}

These are special studies related to transportation hazards falling within the transportation discipline scope per the SRP Transportation Program Plan and the Environmental Assessment (DOE, 1986), but which have not been included in the other major SSP design categories. The hazards included are those arising from low-level aircraft operations in the vicinity of the transportation corridors and movements of hazardous materials along the transportation routes. Emergency response preparedness along the routes will be studied 
to determine the capabilities of dealing with potential consequences of the hazards identified and other project-transportation-related emergencies.

A principal potential source of nuclear emergencies associated with a facility of this type is the extended routes of transportation required for movements of materials and supplies, including nuclear materials, to and from the site. In the transportation mode, the nuclear materials are in closer proximity to the general population, and less shielded and secure, than in any of the other modes of handling and storage.

\subsubsection{Define Aircraft-Overflight Patterns}

It is recognized that aircraft hazards are likely to be low. However, such concerns may be significant in selecting between potential transportation corridors. Accordingly, to provide data to assess the hazards associated with transportation to and from the site in the vicinity of airports, airstrips and areas of low-level flying, such as crop dusting, aircraft-overfight patterns must be identified. Since the transportation corridors are in the site vicinity, data-gathering will be within 50 miles from the site. The aircraft overflight data may be a constraint to the selection of transportation corridors, and therefore. a body of data will be required.

\subsubsection{Define Hazardous-Material-Transportation Patterns}

To provide data to assess the hazardous material concerns associated with transportation to and from the site, hazardous material storage and use locations and transportation patterns in the vicinity of the alternative transportation routes must be established. Inasmuch as the movement of hazardous materials is a statewide subject, this is properly a statewide data-gathering activity.

\subsubsection{Assess Emergency-Response Preparedness}

Emergency-response-preparedness assessments along the transportation routes are the concern of the transportation discipline. A major factor in the selection of preferred transportation routes of not only nuclear materials but also any major transportation effort associated with the site, such as the transportation from the site of excess mined salt, is the suitability of emergency-response capabilities along the alternative routes. Transportation over public routes presents well-known hazards simply by virtue of the transportation activity itself. Thus, the gathering of emergency response data along the alternative statewide-transportation routes is a necessary component of the Transportation SSP.

\subsection{RATIONALE FOR THE SELECTION OF THE STUDY METHOOS}

The transportation study will identify several features about transportation aspects of access to and from the repository site. The definitions and quantification of measurement for all these features (whether in objective or 
subjective terms) must make the identification comprehensive, clear, and concise, since others will depend on these results for subsequent activities. The work plan that accomplishes this consists of specific data collection and surveys of existing and planned facilities, as has been described in Sections 3.1 and 3.2 .

Study results will be used for several purposes in evaluation of the site. Transportation routes' suitability for serving the repository's demands, impact assessments of the transportation effects along routes, and problem area solutions or mitigation will all depend on the information pulled together in this study.

The transportation characteristics must be viewed from the perspective of the site's immediate vicinity and from the broader perspective of a statewide system of modes and routes. This demands that study methods be balanced in precision and cost-effectiveness in determining the amount of information to be processed.

The basis for selecting methods that meet the constraints just described, along with a summarized description of the methods, will be covered in this section. More detailed descriptions of actual procedures to be employed are presented in Section 3.4. Applicable Technical Procedures.

There are two types of operations in the study for which uniform methodology is developed:

- Data collection (or generation) and storage activities

- Study results, data compilation, and presentation activities

Both are equally important for ensuring that accurate, reliable, and useful information is made available in manageable formats for suitability determination, impacts assessment, problem solving, and decision-making.

Data Collection, Generation, and Storage. Data gathering, as has been explained in Sections 3.1 and 3.2 , will primarily be an assembling of currently available data. The information may exist, however, in several different organizations with different formats. There is also expected to be some variety in the level of detail collected from different sources.

Some of the data from the organizations that have been identified will be obtained at no cost. Other sources will charge for the procurement, or at least seek reimbursement for copying costs.

The step-wise method, regardless of mode or source, for data gathering is generally the following routine:

1. Telephone contact with prospective organization

Relate purpose

Relate data sought from them

Confirm availability or identify other source

Determine data's cost and dimensions (weight, volume)

Make arrangement for review (at source or project office)

- Identify other data they have 
- Identify other sources for same data

- Document telephone contact (standard forms)

- Update computer tracking system

2. Review data (at source or in project office)

- Travel to source if necessary

- Analyze data presented for adequacy

- Reject or accept decision

- Attain ownership (purchase, copy, etc.)

- Update computer tracking system

3. Stockpile data

- Deposit data in system files

- Update computer tracking system

4. Consolidate data to usable form

- Manipulate data to format desired

- Post results or raw data on worksheet

- Update computer tracking system

5. Evaluate results

- Expert review

- Comparison between sources

- Update computer tracking system

6. Certify results (by responsible individual)

- Approve worksheet

- Authorize exhibit production

- Update computer tracking system.

The importance of a systematic approach cannot be overstressed in this methodology. There could be challenges to the results published. The backup source data should verify it as the best available or only known source document.

The tracking system is a critical part of the systematic approach. It will enable summary reports or specific inquiries to be handled for status of processing, as well as indicating where source data will be or has been obtained, and where it is filed.

Not all data can be obtained from published information. Where not published, data could still be available by interviewing knowledgeable people. The method for obtaining interview information would follow the same outline as presented above, except that a standard form would be used to conduct an interview at the data review stage. The interview would be performed in person unless travel arrangements or other factors make the cost prohibitive. A telephone interview is the next preferable method, and a letter of inquiry a last choice. The interviewer should be familiar with the technical data being discussed.

Some data for the site vicinity must be collected in the field. Field data collection will generally be in more detail for site vicinity subjects than for statewide subjects. Methods for accomplishing this field work can be categorized as follows: 
- Field inspection and investigation (documented)

- Aerial photointerpretations and mapping

- Traffic studies.

The methods and their selection rationale for field work are not the same for every situation. The following sections will define the methods and rationale for each situation.

Data Results Compilation and Presentation. Before considering each component, it should be pointed out that study results will be compiled and presented in uniform, summarized formats. The data will be portrayed on maps with key planimetric items (cities, water ways, state and county i ines, etc.). State maps of Texas, site vicinity maps, and individual route maps will be used.

The scale of maps will be appropriate to make a $2.5-\mathrm{cm}(1-\mathrm{in})$ dimension on the map represent a significance of $25 \mathrm{~km}$ (15.5 mi) for the state map $(1: 1,000,000), 2.5 \mathrm{~km}(1.5 \mathrm{mi})$ for the site vicinity map $(1: 100,000)$, and 30 meters $(100 \mathrm{ft})$ for the route map $(1: 1200)$. The specific study results that are planned for this format will be identified in the following sections covering each study component. More specific definition of each document is discussed under the technical procedures of Section 3.4. Study activities in the field will use larger scale maps and aerial photos.

In every case, the rationale behind this method of organizing the results is the same. Summarizing and highlighting significant transportation information on a planimetric geographical view is the ideal way to clearly and concisely communicate the results to those involved with other site characterization activities or the subsequent site evaluation phase.

\subsubsection{Methods of Rail-Corridor Characterization}

This study component looks at the alternative railroad routes in the site vicinity. Several factors influence the detail of information needed. The amount of data, the detail, and the precision will be discussed with principals of other study disciplines, who will be dependent on the results, prior to undertaking the transportation study activities. The methods selected, and their selection rationales, are covered in the following sections.

\subsubsection{Existing RaiT-System Survey Methods}

Preferred Methods. Using the routine already described for data collection, the railroad owners and operators will be contacted as the primary source of available information. Government planning and regulatory units may also possess useful information and will be contacted. Key types of information expected from these sources are system maps, as-built plans, traffic volume records, route line diagrams, accident tabulations, etc. Interviews with representatives of these organizations will be conducted to verify and supplement the available information. It is expected that owners and cognizant agencies will possess good data bases on the existing rail systems in the site vicinity. 
Onsite route inspections will be made to document the existing condition of the lines. Onsite inspections will be conducted only after authorizations have been obtained from the owner and all appropriate advance procedures and training have been accomplished. Documentation will be recorded on forms specifically composed for these tasks. Each sheet will cover a defined segment of the line. Segmentation will be by change in key characteristic or condition, or at $1-\mathrm{km}(0.6-\mathrm{mi})$ breaks, whichever is more restrictive. At least one photograph will be taken as an example of condition on the segment.

An aerial mosaic map for the site vicinity with the railroads highlighted will be created by aerial photography methods. The map will either be a roughly controlled (limited use of ground control) or uncontrolled photograph mosaic looking down on the area. The repository site plan will be superimposed onto the image. This will primarily be used as a discussion reference by study team members and others involved in the site study work.

Route strip maps and photologging of each alternative route will be accomplished. The route maps will be made by precision aerial photogrammetry techniques from aerial photographs and ground controlled survey. These maps will give specific details about the elements composing the rail facility. The photologging will be continuous or discrete images of the facility from a ground level view looking ahead on the alignment.

The backup indexing for this base source documentation will be in a standard format on a computerized tracking system. The software for the system used will identify route, segment, status, file location, and general description of the item.

The compilations on the maps already described will be by desired features. As data collection is achieved, a work sheet for each feature map (always in a conspicuous location) will be used to record the preliminary information as a basis for a later exhibit mockup for that feature map.

Alternative Methods. Some alternatives exist to the preferred methods described. The first of these would be to obtain data by means other than organization contacts. This approach would be very difficult and costly. Duplication of work the organizations have completed over many years would be involved. The need to have data on traffic and accidents would require continuous monitoring of each route over a period of at least one year.

Intermittent photologging of key route elements would be less effort than the complete photologging preferred, and could be integrated with condition surveys. This would involve judgments, however, and a questionable documentation of the route could result, to the detriment of future tasks.

Route strip maps compiled from the organizations could be an alternative to the new route maps proposed. Line diagrams, used by some railroad companies, could conceivably be an acceptable substitute to the new map. The alternatives, however, leave the high probability that the documented route characterization on file is not up to date, even if a detailed condition survey is conducted. 
Variaus other alternatives to those described as preferable can be considered as equivalents (such as a manual tracking system for data collection as compared to a computerized system). The advantages of the preferred methods relate to reliability and cost-effectiveness.

Conclusion. The railroad mode for shipments to and from the site is an important element to consider in the characterization study. Results of the study should be very clear in communicating exactly what the railroad route alternatives are in accurate terms. Therefore, good source documentation is necessary to furnish an assurance that dependable results are created at a reasonable cost.

\subsubsection{Methods for Assembly of Repository-Generated Traffic Data}

The SSP does not include prediction of future traffic volumes on the routes selected for study. It does include an organized assembly of repository-generated traffic volumes already forecasted. These predictions will be evaluated further subsequent to site characterization. The OEIS step will probably add traffic volumes. This work plan will seek to get repository traffic predictions in the same format as baseline information.

Annual Traffic Generation Breakdown. The repository-generated traffic includes the spectrum of construction, operations, and decomissioning. The base data, therefore, will be assembled for a year-by-year viewpoint of projected traffic. Both an annual average-daily-volume unit and an annual peak-hourly-volume will be accounted for in the following categorizations:

- Type car (i.e., box car, tank car, flat car, hopper car, etc.)

- Hazardous and nonhazardous cargo

- Origin and destination

- Route assignment.

Data Management. The assembled data will be filed and entered into the indexed tracking system. If revisions to these predictions are issued, the new data will aiso be filed and the new version entered in the tracking system as a clearly denoted change.

Compilation. The data will be displayed on maps of the site vicinity (similar to other data displayed). All features will be indicated by high quality graphics techniques on three maps - one for the construction perjod, one for the years of operation (with ranges), and one for the decommissioning period.

\subsubsection{Identification of Rail-System Alternative Corridors}

The data gathered in this SSP will be used, along with other information, to identify and select alternative rail system corridors in the site vicinity. The methods for this selection are not within the scope of this document. Data collection for transportation characteristics of new routes wil1 be performed using the methods described for existing routes in 3.3.1.1. 


\subsubsection{Rail-Corridor Environmental Characterization Methods}

Methods used for an environmental characterization of the railroad corridors will be described in future drafts of the SSPS for each of the appropriate disciplines. Transportation characteristics, whether for existing or new routes, will be characterized by data collection methods described in 3.3.1.1.

\subsubsection{Preferred Corridor Data Collection Methods}

Sufficient field data must be collected to furnish a comprehensive and accurate characterization of the preferred railroad route's environmental condition. The environmental assessment field data generation will be in accordance with the appropriate discipline-specific SSP. Transportation characteristic data collection will be by methods identified in 3.3.1.1.

\subsubsection{Methods of Highway-Corridor Characterization}

This study component looks at the several existing highway routes in the site vicinity. The amount of data, its level of detail, and its measurement precision will be discussed with the principals of the other study disciplines who will be depending on the transportation study results, prior to undertaking the study activities. The methods selected and their rationale are discussed in the following sections.

\subsubsection{Existing Roadway-System Survey Methods}

Preferred Methods. Organization contacts will be the primary method of collecting information. Federal. State, and local highway agencies are expected to possess excellent data bases on these routes. System maps, traffic volume tabulation and maps, route plans, accident tabulations, etc., will be avallable for extraction of needed route features. Interviews with knowledgeable individuals as defined in the study design (Section 3.1.2.1) will be used to supplement the data. The uniform method for organization contacts and interviews is described at the beginning of this section, under heading 3.3.

Traffic study methods for field data collection will aiso be employed during the site characterization period. The results sought are for two purposes. The first is for establishing pre-site-characterization indicators for existing traffic on the routes selected for characterization. The second is to portray changes in traffic due to site characterization activities. The traffic study methods, therefore, will be employed at appropriate intervals.

Traffic studies will be in accordance with highway engineering and planning industry standard practices. Both automatic and manual counting procedures will be employed. Traffic will be identified by categories (i.e., passenger vehicle, truck, bus), by flow rates (average daily volumes, peak hour volumes), and by parameters defining what generated the trips. 
Investigation of route conditions: preparation of aerial mosaic maps, route strip maps, and photologs; and compilation and indexing of data for roadways will be performed by the methods discussed above for railroads (see Section 3.3.1.1).

Alternative Methods. Limited alternatives exist for studying the existing highway system. It would be possible to directly collect the same data that are available from highway agencies, but the process would be very costiy and time-consuming.

Some alternatives also exist to the methods described for traffic studies. Extrapolations and estimates from existing data could be attempted, but procedures for performing this operation would be very empirical and subject to challenge. There is also the alternative of increasing the amount of traffic data generated by establishing more sites and greater frequency for field work. There is, however, a point of very marginal return relative to the value of additional data generated. An optimum level is discussed in the technical procedures of Section 3.4.

Alternatives to the preferred methods for photologging, route strip maps, and data management were discussed for railroads and are also applicable to highways.

Conclusions. The roadway routes selected for study are one of the most critical components for consideration in site characterization. The operation of the repository is totally dependent on good highway access. Results of the study must communicate a clear definition of these routes.

\subsubsection{Methods for Assembly of Repository-Generated \\ Traffic Data}

The SSP does not include prediction of future traffic volumes on the nighway routes selected for study. It does include an organized assembly of repository-generated traffic volumes already forecasted. These predictions will be evaluated further subsequent to site characterization. The DEIS step will probably add baseline traffic volumes. This work plan will seek to get repository traffic predictions in the same format as baseline information.

Annual Traffic Generation Breakdown. The repository-generated traffic includes the spectrum of construction, operations, and decommissioning. The base data, therefore, will be assembled for a year-by-year viewpoint of projected traffic. Both an annual average-daily-volume unit and an annual peakhourly-volume will be accounted for in the following categorizations:

- Type vehicle (i.e., passenger vehicle, truck, bus, etc.)

- Hazardous and non-hazardous cargo

- Origin and destination

- Route assignment.

Data Management. The assembled data will be filed and entered into the indexed tracking system. If revisions to these predictions are issued, the new data will also be filed and the new version entered in the tracking system as a clearly denoted change. 
Compilation. The data will be displayed on maps of the site vicinity (similar to other data displayed). All features will be indicated by high quality graphics techniques on three maps - one for the construction period, one for the years of operation (with ranges), and one for the decommissioning period.

\subsubsection{Methods of Alternative Statewide Route Characterization}

The statewide characterization considers viable routes for both railroads and highways, including their connection to waterway ports. Airports and aircraft operations are also considered since they may impact other transportation facilities.

The methods that have been selected for the statewide studies are very similar to methods already explained for site-vicinity studies. The major difference is in the accuracy and level of detail of data being accumulated. The management of the data and the concept of portrayal of results on maps is very similar to the site vicinity methods.

To provide an additional set of guidelines for the study activities, the needs of other disciplines for transportation information, if any, will be discussed with them prior to start of data collection. In general, the statewide compilation of data will seek a degree of accuracy and level of detail consistent with the use to be made of the study results.

\subsubsection{Identification of Statewide Multi-Modal Transportation Routes}

The identification of statewide multi-modal transportation routes is a necessary activity preceeding the statewide field data-gathering studies. The methods for this identification are not within the scope of this document.

\subsubsection{Existing Transportation Infrastructure Survey Methods}

Preferred Methods. The methods already presented for the site vicinity components will be utilized for the statewide studies and include the following:

\footnotetext{
- Owner and agency contacts and interviews

- Route condition investigation

- Aerial mosaics and maps of specific facilities

- Backup document indexing

- Feature map compilation.
}

The segments used for route condition investigation and map compilation will be longer than for the site vicinity. For statewide segmentation, routes will be viewed in segments of 30 to $80 \mathrm{~km}$ (20 to $50 \mathrm{mi}$ ).

Alternative Methods. Detailed precise mapping and complete photologging of the statewide routes are viable alternatives. Methods employed would be 
identical to those explained for the site vicinity work. This detailed source data would be useful in subsequent analysis, but it would be extremely expensive to obtain. The utility gain would not warrant the increased expense.

Conclusions. The preferred methods are considered adequate for the level of detail and accuracy needed. Route condition surveys and route aerial mosaics will require considerable effort, but the information they provide assures dependable results for use on subsequent tasks.

\subsubsection{Accident and Incident Survey Methods}

Existing data about vehicle accidents and hazardous material incidents on the various routes are expected to be avaliable from the owners, operators, and agencies. The same sources are applicable for either the site vicinity or statewide viewpoint.

Preferred Method. These data will be included in the organization contact methods previously described. A 5-year history will be gathered, with longer periods (up to 10 years) obtained if little additional effort or cost is involved. A procedure will be identified and implemented for obtaining any updated data that may be published or issued throughout the site characterization period.

Alternative Methods. The only alternative to the preferred method is to perform a comprehensive monitoring program on each route. At most, a 3-year history would be generated. The cost would be extremely high, with no guarantee of any results.

Conclusion. Good accident and incident data are expected to be available from the indicated organizations. Although private railroad companies may be reluctant to release the data, cooperation among Federal Agencies should be effective in obtaining whatever data is determined to be necessary. An independent monitoring program is probably not worth the cost.

\subsubsection{Multi-Modal Route Environmental Characterization Methods}

The statewide multi-modal routes will be characterized on an interdisciplinary basis by the environmental disciplines associated with the site characterization programs. Each discipline will be responsible for its own methods in conducting the route environmental characterization. These methods will presumably be the same as, or derived from, the methods described in subsequent drafts of each discipline's individual SSP. This will ensure a consistency of data with the characterization data developed at the Deaf Smith County site itself. The transportation discipline will not impose methods on the environmental disciplines during route characterization but will limit its efforts to coordination and administration functions.

\subsubsection{Selected Multi-Modal Route Environmental Data Collection Methods}

Methods used for the collection of environmental data for selected statewide routes are explained in the SSP for each of the appropriate disciplines. 


\subsubsection{Methods of Monitoring Studies}

The effect of site characterization activities on the highway system in the site vicinity will be assessed using the traffic study methods discussed in Section 3.3.2.1. No alternative methods are avallable, although the nature and extent of the traffic study could be modified. The preferred method is described here in general terms. The technical procedures in section 3.4 allow for some variations based on continuous analysis of data being obtained.

\subsubsection{Monitoring of Public Road Congestion Method}

The traffic studies performed will have dual functions of furnishing traffic data before site characterization begins and of monitoring site characterization activities as they affect site-vicinity traffic. Traffic studies will be coordinated with other site characterization disciplines having an interest in traffic monitoring to avoid duplication of effort.

Initial Traffic Studies. Ideally, a 1 week long study would be conducted as explained in 3.3.2.1 before site characterization begins. If that is not possible, the one week study will be performed very early in the site characterization period, hopefully before any other activities start. This will produce traffic data without any effect from site characterization efforts.

The studies will include continuous monitoring of volume, traffic classification by vehicle type, turning movements land traffic impedance factors at intersections, and identification of traffic generating factors. Both automatic and manual counting and monitoring procedures will be. employed. study personnel will drive all routes at varying times and record the driving times, to establish time-delay patterns.

Existing Data. Organization contact methods will include a search for data concerning traffic in the site vicinity. These results can be compared with field studies conducted during site characterization. The check provided will permit further investigation for any apparent anomalies found by comparisons. It is anticipated, however, that existing data will be limited.

Follow-up Studies. Periodic traffic monitoring data will be used as needed to establish the level of increase caused by site activities, relative to increases from other factors. Traffic monitoring will occur about four times per year. Interviews for identification of traffic-generating factors will be made once or twice a year.

Arrangements will also be made with the highway agencies to receive any new issues of traffic information in the site vicinity during the site characterization study period.

Results Compilation. The compilation of these data will be placed on a map of the site vicinity to be published immediately after each update. The exhibit will show both annual average-daily-traffic volume (ADT), peak hourly volumes (PHV), percent trucks, directional splits, and turning movement diagrams. Once a year, the dispiay will be updated to show the percent of total traffic attributable to the site characterization activities. 


\subsubsection{Methods for Assembly of Site-Characterization-Project Transportation Data}

The availability of data for the expected traffic to and from the site during characterization is best obtained from the individuals who have specific responsibilities (management, administration, disciplines) for site characterization, rather than from individual employees. Their plans and schedules will give each leader a good idea of what his activity will create in terms of traffic. Care will be exercised to ensure that all activities are included. This data-gathering activity will be conducted by the Socioeconomics discipline, under the direction of the Transportation discipline.

Contacts with Activity Team Leaders. Interviews will be conducted with these individuals very early in the site characterization phase. Each will be asked to furnish the following:

- Estimate of normal day hour-to-hour personnel staffing and where personnel reside

- Times for shift changes

- Vendors, equipment, and suppliers servicing their operation

- Special operations that will affect traffic

- Access road locations to their activity.

A site vicinity map worksheet will be used to accumulate the estimates of total traffic expected to be generated by site characterization.

Data Management. The data assembled will be filed and tracked by the same system used for other data. Revision received will also be tracked.

Results Compilations. The results will be shown on a site vicinity feature map. Number of vehicles per day for the average and peak day will be shown on each route. The peak hour volumes also will be displayed for the average and peak day. A directional split will be given for the peak hour and average daily volumes.

The map will be reissued each year if revised projections have been submitted.

\subsubsection{Methods of Aircraft-Overflight, Hazardous-Materia1-Transportation, and Emergency-Response Preparedness Characterization Studies}

The methods used for each of these components will be by organization contacts and interviews as has been explained for other components. The data obtained will be filed and entered in the computerized indexed tracking system as has been explained for other study components. The following subsections explain methods of compiling data for each of these three study components and identifies most probable sources of data. No viable alternatives exist for these methods. 


\subsubsection{Methods for Survey of Aircraft-Overfight Patterns}

Commercial airline data will most probably come from each airline (including commuters and charter companies), commercial airport operators, the Federal Aviation Administration (FAA), and the State's Division of Aeronautics. Private flight information will be obtainable to some degree from a irport operators, FAA, the State, and private aircraft associations. Military data may be available from FAA, the State, and Department of Defense.

The data obtained will be compiled to permit identification by location and capacity of air terminal facilities, airfields, and traffic patterns inciuding number of fights per day. These compilations will be placed on a site vicinity feature map.

\subsubsection{Methods for Survey of Hazardous-Materials- Transportation Patterns}

Federal, State, and local governmental agencies will have most of the existing data for this study component. Other sources will be private companies, especially utilities.

The data should include accidents or incidents occurring in the last five years.

A site vicinity map will display the resulting consolidations of data by routes used, type of material transported or used, and number and severity of accidents.

\subsubsection{Methods for Assembly of Emergency-Response Data}

Federa1, State, and local government units will have a majority of these data. Other potential sources include private services (such as ambulance services) and construction companies.

Three types of statewide and specific area feature maps will be used to portray the results. One category will show the response capability that is found to exist. A second will show disruptive weather phenomena that have occurred at various places in recent years. The third type will show other sources of potential disruptions or hazards that may be identified. A statewide map and a site vicinity map will summarize all data for each category.

\subsection{DESCRIPTION OF APPLICABLE TECHNICAL PROCEDURES}

Transportation systems are largely linear in nature. Interconnecting lines represent routes used, regardless of transportation mode. Each route can be viewed as line segments with some specific feature at each end of a particular segment. These end points or terminals can be population centers, junctions with other routes, junctions with other modes, and many other special situations. 
To analyze and evaluate transportation systems, both the macro-and microviewpoints usually are contemplated depending on the particular item of interest. The macro-viewpoint considers the overall image of many interconnecting routes regarding what is occurring on each route. The micro-viewpoint is in much more specific detail concerning what occurs on a route segment. The micro-viewpoint also considers the details of a wide zone along the route center line.

Technical procedures for transportation aspects of the site characterization follow this division. Study procedures are different for the statewide macro-viewpoint and the site-vicinity micro-viewpoint. Both, however, will have a common document format. Data collected or generated will be displayed on maps: the macro-viewpoint on a Texas State base, and the micro-viewpoint on a site-vicinity base. The micro-viewpoint will also involve detailed routefeature documentation in the site vicinity.

The following procedures describe and indicate what documents will be created that furnish characterization of the site for the various transportation elements (both macro and micro-viewpoints) in a form useful for suitability and impact comparisons and decisions.

\subsubsection{Railroad-Survey Procedures}

Both site-vicinity and statewide railroad systems will be surveyed to an appropriate level of detail useful for evaluations and analysis. Onsite inspections will be conducted only after authorizations have been obtained from the owner and all appropriate advance procedures and training have been accomplished. Segmentation may be different for each study feature. Data from the railroad owner-operators and from governmental agencies will be a main source of information. That information will be supplemented by significant field work for the site vicinity. Maps compiled from these data, and indexed logs of existing conditions, will be products of the technical work.

\subsubsection{Statewide Railroad Surveys}

Surveys will be conducted primarily to collect relevant data from the railroad companies and governmental agencies. The specific data sought will be guided by several end products. These products are system maps identifying special features of the statewide system. Six maps are needed, namely, system-identification, structural-capacity, current traffic-volume, future traffic-volume without repository, traffic-volume with repository, and accident-rate. A route-condition evaluation is also part of the survey.

The system maps will be on a base map of Texas at a scale of 1:1,000,000 with all railroad operating lines shown. High-quality graphic techniques will differentiate the various features.

System-Identifica:ion Map. This map will identify Texas railroad lines during the first year of site characterization and the owner and operator(s) on each operating line segment. Segments will be bounded at significant termini such as major communities, junctions, or standard changes. The map wi11 also show the number of continuous tracks in the segment and the industry-recognized classification for that segment. 
Structural-Capacity Map. This map possibly could be combined with the system-identification map, but will be planned as a separate map until the combination scenario is found to be clearly viable. This map will identify the weaker links in terms of the system's structural integrity.

The units to be shown will be determined during evaluation of data collected. The key aspects are expected to be the wheel-loading rating for the track, the wheel-loading capacity of the bridges, and the designated operating speed for each segment.

Current-Traffic-Volume Map. The average number of trains per day and the total tonnage per year will be shown by system segments. Segment termini will be seiected as points at major communities, junctions, or other logical points of volume change. The current year will be selected as the calendar year immediately preceding the year in which the repository begins operations.

Future-Traffic-Volume Map Without Repository. This map will be similar to the map for the current year, but with values forecasted in the last year of repository operations, without the repository-generated traffic included. This map would, however, include any probable system improvements not related to the repository.

Future-Traffic-Volume Map with Repository. This map would portray tr.affic in the same future year as the preceding map but with the inclusion of repository-generated traffic. It also would show probable system improvements, including those related to the repository.

Accident-Rate Map. This map will compile and visually designate the accident rate on the existing system over the past 5 years. Either the number of accidents-per-year per train-mile traveled or the number-per-year per tonmile of freight hauled may be computed. This map will evaluate accidentfrequency potential and the best indicator of that should be used.

Route Improvement Map (Optiona 1). If data collected indicates a substantial amount of improvements are planned on the statewide routes, then another map will be complled indicating the location and identifying codes for the improvements. The map will also feature the cost, funding source, and expected year of completion for the planned improvement.

Route Condition. This plan will provide backup for data collected from interviewing the appropriate organization by completing a reconnaissance inspection of the alternative routes, and by producing an aerial mosaic of the routes. The procedures, similar in approach to those outlined for the sitevicinity study component, will positively document the routes' primary features. Less detail and accuracy will be sought for statewide alternative routes.

The inspection will consider 30-to $80-\mathrm{km}$ (20-to 50-mi) segments unless review of data collected from owners and agencies indicates otherwise, or unless major changes in character occur (rural to urban, change in number of tracks, different size rail, etc.) and will be performed primarily by a trained technician traversing the line on a "high-rail" equipped vehicle. A standard condition log will be prepared for each segment as described for site-vicinity inspections. 
Uncontrolled aerial mosaics, including at least $1.6 \mathrm{~km}$ ( $1 \mathrm{mi}$ ) on each side of the route, will be at a scale of $1: 24,000$. The mosaic will be compiled from aerial photography taken from an altitude appropriate for the planned scale.

These sets of backup data will be filed, and their identity included on an overall map and on the computerized indexed tracking system.

\subsubsection{Site-Vicinity Railroad Surveys}

Technical procedures for railroad surveys in the site vicinity include preparation of an overall map, route maps, photographic route logs, facilitycondition logs, traffic-volume map, and the coordination with owners and operators necessary to generate the data.

Overa11 Map. An overall system map of the project vicinity will be compiled with existing data and the results of previous studies. The map will show both existing railroad lines and proposed lines, including new lines into the repository. The map will be at a scale of 1:100,000 with high-quality graphic techniques (such as color coding) to distinguish between existing and proposed facilities. Other overall characteristics, such as classification and number of tracks, will also be shown.

Route Maps. To define each route's specific elements, 1:1,200 strip maps will be compiled from aerial photography taken very early in the site characterization work. The maps produced will cover a width sufficient to show the area 60 meters $(200 \mathrm{ft})$ on each side of the existing and proposed alignment. Maps will be produced as orthophoto maps with $.5-m(2-f t)$ contours. A profile of the route centerline ground and grade elevations will be included below the orthophoto plan view on the same sheet.

Routes will be shown as they exist at the time of the aerial flight. Separate maps will be made for any proposed improvements to the facility, with the improvement clearly shown in the planimetric view. Proposed changes will include those planned both including and excluding the presence of the repository. Long segments of new routes will also be mapped with the planimetric view for the new facility clearly indicated. This view will include cut-and-fill toe lines. The map will also include the centerline profiles as explained for the existing routes.

Photographic-Route Log. A color-photo log will be kept for both existing and proposed routes to completely document the ground-view condition of each route at the start of site characterization. Either of two techniques can be used, but in some cases, both could be justified. The two techniques are

- Video tape taken from a unit moving along the main track at low speed

- 35-mm photographs taken about $2 \mathrm{~m}(7 \mathrm{ft}$ ) above the track at $30-\mathrm{m}$ (100-ft) intervals along the main track.

Each technique would be indexed to an exact milepost or station on the line and each would be a straight-on view in the direction of increasing 
mileposts or stations. The video-tape technique is recommended for existing routes. The 35-mm-still-photo technique is recommended for new routes, mainiy because a vehicle could probably not travel smoothly at any reasonable speed over the new alignment.

Facility-Condition Log. A facility-condition log will also be kept to complement the visual-image documentation. This consists of an indepth field inspection of existing facilities, and an indepth field review of purposed new routes. It is absolutely imperative that the condition inspection be conducted by an individual with extensive experience in both engineering and operation of railroads.

Facility-condition inspection will be performed for each 1-km (0.6-mi) segment, or wherever there is a change in a key characteristic or condition. The inspection will be documented on field data sheets. The data sheets will include the date, the inspector's name and signature, and a route-segment location indicator clearly linking it with the milepost or station system used in the photo $10 \mathrm{~g}$. Ideally, this field inspection would also be used to add notes to the route orthophoto maps for better identification of specific features (e.g., size of culverts, frog number of turnout).

The following are among the more important features to be recorded for existing routes:

- Road bed

- Horizontal width

- Side-slope steepness

- General relationship to natural ground (cut or fill)

- Track

- Number of tracks

- Rail - weight, joint or CWR (continuous rail), wear, end batter

- Tie plates - size, number of spikes, condition

- Ties - material, size, length, condition, remaining life

- Ballast - width, depth, type material, conditions

- Turnouts

- Configuration

- Frog angle or number

- Length transition

- Switch actuation mode

- Wear, end batter

- Bridges and culverts

- Lengths, spans, diameters, etc.

- Materials - substructure and superstructure

- Foundation type

- Width

- Condition

- Load rating

- Signals

- Operating system 


$$
\begin{array}{ll}
\text { - } & \text { Type } \\
\text { - Condition. }
\end{array}
$$

Field inspection for new routes will be directed toward recording features like the following items:

- Existing land use and ownership

- Surface-soil type .

- Improvements (including fences)

- Vegetation cover

- Existing drainage and utilities

- General slope - steepness and direction.

Traffic-Volume Maps. Two additional system maps of the vicinity will be compiled based on the collection of existing data and the analysis of repository needs. Both maps will be at a scale of $1: 100,000$ with high-quality graphic techniques (including color) to clearly define differences in traffic volume.

One map will portray the volume of traffic on the route during the first year of site characterization. Routes will be segmented to reflect points of change (branching points). Traffic levels will be indicated by average daily number of trains, peak-day number of trains, and directional split for each segment.

The other map will show the same type information as the first, but with all proposed new routes in place and in future-year configuration with the full-operating repository in place. This map will also indicate traffic volumes for the average year and for the peak year, considered over the entire life of the repository's operations.

Coordination with Owners and Operators. Close coordination and cooperation with the railroad companies and other land owners will be required by the transportation site-study team to accomplish this site-vicinity survey. Most of the work necessary to compile the maps and logs needs to be accomplished early in the site characterization. The following are among the more important activities that require the interrelationship of the owners and operators:

- Field-control surveys and marking for aerial mapping

- Access permission for field inspections

- Access and scheduling for photo logging

- Collection of documents for existing usage plans, operations, etc.

\subsubsection{Roadway-Systems Survey Procedures}

Both site-vicinity and statewide roadway systems will be surveyed to an appropriate level of detail in a manner similar to the procedure described for railroads. Much information will be available from State and local highway 
agencies, particularly for the statewide viewpoint. A considerable amount of field work will be required to survey roadways in the site vicinity. Products resulting from the survey work (maps and indexed logs) will be similar to those produced for the railroads.

\subsubsection{Statewide Roadway Surveys}

Surveys will be conducted primarily to collect relevant data from the Federal, State, and local highway authorities. The specific data sought from them will be guided by several end products proposed. These products are system maps identifying special features of the statewide highway system. Five maps are needed, namely, system-identification, capacity, current traffic-volume, future traffic-volume, and accident-rate. A log of route conditions is also needed. A sixth route-improvements map may also be needed.

The system maps will be on a base map of Texas at a scale of $1: 1,000,000$ with all public roadways shown. High-quality graphic methods will differentiate the features.

System-Identification Map. This map will identify the highway segments according to the uniform nationwide system. The route number will be indicated along with an indicator for number of lanes.

Capacity Map. This map will identify the average daily traffic (ADT), which represents the current volume on the facility. The posted speed and the design speed for each segment will be shown.

Current-Traffic-Volume Map. ADT (number of vehicles) and a design hourly volume indicator, most likely the 30th highest annual hour (number of vehicles), will be shown on this map for the current year. Current year will be selected as the calendar year immediately preceding the year in which the repository begins operations.

Future-Traffic-Volume Map. This map will be similar to the map for the current year, but with values forecasted in the last year of repository operations. The map will include planned new routes, including those to the repository.

The initial plan is to map future roadway traffic with and without the repository on one map. The traffic volumes generated by the repository most likely will have an insignificant effect on future traffic forecasts at the statewide level. Should analysis of the data show that significant differences are created by the repository activities, this map would become two, one with and one without the repository's effect.

Accident-Rate Map. This map will compile and visually display the accident rate on each segment over the past 5 years in number-of-accidents per million vehicle-miles traveled.

Route-Improvement Map. If data collected indicates a substantial amount of route improvements are $p l a n n e d$ on the statewide routes, then another map will be compiled indicating the location and identifying codes for the 
improvements. The map will also feature the cost, funding source, and expected year of completion for the planned improvement.

Route Condition. This plan will provide backup for data collected from the appropriate organization by completing a reconnaissance inspection of the alternative routes and by producing an aerial mosaic of the routes. The procedures, similar in approach to those outlined for the site-vicinity study component, will positively document the routes' primary features. Less detail and accuracy will be sought for statewide alternate routes.

The inspection will consider 30-to 80-km (20-to 50-mi) segments unless review of data collected from agencies indicates otherwise, or uniess major changes in character occur (rural to urban, change in number of lanes, different type pavement, etc.) and will be performed primarily by a trained technician traversing the route by vehicle. A standard condition $\log$ will be prepared for each segment as described for site-vicinity inspections.

Uncontrolled aerial mosaics, including at least $1.6 \mathrm{~km}$ ( $1 \mathrm{mi}$ ) on each side of the route, will be at a scale of $1: 24,000$. The mosaic will be compiled from aerial photography taken from an altitude appropriate for the planned scale.

These sets of backup data will be filed, and theip identity included on an overa11 map and on the computerized indexed tracking system.

\subsubsection{Site-Vicinity Roadway Surveys}

Technical procedures for roadway surveys in the site vicinity include preparation of an overall map, route maps, photographic route logs, facility condition logs, a traffic volume map, and the coordination with owners and agencies necessary to generate the data.

Overall Map. An overall roadway system map of the project vicinity will be compiled with existing data and the results of previous studies. The map will show both existing and proposed roadways, including access roads to the repository. The map will be at a scale of 1:100,000 with high-quality graphical methods (color, shading, etc.) to distinguish between overall characteristics, such as Federal and State classification, number of lanes, and design speed.

Route Maps. Each route's specific elements will be defined by generating $1: 1,200$ orthophoto strip maps complied from aerial photographs taken very early in site-characterization work. These maps, made with .5-m (2-ft) contour intervais, will include the area $60 \mathrm{~m}$ (200 ft) outside each existing or proposed right-of-way. A ground and grade elevation profile for the roadways centerline will be shown on the same sheet with the plan view.

Routes will be shown as they exist at the time of the aerial flight. Separate maps will be made for any proposed improvements to the systems, with the improvements clearly shown in the planimetric view. Proposed changes will include those planned both including and excluding the presence of the repository. Any new routes will also be mapped with the planimetric view for the new facility clearly indicated. This view will include cut-and-fill toe 
lines. The map will also include the centerline profiles as explained for the existing routes.

Photographic-Route Log. A color photo log will be kept for both existing and proposed routes to completely document the ground-view condition of each route at the start of site characterization. Either of two techniques can be used, but in some cases, both could be justified. The two techniques are

- Video tape taken from a unit moving along the roadway centerline at low speed

- $35 \mathrm{~mm}$ photographs taken about $2 \mathrm{~m}(7 \mathrm{ft})$ above the roadway centerline every $30 \mathrm{~m}(100 \mathrm{ft})$.

Each technique would be indexed to an exact milepost or station on the road and each would be a straight-on view in the direction of increasing mileposts or stations. The video-tape technique is recommended for existing routes. The 35-mm-stil1-photo technique is recommended for new routes, mainly because a vehicle could probably not travel smoothly at any reasonable speed over the new alignment.

Facility-Condition Log. A facility-condition log will also be kept to complement the visual image documentation. This consists of an indepth field inspection of existing facilities, and an indepth field review of any proposed new routes. It is absolutely imperative that the condition inspection be conducted by an individual with extensive experience in engineering and maintenance of highways.

Facility-condition inspection will be performed for each $1-\mathrm{km}(0.6 \mathrm{mi})$ segment, or wherever there is a change in a key characteristic or condition. The inspection will be documented on field data sheets. The data sheets will include the date, the inspector's name and signature, and a route-segment location indicator clearly linking it with the milepost or station system used in the photo $\mathrm{log}$. Ideally, this field inspection would also be used to add notes to the route-orthophoto maps for better identification of significant features (e.g., size of culverts, depth of ditches).

The following are among the important features to be recorded for existing routes:

- Roadbed

- Horizontal width

- Side-slope steepness

- General relationship to natural ground (cut or fi11)

- Pavement

- Type

- Extent of deterioration and cracking

- Width, apparent thickness

- Condition of markings (striping)

- Roughness (preferably recorded by a dynamic, continuousrecording mobile device)

- Structural capability (preferably recorded by a continuousdeflection mobile recorder) 
- Bridges and culverts

- Lengths, spans, diameter, skew, etc.

- Materials - substructure and superstructure

- Foundation type

- Width

- Condition

- Load rating

- Signing

- Regulatory, warning, and advisory

- other (including billboards and other advertising)

- Traffic signals and lighting (if any)

- Type, spacing, etc.

- Electric supply system and controls

- Condition

- Roadside

- Vegetation

- Trash accumulation

- Drainage.

Field inspection for new routes will be directed toward recording features like the following items:

- Existing land use and ownership

- Surface-soil type

- Improvements (including fences)

- Vegetation cover

- Existing drainage and utilities

- General slope - steepness and direction.

Traffic Volume Maps. Two additional system maps of the vicinity will be compiled based on the collection of existing data and the analysis of repository needs. Both maps will be at a scale of 1:100,000 with high-quality graphic techniques (including color) to clearly define traffic volume differences.

One map will portray the volume of traffic on the route during the first year of site characterization. Routes will be segmented to reflect points of change (junction points). Traffic levels will be indicated by average daily number of vehicles, peak-hour number of vehicles, and directional split for each segment. It will also portray the current "level of service" on each segment.

The other map will show the same information as the first, but with any proposed new routes in place and in a future-year configuration with the fulloperating repository in place. This map will also indicate traffic volumes for the average year and for the peak year, considered over the entire life of the repository's operations. Traffic will be shown for average daily traffic, peak-hour volumes, and "level of service" indicator.

Coordination with Owners and Agencies. Because actual surface area is involved, close coordination and cooperation with the public highway agencies, 
law enforcement officials, and land owners will be required by the transportation site study team to accomplish this site-vicinity survey. Most of the work necessary to compile the maps and logs needs to be accomplished early in the site characterization. The following are among the more important activities which require the interrelationship of the owners and agencies.

- Field-control surveys and marking for aerial mapping

- Access permission for field inspections

- Access and scheduling for photologging

- Collection of documents for existing usage plans, operations, etc.

\subsubsection{Port Facility Survey Procedures}

This survey will be applicable to the statewide viewpoint only, since no ports exist in the immediate vicinity of the site. All ports to be surveyed exist in Texas from ocean access via the Gulf of Mexico directly or indirectly. A master index map showing all port cities and individual ports will be produced on a base map of the state of Texas at a scale of $1: 1,000,000$.

\subsubsection{Port City Maps}

The collection of data will be guided by the need to generate five maps for each port city. The maps will be at a scale of $1: 24,000$. High-quality graphic techniques will be used to distinguish the features designated on each map. The necessary maps for each port city include port-identification, portoperations, current-cargo-volume, future-cargo-volume, and accident-rate.

Port-Identification Map. This map will identify the location of each port facility considered, along with its waterside draft, navigation facilities, marine approaches, total number of berths, and owner(s) and operator(s).

Port-Operations Map. This map will show the existing and future planned cargo handling capability for each port facility under consideration differentiated by type of packages (i.e., containers, buik). The map will also indicate the existing and planned transfer capability by interfacing mode (i.e., rail, truck). Capability indicators will be shown for both loading and unloading activities in units such as tons-per-hour. This map will also designate any existing or planned capability to handle nuclear waste packages.

Current-Cargo-Volume Map. This map will show the current volume of cargo being handled by each port facility for both waterside and intermodal points in tons per average day of the current year and total tons for the current year. The current year will be the calendar year immediately preceeding the year in which the repository begins operation. The volumes will be segregated by type of packages (i.e., containers, bulk). 
Future-Cargo-Volume Map. This map will show the same information as the previous one, except with values forecasted in the last year of repository operations. No distinction is needed for repository impacts since these are likely to be insignificant. The volumes shown, however, will reflect any improvements made to the port facilities, either waterside or intermodal points. Any additional facilities required for handling nuclear waste packages will be indicated.

Accident-Rate Map. This map will indicate a measure of accidents within the last 5 years for each port facility.

\subsubsection{Port Facility Maps}

In addition to the maps described above, a detailed facility map will be prepared for each port facility. These maps will be to a scale of $2.5 \mathrm{~cm}=$ $30 \mathrm{~km}(100 \mathrm{ft})(1: 1,200)$ and will be orthophoto maps produced from aerial photographs. These maps will include .5-m (2-ft) contour intervals, and will show all existing structures and installations at the subject facility. Underground, surface and overhead utilities will also be plotted, from portsupplied information. The marine features, including wharves, berthing and turning basins, dolphins and buoys will also be shown.

\subsubsection{Traffic-Study Procedures}

The statewide component of transportation studies will be conducted using existing data collected and assimilated in a form appropriate for analysis and evaluation. Some existing data will also exist for the specific site vicinity, but the micro-analysis and evaluation needed for the site-vicinity studies creates a need for field data collection during site studies. To a significant extent this work is for obtaining baseline information, as has been described for the photo $10 \mathrm{~g}$ and condition inspections. The traffic-study data will be included on the computerized indexed tracking system that has been described for data gathering study components.

To properly characterize roadway usage and impacts, field data are needed for both the existing traffic situation and the situation during site-characterization efforts. Data obtained from these traffic studies will become critical in creating site-vicinity-roadway-survey maps. Since no railroad currently serves the site vicinity, the baseline studies are not applicable for the railroad mode. Seasonal effects of weather and agricultural activity will be considered. Buried sensors and data transmission to remote counters will be employed if vandalism or roadway uses require such an approach.

\subsubsection{Initial Traffic Studies at Site Vicinity}

The only way to assure a true baseline is for initial traffic studies to be performed before any other site studies get underway. Since only 1 week will be required to accomplish the initial data collection, this will not be a serious constraint to other activities. The Transportation SSP will, therefore, commence site-vicinity traffic studies within 30 days of a notice to proceed with site characterization. 
Five types of data collection procedures will be performed. The four studies are

- Continuous automatic counts

- Manual turning-movement counts

- Manual counts by vehicle classification

- Origin-destination studies

- Time-delay route studies.

These are widely-used techniques in the highway-planning discipline which have proven to produce reliable data. If traffic signals exist at intersections, additional data on signal operations will be recorded. Manual counts may be omitted in favor of automatic counting if substantial programmatic or budgetary incentives to do so are found to exist.

Continuous Automatic Counts. Continuous automatic counters, which provide accurate counts of total number of vehicles for any hour and for any day, will be set up at selected locations and put into operation as rapidly as possible. Monday of the week selected for traffic studies would be ideal. The counters may be left in place throughout the entire site-characterization period. A printout will be collected periodically (probably once a week). The device will be checked each work day to assure that it is operating correctly.

Turning-Movement Manual Counts. This study will be conducted, ideally, only after the continuous counter has been in operation for 2 days. The manual counts will be taken at key route intersections by trained technicians (one per intersection is anticipated, although two per intersection may be necessary). The counts will be made on at least 3 days: Wednesday, Friday, and Saturday. Wednesday represents a typical weekday. Friday represents a transition from weekday to weekend. Saturday represents weekend conditions. . on weekdays, counts will be taken at the peak periods indicated by the continuous counter. It is anticipated that two peaks will be involved: a 2-hour period in the morning, and a 2 -hour period in the late afternoon. Saturday turning movements will be taken from dawn until midnight.

The turning movements will be recorded on a form specifically developed for the procedure. It will differentiate direction both for the "from" and "to" movement of each vehicle through the intersection. General intersection operational features will also be noted, such as length of queve for left turns.

Manual Counts and Categorization. This study will take place on the same days as the turning movement counts. The counts by vehicle classification will be performed for a 24-hour continuous period at selected locations. The counts will be accumulated by type vehicle (passenger automobile, single unit truck, bus, etc.). This segmentation of type traffic can be applied by proportions to the totals for any period taken from the continuous counter. If unpredicted results are obtained from these counts, additional 24-hour counts will be necessary to confirm study accuracy.

Time-Delay Route Travel Studies. The various routes to and from the site within the site vicinity will be analyzed for congestion and delay by timed repetitive driving of the routes under varying conditions at predetermined 
times of the day for predetermined days of the week. The travel delay studies will be conducted on a least 3 days: Wednesday, Friday, and Saturday, as with the manual counts. These two study activities will be coordinated for data-correlation purposes.

Oriain-Destination Studies. A crucial component of the transportation aspects of site characterization will be forecasts of the repository's construction and operational years. For that forecast, repository-generated traffic for the future is combined with forecasts for traffic increases generated by other factors.

The origin-destination (080) studies will provide data for use in conjunction with other data (i.e., population growth, other economic activity) by a transportation planner to forecast anticipated traffic growth not attributable to repository activities. The 0\&D studies will determine what factors are causing the existing traffic on the road.

The O\&D studies will include interviews with vehicle operators in a sampling of the traffic at the site. This will require assistance from police or security personnel, in that the traffic must be safely stopped or diverted into an interview station. O\&D studies will be performed on at least one day in the traffic study week, although better results would be obtained from a 2-day or 3-day sampling. Tuesday or Thursday is preferred if only one day is used, Friday is preferred as a second weekday, and Saturday is preferred as a third day. Although a 24-hour continuous operation is ideal, a dawn to midnight operation could suffice. The amount of interviewing actually performed during these 080 studies will depend primarily on what is acceptable to site characterization project and Texas State officials.

Each vehicle's operator will be asked a set of standard questions, such as the following:

- Where did your trip start?

- Where will it end?

- Purpose of the trip (e.g., hauling freight, pleasure, business, etc.)?

- How often do you take the same trip (i.e., with same origin and destination)?

- If the same trip is frequently made, are other routes ever used?

\subsubsection{Follow-up Traffic Studies}

The initial studies will provide adequate baseline data. Since site characterization will be conducted over a multi-year span, additional traffic studies are planned. The follow-up studies will accomplish three purposes:

(1) Confirmation of initial data results

(2) Indication of growth in traffic without the project 
(3) Indication of traffic generated by site characterization
activities.

The same types of procedures will be involved as were described for the initial studies. A less intense level, however, is needed.

Continuous Counter. During the first year of site characterization, the counter will be left in place for specific, previously determined periods of time. If very predictable results are being obtained after 2 months of operation, the counter will be removed. It will be installed again after 2 months and left in operation for 2 months. If little variation is noted, the offtime will be increased to 3 months or whatever seems appropriate.

If significant variations are recorded in traffic from day to day or week to week, or if significant traffic growth is apparent, the monitoring device may be left in place all the time.

Turning Movement Counts. Turning movement counts will be made every 3 months after the initial studies during site characterization. A 1-day (midweek) count during the peak hours will be made.

Manual Count by Vehicle Classification. These counts will be taken every 3 months after the initial studies on the same day as the turning movement count. A 24-hour period will be studied.

O\&D Studies. These follow-up studies will be taken at least once each year after initial studies, but preferably every 6 months. Each study wi11 be made during mid-week, preferably for a 24-hour duration.

If traffic signais exist at intersections being studied, signal operation data will be recorded.

\subsubsection{Data Collection by Others}

During site characterization studies, highway planners working for local, State, and Federal jurisdictions not associated with the project will collect various types of data for planning purposes. It would be, however, a very valuable supplement to the field work done specifically for the repository site characterization.

The agencies and groups responsible for these studies will be contacted regularly to obtain current data. The exact procedure for accomplishing this will be established during the initial contact performed in accordance with methods described in Section 3.3. All data obtained will be identified on the computerized tracking system.

One likely set of data will be short duration traffic counts taken at various locations in the site vicinity as part of a regular program. Although it is not likely these data will be collected at the same places as site characterization counts, they should serve as an excellent check. 
The other important data item to pursue is accident occurrences in the site vicinity. These data are normally originated by law enforcement investigations, but documented by highway agencies.

\subsubsection{Site Characterization Project Transportation Data}

These data will be collected from project management sources, not individual employees. The data-gathering will be accomplished by the socioeconomics discipline, under Transportation discipline direction.

\subsubsection{Flight-Path-Assessment Procedures}

Aircraft use of airspace in the vicinity of the potential transportation corridors must be analyzed during site characterization. This plan seeks to identify the number and type of civilian and military low-level overflights such as takeoff and landing approaches, crop dusters, and other such potential aircraft hazards to be expected along the routes. The commercial aircraft data should be fairly easy to obtain and are expected to be reasonably accurate. Data regarding private air traffic will be difficult to acquire and estimates may be necessary. Data, or even estimates, on military air traffic may be very difficult to obtain since security classification may be involved. The Federal agencies involved with air traffic are good sources of information, and their input will be relied on to a great extent.

Maps will be compiled to document the air traffic aspects. One will be for the site vicinity. Also, maps of large-scale viewpoints as required along the transportation corridors and at the repository site vicinity will also be prepared.

Site-Vicinity Viewpoint. This map will be on a site-vicinity base at a scale of 1:100,000. It will show any approach and departure patterns in the airspace of the site vicinity. The existing and future average daily number of aircraft in the patterns will be shown. The map will aiso portray statewide low-level overflight patterns that cross or enter the site-vicinity airspace. The existing and future volume of air traffic will be included for each such pattern.

Specific Route Location Viewpoints. These maps will be prepared for each location where the transportation corridors being studied are in proximity to an airport or other aircraft facility or is in an area of low aircraft flight patterns, such as crop dusting areas. The maps will show any approach and departure patterns in the airspace of the area under consideration. The existing and future average daily number of aircraft in the patterns will be shown. The maps will also portray low-level overflight patterns that cross or enter the airspace of the area under consideration. The existing and future volume of air traffic will be included for each such pattern. Unless the conditions indicate otherwise, a scale of $1: 12,000$ will be used. 


\subsubsection{Hazardous-Materials-Survey Procedures}

Similarly to the flight path assessment procedures described in the preceding section, maps will be compiled showing hazardous materials activity in the site vicinity and along the alternative statewide transportation routes. High quality graphical techniques will be employed to differentiate the specific features of the information. Until the data are obtained, it is premature to indicate exact types of features to be included. If substantial characterization features become involved, more than one map may be needed for each area under consideration.

Statewide Viewpoint. This map will be a Texas base at a scale of $1: 1,000,000$. High quality graphic techniques will be used to differentiate the features. It will show both existing and planned hazardous material storage or use locations. Notations and legends will be used to identify general classifications of hazardous materials involved.

Site-Vicinity Viewpoint. This map will be on a site-vicinity base at a scale of 1:100,000. It will show specific locations of hazardous materials storage or use, together with an identification of the user and the material or materials involved.

Specific Route Location Viewpoints. These maps will be prepared for each location where the transportation route being studied are in proximity to locations where major concentrations of hazardous materials pose a significant hazard to site-related shipments. For example, nearby petrochemical refineries or nuclear-weapons assembly plants would be identified as such locations. Unless conditions indicate otherwise, a scale of $1: 12,000$ will be used.

\subsubsection{Emergency-Response-Survey Procedures}

A statewide map of Texas at a scale of 1:1,000,000 will depict 1ocation, type, and capacity for salient emergency response capability. The data collection will be handled in the same manner as for other study components, including indexed tracking. The compilation of data for meaningful consolidation, will include only the response capability that can be depended upon. Another statewide map will identify areas of Texas where weather phenomenon occur that could hamper response operations, and a third will identify other hazards. A fourth statewide map will summarize the foregoing information. Similar maps will be prepared for the site vicinity viewpoint at a scale of $1: 100,000$ and specific route location viewpoints to be identified at scales of $1: 12,000$.

\subsection{EQUIPMENT AND MATERIALS}

For transportation aspects of the site characterization, equipment and materials will be needed for three distinct task groups:

- Statewide collection of available data

- Site-vicinity data generation

- Feature maps compilation. 
The identification and use to be made of the equipment and material, how they are to be procured, and the logistics of their operations, will be covered in turn for all three task groups.

\subsubsection{Equipment Use}

The previous sections of Chapter 3 have identified the methods and procedures needed for the transportation studies. In several instances the equipment has already been identified and its use described. This section summarizes all the specific equipment and major materials needed for the transportation study as currently planned.

\subsubsection{Available Data Collection Tasks (Statewide Routes)}

Four transportation modes (railroad, highway, waterway, and aircraft) must be covered by the data collection operations. No magical "black box" exists to do these tasks, although some of the data may be on computerized database storage systems. The task requires a persistent, determined group of team members talking to knowledgeable individuals, visiting offices or institutions where the data are stored, and generally tracking all leads until the data base identified by the technical procedures is obtained.

Some of the data will be difficult to obtain, requiring the individuals assigned to the task to be ingenious and resourceful. An example is the need for military aircraft fight data.

other data may be very easily obtained by verbal or written request. It is anticipated that all highway data can be obtained by contacting the Texas State Department of Highways and Public Transportation.

These data collection techniques, regardless of transportation mode, are essentially identical. The equipment and materials needed are described in the following paragraphs.

Computerized Indexing System. A computer or word processor is needed to track the data collection process. Comnercially available software packages will most likely suffice. The computer can be shared with other site study functions if its avallability for transportation aspect uses are good.

Miscellaneous Equipment and Materials. Standard drafting and graphical arts paraphernalia will be needed to make "mock-ups" of the worksheets for map compilation processes.

\subsubsection{Site Vicinity Data Generation Tasks}

Data generation in the site vicinity targets several highway and railroad routes for indepth analysis. The work involved is within one of four tasks:

1. Aerial photography and ground control

2. Photologging 
3. Condition inspections

4. Traffic studies.

The equipment and materials needed for each task are itemized in broad terms only.

\section{Aerial Photography and Ground Control}

- Land survey equipment

- Modern angle-distance instruments (third order accuracy)

- Targets, stakes, plumb bobs, 100-foot chains, etc.

- Color flagging, lath, and markers

- Survey monuments

- Reinforcing steel bars (\#5 and \#6)

- Brass caps and stamping equipment

- Aerial targets

- Plastic material on rolls (for natural ground)

- Spray paint and templates (for pavement)

- Vehicles (two per survey team)

- Pick-ups

- Suburban, carry-a11, or vans

- Aerial photo unit

- Aircraft

- Aerial camera (suitable for map scale desired)

- Film and plates

\section{Photologging}

- Camera

- Video recording camera with indexing capability

- $35 \mathrm{~mm}$ SLR camera

- Film

- Audio tape recorder

- Dictation type hand-heid recorder

- Disks

- Vehicle

- One equipped to handle video camera on rails

- Four-wheel drive autos (for new routes)

- Storage area file containment

- Wa11-mounted indexing system 


\section{Condition Inspections}

Standardized forms for recording information

- Four-wheel drive auto

- $35 \mathrm{~mm}$ camera

- $35 \mathrm{~mm}$ film

- Storage area file containment

- Wall-mounted indexing system

\section{Traffic Studies}

- Continuous counters

- Automatic, battery operated units

- Chains and padlocks (for security)

- Forms for summarizing data

- File storage for data

- Wall display for current results

- Counter recording tapes

- Turning movements

- Automobile suitable for operations

- Standard forms for recording

- Standard forms for summarizing

- Intersection count boards

- File storage for data

- Wall display for current results

- Manual count categorization

- Automobile suitable for observations

- Standard forms for recording

- Standard forms for summarizing

- File storage for data

- Wall display for current results

- Manual counters

- Origin - destination studies

- Van suitable for the procedure

- Traffic signs and markers (cones and barrels)

- Lighting plant (with generator)

- Safety vest (luminous)

- Standard forms for recording interview

- Standard Forms for summarizing

- File storage

- Wall display for current results.

\subsubsection{Feature Maps Compilations}

The maps identified by the technical procedures can be compiled by standard mapmaking techniques, but state-of-the-art equipment should be 
employed to assure clear, concise, and comprehensive information is portrayed. The following kinds of maps are involved:

- Statewide planimetric color maps (Texas base, 1:1,000,000)

- Site vicinity planimetric color maps $(1: 100,000)$

- Route strip maps, plan (orthophoto) and profile $(1: 1,200)$.

- Specific area maps (orthophoto) $(1: 24,000,1: 12,000$ and $1: 1,200)$.

The first two categories will all have the same base, with each version showing different special features. The latter two will be processed individually through precision mapmaking techniques.

Statewide and Site-Vicinity Maps. Equipment and materials needed for compilation of both these categories are the same. Each will require at least one base map with existing transportation routes and terminais shown. Major communities will aiso be on the base maps. Prints of the base maps will be used as worksheets for drafting on both collected and generated data to make the various feature maps called for by the technical procedures. Since a wide variety of processes can accomplish this process, the equipment and materiais are listed by very general definition:

- Drafting tables and equipment

- Standard graphical art supplies

- Photographic color reproduction machines

- Computer-aided design and drafting (CADD) system.

This equipment and material for transportation study maps can be shared with other disciplines doing similar work as long as availability for transportation aspects is timely.

Route Strip Maps, Specific, and Area Maps. These maps will be based on aeria photography and ground control surveys. Sophisticated orthophoto map production equipment will be needed. Several types of processes are acceptable, but the following are general definitions of the equipment and materials needed:

- Flight strip film development

- Plate production and control point marking

- Platter for orthoprojection

- Orafting tables and equipment

- Plan and profile marked mylar

- Reproducing machine and print paper.

This equipment and material can be shared with the other disciplines if its availability for transportation aspects is timely.

\section{5 .2 Procurement}

The equipment and materials needed are not items that are difficult to obtain. Several factors combine in determining how best to procure this equipment. As already mentioned, much of the equipment can be shared with other disciplines, and its procurement will be coordinated with these other disciplines to obtain cost effectiveness. 
Some can be purchased directly from competent, reliable suppliers. As noted in the discussion of the equipment's use, some of it will be purchased as part of equipping a site study project office.

other items may be rented or leased. This is possible for specialized vehicles and traffic counters. This will be the preferred method where only short-term use is involved and rental or leasing arrangements are readily available.

In many cases it may not be necessary to actually acquire the equipment. Much of the technical procedures can be accomplished by service subcontractors who already possess the appropriate equipment. Examples of services conveniently procured include field land surveying, map production, and photologging. Subcontractors could be selected from communities in the Texas panhandle or communities close to the site.

The procurement of items and services is controlled to ensure conformance with project contract requirements. The selection of suppliers and subcontractors will be based on an evaluation of their capabilities using one or more of the following methods:

- Direct survey

- Evaluation of the supplier's history, including user experience and records

- Evaluation of the supplier's current quality records, including evaluation of the quality assurance program, and procedures to ensure that the applicable requirements of ANSI/ASME NQA-1 (ASME, 1986) are met.

When it is determined that the selected supplier is capable of providing the items or services specified, measures will be taken to verify that the supplier is implementing appropriate controls. This verification is accomplished by specifying quality requirements within the procurement documents and then monitoring the supplier's performance and correcting the performance as required. Monitoring is accomplished through a combination of document review, source surveillance, hold and witness inspections, receipt inspections, and audit activity.

\section{5 .3 Logistics}

To support the equipment's use, some logistics will be involved. Except for data collection activities requiring travel to other locations within the State of Texas (such as ports along the Guif Coast) and locations elsewhere in the U.S. (such as AT\&SF headquarters in Chicago, IL), the logistical aspects of site characterization activities will take place at the study's project office or within the site vicinity. Many activities involve short duration tasks that allow support services to be shared with other discipline studies. 
The discipline leader of the transportation study will schedule activities to minimize the cost of the work while maintaining the quality and reliability of study results. The following items are some of the important logistic support items that will be required:

- Anchoring system and security locks for traffic counters

- Weekly collection of data from traffic counters

- Law enforcement and traffic control for O\&D interviews

- Traffic control for photologging activities.

\subsection{DATA ANALYSIS}

This section discusses how the data obtained through field collection activities (discussed in Sections 3.1 through 3.4) will be analyzed. The data analys is will be conducted in part as an SSP activity within the scope of work defined by this document and in part within the scope of other activities not included in this SSP. The following sections summarize the nature of the data analyses and indicate whether such analyses are iricluded within the scope of work of this SSP. Where analyses are included within this scope, a more detailed description of the analysis procedure is presented.

\subsubsection{Rail Corridor Characterization Studies}

Within the site vicinity, data will be collected to characterize alternative rail corridors and confirm the selection of a preferred corridor. The data collection activities are as follows:

- Survey existing rail systems in project vicinity

- Assemble projections of repository-generated traffic

- Assess alternative corridor environmental conditions

- Collect environmental data to confirm preferred corridor selection.

The transportation effects of the repository are expected to be most intense within the site vicinity. A rail spur will be provided to the site, and projections of rail traffic appear to not warrant concern for exceeding rail infrastructive capacity (EA, Section 5.3.1.1). However, the following two railroad-transportation data-analysis programs will be included in this SSP:

- Superimpose projections of repository-generated rail traffic onto existing rail traffic data for the site vicinity

- Summarize projected impacts of repository traffic on the rail system in the site vicinity. 
Superimpose Projections of Repository-Generated Rail Traffic. The repository designer will develop forecasts of repository-generated traffic for the construction, operation, and decommissioning phases of the project. Similar forecasts have also been developed in the Environmental Assessment. These forecasts will be obtained, compared, and rationalized to develop one master compilation of traffic forecast data (refer to Section 3.1.1.2).

Summarize Projected Repository Impacts. The foregoing data will then be added to the traffic data defining existing traffic levels in the site vicinity (refer to Section 3.1.1.1). The resulting information will be categorized according to the following parameters:

- Origin and destination

- Time of day of travel

- Route followed

- Number and type of cars.

These data will be computerized for ease of retrieval, reporting, and summarization. Before and after repository summaries will be prepared.

\subsubsection{Highway-Corridor Characterization Studies}

Within the site vicinity, similar to the rail corridor studies described in the preceeding section, data will be collected to characterize alternative roadway corridors and confirm the selection of preferred corridors. In the case of roads, the potential exists for multiple access corridors whereas for rail, only one access spur will ultimately be selected. The highway-corridor data collection activities are as follows:

- Survey of existing roadway systems in project vicinity

- Collect repository-generated traffic data.

The transportation effects of the repository is expected to be most intense within the site vicinity. Since an access road will be provided to the site, and since projections of highway traffic to the site appear to warrant concern for exceeding existing roadway infrastructure capacity (Environmental Assessment Section 5.3.1.1), the analys is of repository affects on the transportation infrastructure conducted from this SSP will require a study of the local roads and highways.

The two highway-transportation data-analys is programs included in this SSP will superimpose projections of repository-generated traffic onto existing traffic data for the site vicinity and summarize projected affects of repository traffic on the roadway system in the site vicinity.

Superimpose Repository-Generated Traffic. The repository engineering design contractor will develop forecasts of repository-generated traffic for the construction, operation, and decommissioning phases of the project. Similar forecasts have also been developed in the Environmental Assessment. These forecasts will be obtained (refer to Section 3.1.2.2), compared, and rationalized to develop one master compilation of traffic forecast data. 
Summarize Repository Impacts. The foregoing data will then be added to the traffic data defining existing traffic levels in the site vicinity (refer to Section 3.1.2.1). The resulting information will be categorized according to basic traffic engineering parameters including:

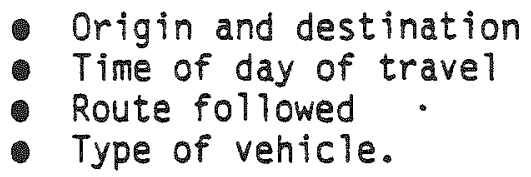

These data will be computerized for ease of retrieval, reporting, and summarization. Before and after repository summaries will be prepared.

\subsubsection{Alternative Statewide Route Characterization Studies}

Throughout the State of Texas, data will be collected to characterize a ternative multi-modal transportation routes to the site vicinity and to confirm the selection of preferred statewide routes. The statewide data collection activities are as follows:

- Survey existing statewide transportation infrastructure along identified alternative routes

- Survey accident and incident data along identified routes

- Assess environmental conditions along identified routes

- Collect baseline environmental data to confirm selection of preferred statewide routes.

For transportation requirements extending throughout the State of Texas, two data analysis functions will be carried out: identify required upgrades and improvements to statewide routes, and calculate radiological exposure risks along statewide routes.

Identify Required Upgrades and Improvements. Two data-gathering activities, Survey of Existing Statewide Transportation Infrastructure (3.1.3.2) and Survey of Accident and Incident Data (3.1.3.3), will provide data to be used for identifying locations or facilities that require upgrading or improvement to meet the transportation needs of the project. Many such requirements will be known by the Federal, State, and local officials responsible for transportation planning and maintenance along the routes. Each needed upgrade will be identified by location and reason for the need. For each upgrade, the following data will be generated:

- Design parameters of required work

- Cost estimates of work

- Construction schedule and an assessment of construction impact 
- Effects of upgrade

- changes in future traffic

- environmental effects

- Tand use effects

- community/socioeconomic effects

- population effects

- effects on radioactive risk.

Calculate Radiological Exposure Risks To calculate radiological exposure risk, population, employment, and environmental data will be coupled with data on operational characteristics such as slowdowns and stops associated with a particular transportation mode and emissions of radioactivity from shipping casks. One-half mile on either side of a potential route will be evaluated.

An approach similar to that found in Appendix $A$ to the Environmental Assessment will be followed.

\subsubsection{Monitoring Studies}

A major concern to be studied during the site characterization phase is the impact on local and regional communities within the site vicinity from both the construction of the road and rail access routes and the traffic generated by site characterization activities. To provide the necessary data to support the evaluation of transportation impacts in the site vicinity, the traffic effects of site characterization activities will be monitored. The traffic monitoring data collection activities during site characterization are as follows:

- Monitor public road congestion in the project vicinity

- Assembie site characterization project transportation data.

The raw data collected will be entered into the data management system as described in Chapter 4, Section 4.2. The data will then be extracted as desired for additional analyses which are not included in this SSP. These analyses include ongoing assessments of site characterization transportation effects by program management and extrapolation of site characterization data to be used in projecting the effects of transportation associated with the repository facilities themselves, by transportation infrastructure designers.

\subsubsection{Aircraft-Overfiight, Hazardous-Material Transportation, and Emergency-Response- Preparedness Characterization Studies}

These studies relate to concerns regarding aircraft crashes, hazardous waste incidents, and emergency response as related to evaluations of the suitability of the identified alternative transportation corridors and routes. The statewide data-collection activities are as follows:

- Survey aircraft overflight and airport landing and takeoff patterns along identified transport corridors 
- Survey hazardous-material transportation and use patterns along identified statewide routes

- Assemble emergency-response data along statewide routes.

\subsection{APPLICATION OF THE RESULTS}

This section discusses how the analyzed data described in Section 3.6 will be used. The following section summarizes the application of the data derived from the various transportation studies.

\subsubsection{Rail Corridor Characterization}

The data collected will be entered into the data management system as described in Section 4.1. The data will then be extracted as desired for incorporation into the rail system condition maps, the preparation of which is described in Section 3.4.1.2. The data presented on the condition maps will be used to characterize all identified existing alternative rail routes in the site vicinity as to their capability for accepting additional transportation needs of the site when developed.

Additional analyses in which the collected data will be used, but which are not included in this SSP, are discussed in other sections of this document as follows: selecting a preferred rail corridor in the site vicinity (Section 3.1.1.5), confirming preferred rail corridor in the site vicinity (Section 3.1.1.5), confirming preferred corridor selection (Section 3.1.1.5), identifying alternative statewide transportation routes (Section 3.1.3.1), selecting preferred statewide routes (Section 3.1.3.5), and confirming preferred statewide route selection (Section 3.1.3.5). Also, the design and construction of the new rail spur to the site will involve analysis of the data developed in this SSP activity.

\subsubsection{Highway-Corridor Characterization Studies}

The data collected will be entered into the data management system as described in Section 4.1. The data will then be extracted as desired for incorporation into the highway system condition maps, the preparation of which is described in Section 3.4.2.2. The data presented on the condition maps will be used to characterize a.1 identified alternative road routes in the site vicinity as to their capability for accepting additional transportation needs of the site when developed.

Additional analyses in which the collected data will be used, but which are not included in this SSP, are discussed in other sections of this document as follows: identifying alternative statewide transportation routes (3.1.3.5), and confirming preferred statewide route selection (3.1.3.5). Also, the design and construction of any new access roadway to the site facilities will involve the use of the data developed in this SSP activity. 


\subsubsection{Alternative Statewide Route Characterization Studies}

The data collected will be entered into the data management system as described in Section 4.1. The data will then be extracted as desired for incorporation into the statewide route condition map, the preparation of which is described in Sections 3.4.1.2, 3.4.2.2, and 3.4.3. The data presented on the condition maps will be used to characterize all identified statewide routes as to their capability for accepting transportation needs of the site, particularly with respect to transporting nuclear waste to the site and excess mined salt from the site. Additional analyses in which the collected data will be used, but which are not included in this SSP, are discussed in other sections of this document as follows: identifying alternative statewide transportation routes (3.1.3.1), selecting preferred statewide routes $(3.1 .3 .5)$, and confirming preferred statewide route selection $(3.1 .3 .5)$.

\subsubsection{Monitoring Studies}

The data collected during this study will be entered into the data management system as described in Section 4.1 . The data will then be used to analyze existing and projected traffic congestion in the site vicinity. The data will also be a major input for the evaluation of potential transportation mitigation measures. Finally, the data will be used to predict traffic and congestion during repository construction, operation, and decommissioning.

\subsubsection{Aircraft-Overflight, Hazardous-Material Transportation, and Emergency-Response- . Preparedness Characterization Studies}

The data collected will be entered into the data management system as described in Section 4.1. The data will then be extracted as desired for incorporation into the summary maps, the preparation of which is described in Sections 3.4.5, 3.4.6, and 3.4.7. The data will be used to evaluate all identified statewide transportation routes as to their capability for accepting the additional transportation needs of the site when developed. 


\subsection{DATA MANAGEMENT}

This chapter describes the management and reporting of the field and laboratory data produced under this plan. Included is a description of the strategy for managing the data to ensure secure and efficient handling and to make it readily available for technical use and general information purposes. This chapter also describes the reporting policies to make the study data and data analysis available in a timely manner to the technical community and the public. The data to be managed is generated from direct field observations and measurements, and by laboratory testing of field samples. The management of field samples is discussed in Section 6.2 .

\subsection{DATA REDUCTION}

Data Reduction is the summarization of digital and nondigital numeric data in a statistical fashion to reduce the number of data points to a manageable number for analysis or reporting. Data reduction, data analysis, and application of the results is presented in Section 3.6. This section discusses the reduction of data obtained from the transportation studies.

\subsection{DATA MANAGEMENT}

Three types of data will be generated by the transportation field studies: (1) digital data, (2) data sheets and logbooks, and (3) supplemental data such as maps and photographs. These data will include measurements and observations recorded both in the field and from the analysis of field samples in the laboratory. The data formats to be used are data sheets specified and presented in the Technical Procedures for Transportation Site Studies (ONWI, 1987c). Each data sheet has been designed to be compatible with the office of Nuclear Waste Isolation's (ONWI) centralized Integrated Data Management System (IDMS). The following is a description of the different types of field data and the strategy to manage these data.

1. Digital data will consist of field monitoring data made avajlable on magnetic tape. For the transportation work, these data will include vehicle counts derived from traffic monitoring with continuous counters. Digital data will be inputted into the Field Data Analysis system (FDAS) computer information system.

2. Data sheets and logbooks include all nondigital alphanumeric data recorded on paper that can be input into the FDAS computer information system. They will include the following:

- Information regarding the time, location, measurement, and observations of field activities and conditions including traffic study, route condition inspection, and environmental data

- Organizational contact information including interview notes, reports, tabulations, and drawings. 
3. Supplemental data will include topographic maps and aerial photos showing the locations of such items as monitoring activities, transportation infrastructure, route condition inspections, and environmental conditions. Also included will be route photologs $(35 \mathrm{~mm}$ photographs and video tapes), which will be used to document route conditions.

The flow of transportation data is presented in Figure 4-1. Digital field data and data recorded on data sheets will be stored in one or more component systems that comprise IDMS. Supplemental data will be tracked using IDMS. Storage of supplemental data and storage of data sheets, however, will occur at the Controlled Technical Reference Center (CTRC). All data that have been entered into the IDMS computerized system, as well as supplemental data stored at the CTRC, will be accessible to the technical community and the public through DOE.

The following is a brief description of the IDMS component systems that will be used to manage data:

FDAS The Field Data Analysis System is the software component that will process and store data. Raw data from digital data, data sheets, and logbooks will be permanently stored in FDAS. Each magnetic tape and disk will be indexed to identify its content.

ARS The Automated Records System is a computer component that will be used to track documents. The system will iist and/or describe all nondigital data documents and identify their content.

SRP/TDB The Salt Repository Project Technical Data Base is a component of IDMS that will provide processed baselined numerical data and information about reports on these data. When fully operational the SRP/TDB will provide numerical and descriptive information needed to support site characterization and licensing requirements of the SRP.

CTRC The Controlled Technical Reference Center will provide secured storage for hard copies of field study documents. The CTRC is not a part of IDMS but a functional extension of the system.

Review of raw and processed computerized data can be made by accessing the IDMS system on a computer terminal monitor. Inspection of original data sheets, logbooks, maps, photos, and so forth can be made through the CTRC. Documents may be copied upon approved request.

The FDAS will interface with nearly all of the subsystems contained within the IDMS, including the Salt Repository Project Technical Data Base (SRP/TDB). Data entered into the SRP/TDB will be derived from data entered into the FDAS. The FDAS data must first be properly reviewed, approved, and documented, and finally undergo a summary analysis, before it can be entered into the SRP/TDB. 


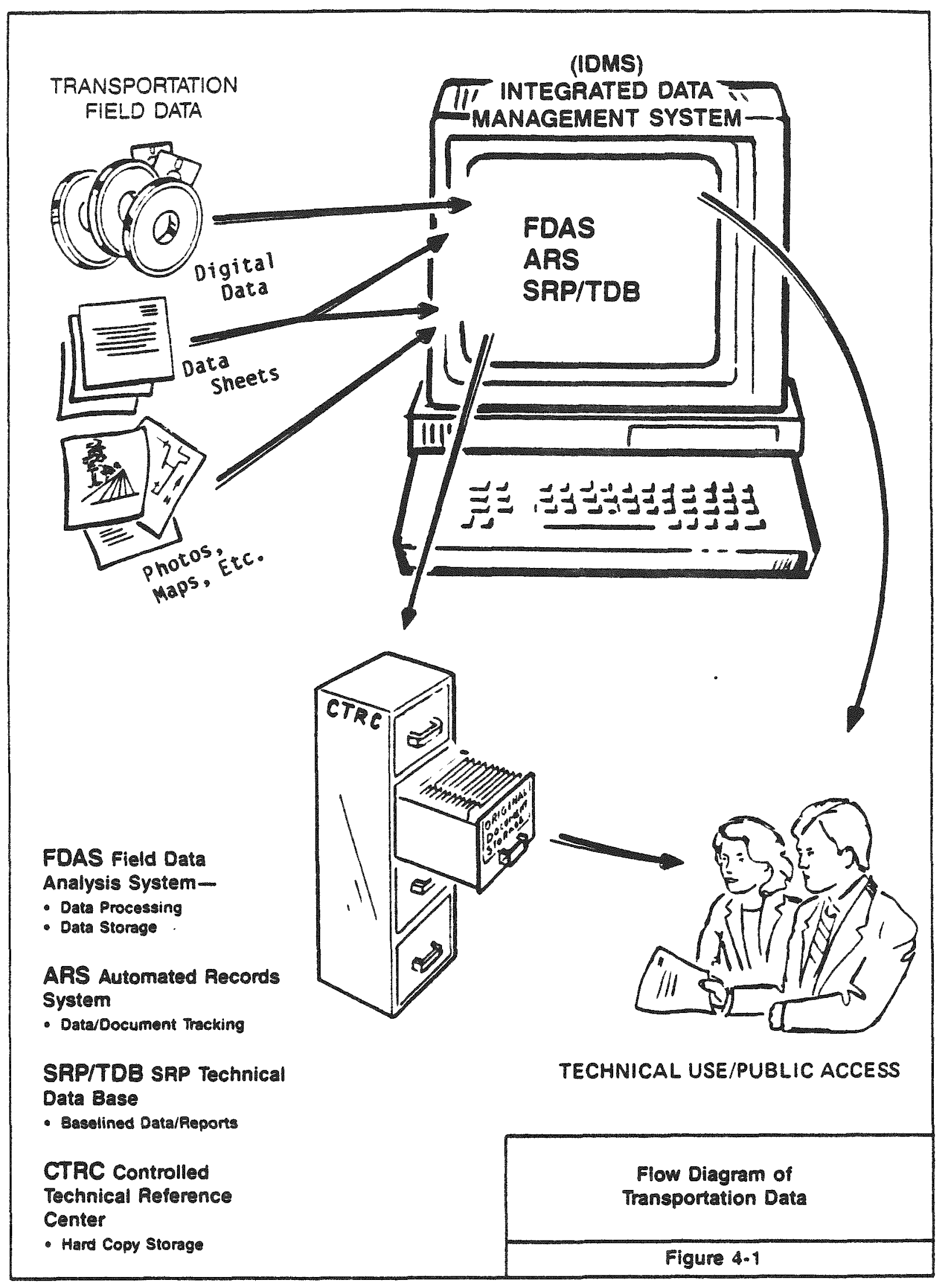




\subsection{DATA REPORTING}

The reporting of data will occur at numerous points during the study. The DOE will make information/data about site characterization available to the technical community and the public by providing the following: (1) data reports, (2) topical reports, (3) indexes from the computerized information system, (4) design drawings, and (5) processed data from the SRP/TOB.

The policies to be used to report the transportation data are as follows:

1. Providing Data Reports Within 30 to 45 Days of Collection

Unanalyzed data can be available to interested parties in the form of data reports 30 to 45 days after collection. A "Notice of Avai]ability" will be sent for each report to those persons on the DOE mailing list who have signed up for the relevant subject category. In addition, upon request, unanalyzed data can upon DOE approved request be made available for inspection on site.

2. Providing Reports

Copies of topical reports will be provided via the ONWI report distribution system using established mailing lists.

3. Providing Computerized Information System Indexes

Indexes tailored to meet specific needs of interested parties will be created and made available on an approved request basis. Indexes of wide general interest will be maintained and updated on a continuing basis.

4. Providing Design Drawings

Design drawings will be available for viewing by interested parties at the ONWI Engineering Records Center. Copies will be made available on a specific approved request basis.

5. Providing Processed Data From the SRP Technical Data Base

Accepted technical data will be available to any interested parties upon request subject to DOE approval. 


\subsection{SCHEDULE ANO MILESTONES}

The transportation field studies and related activities will be performed in seven areas: site vicinity rail-corridor study, site vicinity highwaycorridor study, Texas route studies, repository characterization studies, and overfight, hazardous-materials, and emergency-response studies. This chapter presents the schedule and milestones for these studies.

\subsection{SITE STUDY SCHEDULE}

The Transportation SSP will perform seven field activities to characterize the transportation corridors and routes linking the Deaf Smith County site to the surrounding communities, in-state generators of nuclear waste materials, excess mined salt disposal sites, and the CRWM national transportation program. These activities are shown on Figure 5-1. The schedule for the Transportation SSP is described in the following sections and shown on Figure 5-2. Programs that support the Transportation SSP, and key milestones representing program decisions outside the scope of the Transportation SSP on which transportation activities depend, are also identified.

\subsubsection{Site Vicinity Studies}

Within the site vicinity, characterization studies will be conducted for alternative rail corridors and highway corridors. Site vicinity study work will not commence until site access has been granted by the DOE.

\subsubsection{Rail-Corridor Study}

The rail-corridor characterization study will commence 18 months after site access is granted. Existing rail systems in the site vicinity will be surveyed during the first 8 months of this activity.

Decisions will be made by other CRWM programs to identify the alternative rail corridors to be characterized in the site vicinity. Once this corridor identification has been furnished, environmental conditions within the designated corridors will be determined. These determinations will be conducted by the appropriate specialty disciplines within the overall site characterization program, but will be integrated by the transportation discipline. These determinations will include:

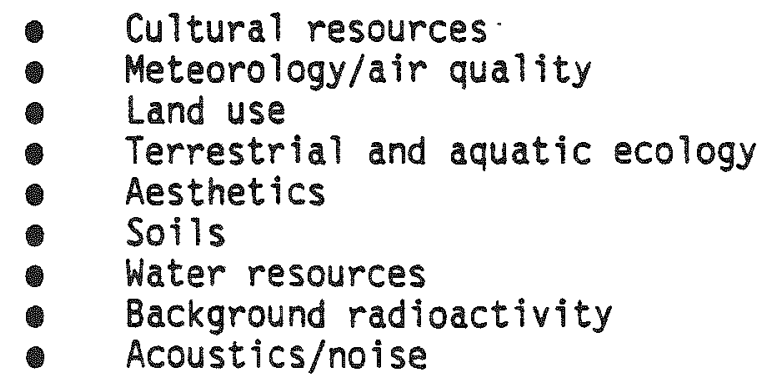



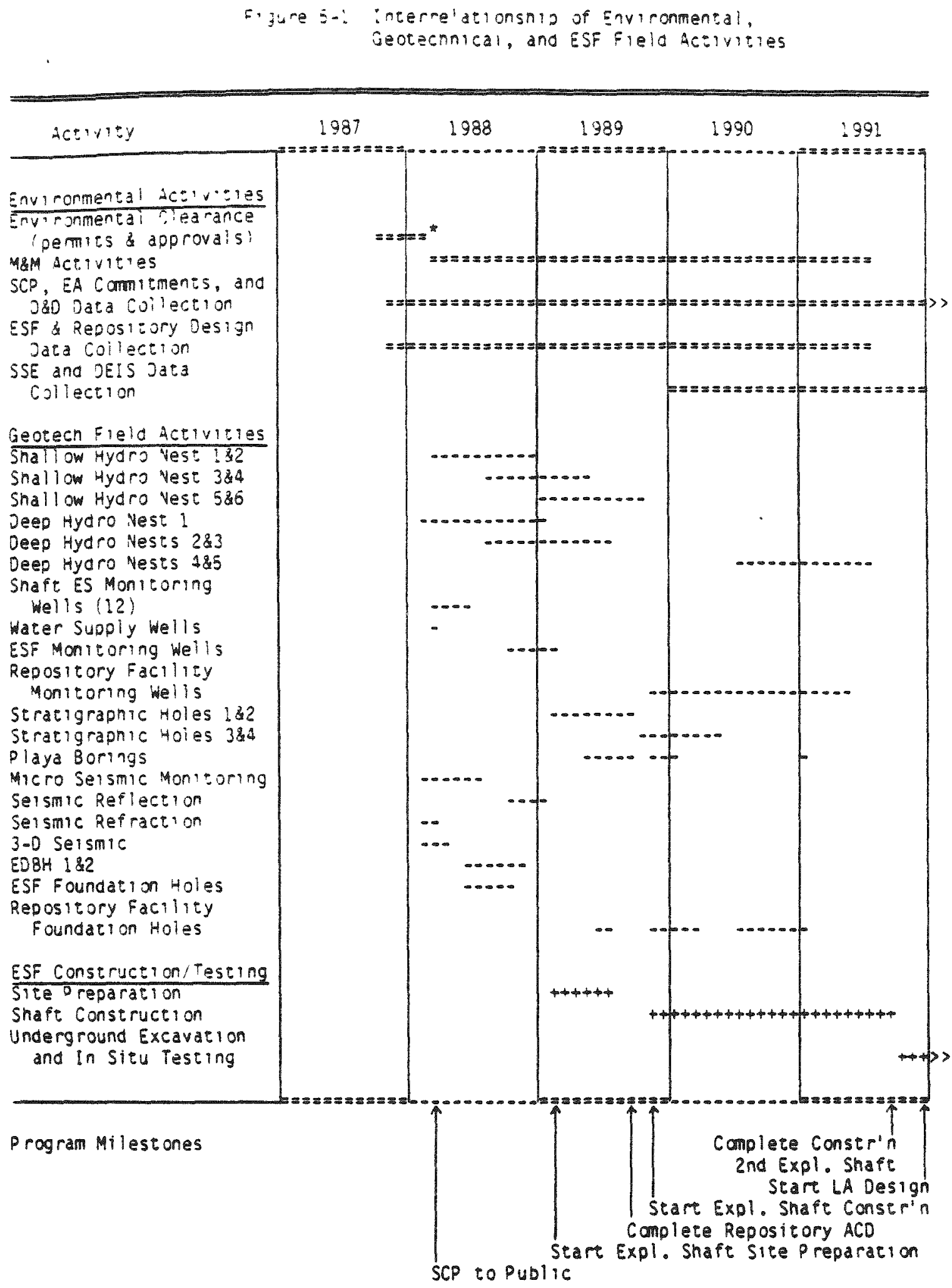

- Incluces culiural resources, inreacened and endangered species, and otner applicaole clearances required to degin che indicaced geocechical and Esf activicies. 


$$
\text { Frure 5-2. ionedule for Transportacion Fida scjoles }
$$

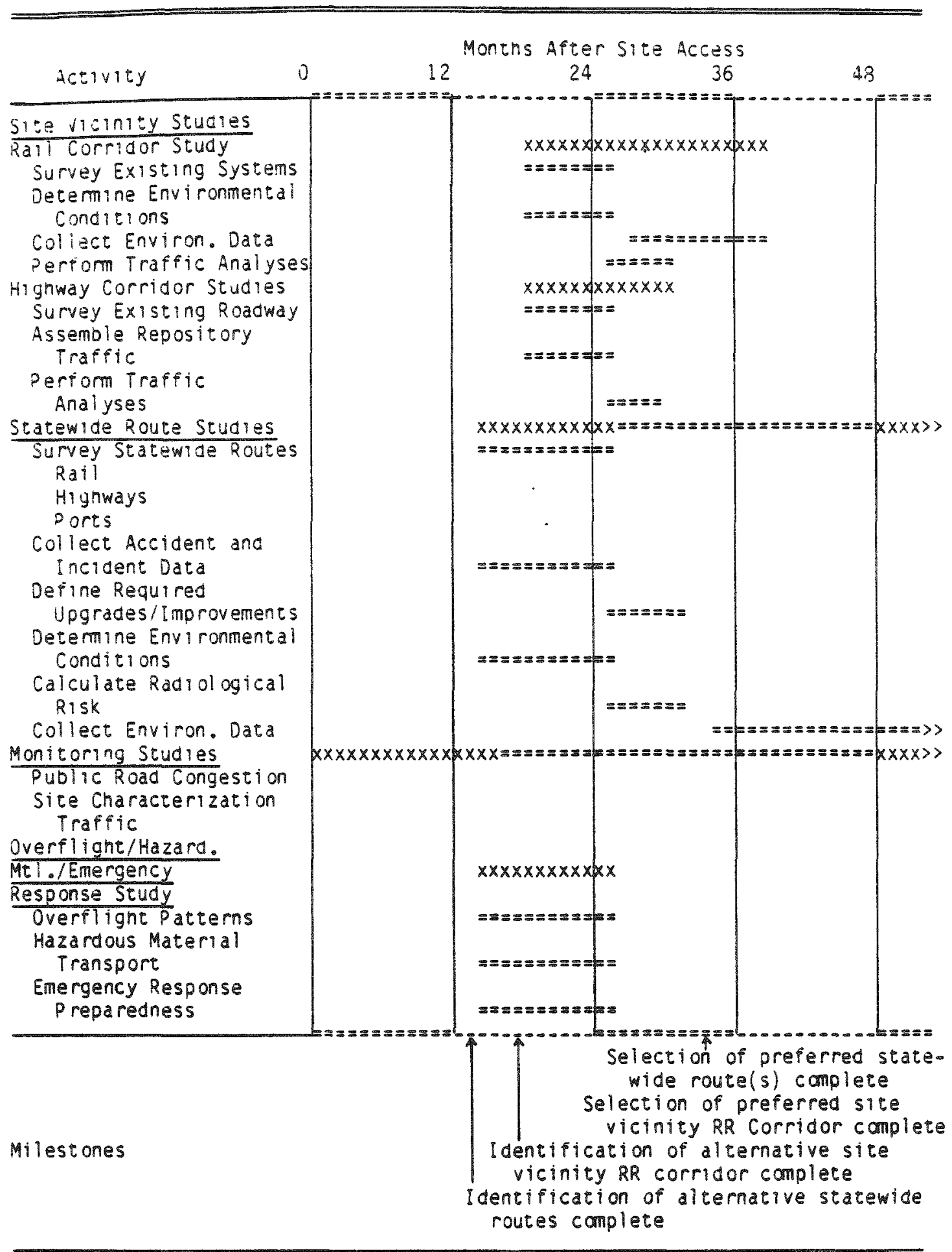

Legend:

$x \times$ Continuous field activity
$=$ Sub-activity 


\section{- Socioeconomics/population \\ - Geotechnical.}

Eight months are allocated for these determinations. Following the survey of existing rail systems and the determination of environmental conditions within the alternative rail corridors, the data collected will be used to assist other CRWM program elements in making a selection of a preferred rail corridor from among the identified aiternatives. Once this selection has been made, data to confirm this selection will be collected. This will include a more detailed determination of environmental conditions. These determinations and characterizations will be performed by the appropriate specialty disciplines within the overall site characterization program. The transportation discipline will be responsible for the topographic surveying and mapping of the preferred corridor. Twelve months have been allocated for the completion of characterizations of the selected preferred rail corridor. Following the survey of existing rail systems, collected data will be analyzed for the purpose of superimposing repository-generated rail traffic forecasts onto existing traffic data. This analysis will be summarized to predict repository trafficrelated impacts within the site vicinity. Six months have been allocated for this activity.

The completion of the preferred corridor characterization studies will mark the conclusion of Transportation SSP work for the site-vicinity rail corridor. Twenty-two months are allocated for this major activity, including two months awaiting the selection of the preferred site-vicinity rail corridor.

\subsubsection{Highway-Corridor Study}

The Highway corridor characterization study will commence 18 months after site access is granted. Existing road and highway systems in the site vicinity will be surveyed during the first 8 months following study initiation.

During the vicinity road and highway survey, forecasts and projections of repository-generated traffic will be assembled. This will be completed in the same 8-months time as the road and highway survey.

The completion of the assembly of repository-generated traffic data and the survey of existing systems will mark the end of field work associated with highway corridors in the site vicinity. The collected data will be analyzed for the purpose of superimposing repository-generated traffic forecasts onto existing traffic data. This analysis will be summarized to predict repository traffic-related impacts within the site vicinity. The traffic analysis effort will take about 6 months.

The completion of the traffic analysis activity will conclude TransDortation SSP work for the site-vicinity highway corridors. Fourteen monchs are allocated for this major activity. 


\section{1 .2 Statewide Route Studies}

Routes within Texas will be characterized for transportation purposes. The following activities will be conducted:

- Identify alternative statewide routes (not part of this SSP)

- Survey statewide transportation infrastructure

- Rail

- Highway

- Ports

- Collect accident and incident data

- Define required upgrades and improvements

- Determine environmental conditions along the routes

- Calculate radiological exposure risks

- Select preferred statewide routes (not part of this SSP)

- Collect environmental data for preferred routes.

These activities will commence fifteen months after site access, and are described in more detail below. A total of 46 months have been allocated for this major activity.

\subsubsection{Identify Alternative Statewide Routes}

Alternative routes must be identified before the data-gathering tasks can be performed. This identification is not an SSP activity. Routes will be identified by other CRWM programs and the State of Texas.

\subsubsection{Survey Statewide Transportation Infrastructure}

Surveys will be conducted along alternative statewide routes once these routes have been identified. This statewide survey effort, covering railroads, highways, and ports, will take about 12 months.

\subsubsection{Collect Accident and Incident Data}

Accident and incident data along the statewide routes will be collected during the same 12 months as the survey of route infrastructure.

\subsubsection{Define Required Upgrades and Improvements}

Areas where improvements or remedial measures are required to make the alternative routes acceptable for the intended transportation will be identified and defined following completion of the infrastructure survey. This activity will be completed in about 6 months.

\subsubsection{Determine Environmental Conditions Along the Routes}

Environmental conditions along the designated alternative routes will be determined concurrently with the collection of accident and incident data, and 
with the infrastructure survey. This determination will be conducted by the appropriate specialty disciplines within the overall site characterization program, but will be coordinated by the transportation discipline. Twelve months are allocated for completion of the environmental determinations. These will be conducted by the following disciplines:

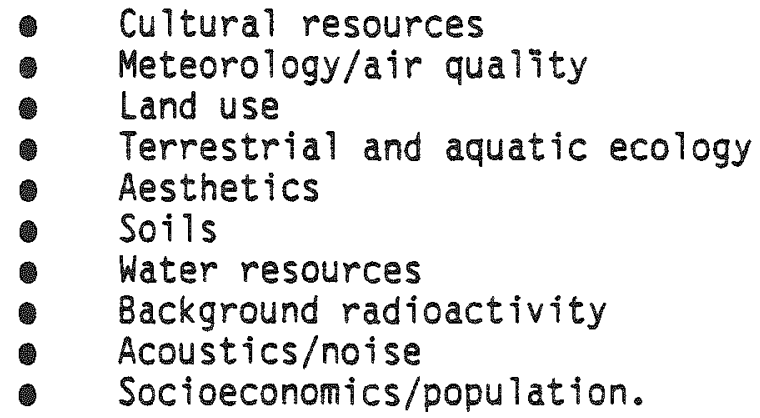

\subsubsection{Calculate Radiological Exposure Risks}

Radiological risks will be calculated for each identified statewide route from the environmental, sociological, and infrastructure data collected in praceding activities. This will follow completion of the referenced data gathering activities and will require 6 months to complete, in parallel with the definition of required upgrades and improvements discussed in Section 5.1.2.4.

\subsubsection{Select Preferred Routes}

From the data obtained in the preceding activities, preferred statewide routes will be selected from among the identified alternatives. This is not an SSP activity, but is required for subsequent SSP work to proceed. Other CRWM programs and the State of Texas will make this selection. Four months have been allocated for this selection milestone to be accomplished.

\subsubsection{Collect Environmental Data}

Once the selection of preferred statewide routes has been completed, environmental data necessary to confirm preferred route selection will be collected. This will include a more detailed determination of environmental conditions for the disciplines described in Section 5.1.2.5. These determinations and characterizations will be performed by the appropriate specialty disciplines within the overall site characterization program. Characterization of the preferred statewide routes will be completed in 24 months.

\subsubsection{Monitoring Studies}

During site characterization in the repository vicinity, transportation studies will be conducted to generate data for use in projecting future repository impacts. The following studies are required: 


$$
\begin{aligned}
& \text { - Monitor public road congestion } \\
& \text { - Quantify site characterization traffic activities. }
\end{aligned}
$$

This major activity will continue for the duration of the site characterization.

\subsubsection{Monitor Public Road Congestion}

Public road congestion will be monitored during site characterization activities. Scheduled duration for this monitoring corresponds to the duration of the overall site characterization field program.

\subsubsection{Quantify Site-Characterization Traffic Activities}

Traffic activities will be quantified during site characterization activities, similar to the preceding study.

\subsubsection{Overflight, "Hazardous-Material, and} Emergency-Response Studies

Special studies falling within the Transportation SSP scope, but not included in foregoing major activities, include the following:

- Aircraft-overflight pattern determinations

- Hazardous-material-transportation determinations

- Emergency-response-preparedness determinations.

A total duration of 12 months has been scheduled for the completion of these activities. These special studies will be performed concurrentiy with the surveys of statewide transportation infrastructure (Section 5.1.2.2).

\subsubsection{Aircraft-Overflight-Pattern Determinations} 12 months.

Aircraft-overfight patterns will be determined in the site vicinity over

\subsubsection{Hazardous-Material-Transportation Determinations}

Hazardous material transportation will be determined statewide during a 12-month period, starting concurrently with aircraft overfight pattern determinations.

\subsubsection{Emergency-Response-Preparedness Determinations}

Emergency-response-preparedness determinations will commence at the same time as the two foregoing activities. A duration of 12 months has been allocated. 


\subsection{MILESTONES}

Major milestones for the transportation program include:

- Identification of alternative rail corridors within the site vicinity

- Identification of alternative statewide multi-modal transportation routes

- Selection of a preferred rail corridor in the site vicinity

- Selection of preferred statewide multi-modal routes.

Section 5.1 discusses the reasons these milestones are significant and critical to the scheduled performance of the Transportation SSP.

\subsection{CONCURRENT STUDIES}

A number of Transportation SSP activities require the active participation and involvement of other disciplines within the overall site characterization program. The following table (Table 5-1) identifies three disciplines which will interact with transportation during the first year after site access. Future transportation SSP revisions will identify interactions with additional disciplines. 
Table 5-1. Concurrent Study Programs That Interact With Transportation Program

\begin{tabular}{|c|c|}
\hline Concurrent Study Program* & Interaction With Transportation \\
\hline Acoustics & $\begin{array}{l}\text { Receives from Transportation traffic } \\
\text { information for use in identifying peak } \\
\text { traffic periods. }\end{array}$ \\
\hline Aesthetics & $\begin{array}{l}\text { Receives from Transportation the traffic } \\
\text { volume of existing roads in the area to } \\
\text { determine visual sensitivity, location, } \\
\text { design (cut and fill) and volume of } \\
\text { proposed corridors to determine visual } \\
\text { effects of alternative transmission } \\
\text { corridors. }\end{array}$ \\
\hline & $\begin{array}{l}\text { Supplies to Transportation the visual } \\
\text { effects of alternative transportation } \\
\text { corridors to assist in identification of } \\
\text { suitable transportation corridors. }\end{array}$ \\
\hline Aquatic and Terrestrial Ecology & $\begin{array}{l}\text { Receives from Transportation the traffic } \\
\text { monitoring locations and flows to monitor } \\
\text { trends in lillife fatalities. }\end{array}$ \\
\hline
\end{tabular}

* No study program interaction exists between Transportation and Background Environmental Radioactivity, Cultural Resources, Land Use, Meteorology/Air Quality, Salt, Soils, Utilities and Solid Waste, and Water Resources during the first year of the site access. 


\subsection{ORGANIZATION/MANAGEMENT}

This chapter describes the management of the transportation site studies, including manpower requirements, organization and qualifications of personnel, sample management, and health and safety.

\subsection{MANPOWER REQUIREMENTS AND ORGANIZATION}

This section describes the field staff requirements and the organization, responsibilities and qualifications of key personnel.

\subsubsection{Field Staff Requirements}

The site investigations described in this SSP for the transportation program will require nine employees on site and the partial services of a field manager during the second and third years after site access. A total of ten personnel will therefore be required on site for the activities described in this SSP.

The onsite staff will consist of a MKE Field Manager, a Principal Investigator (PI), and a transportation engineer, a civil engineer, two transportation planners, and four technicians. Figure 6-1 shows the relationship of the MKE Field Manager and the PI to the Technical Field Services Contractor (TFSC) Field Manager.

Immediately after site access, as shown in Figure $5-1$, the field program for transportation will begin. At that time there will be a visit to the vicinity of the site to identify locations for congestion monitoring. Monitoring will begin as soon as the necessary equipment can be installed.

Monitoring activities during the first year will require the half-time services of the transportation principal investigator and transportation engineer and the full-time services of three technicians.

The level of effort for conducting the field component of the transportation studies is presented below to the nearest one-half full-time-equivalent (FTE) staff personnel. Staffing levels are based on an assumed field access date of October 1987.

$\begin{array}{cc}\text { Calendar Year } & \text { FTE Staff } \\ 1987 & 0 \\ 1988 & 4 \\ 1989 & 7 \\ 1990 & 9 \\ 1991 & 4 \\ \text { out years } & \text { TBD }\end{array}$




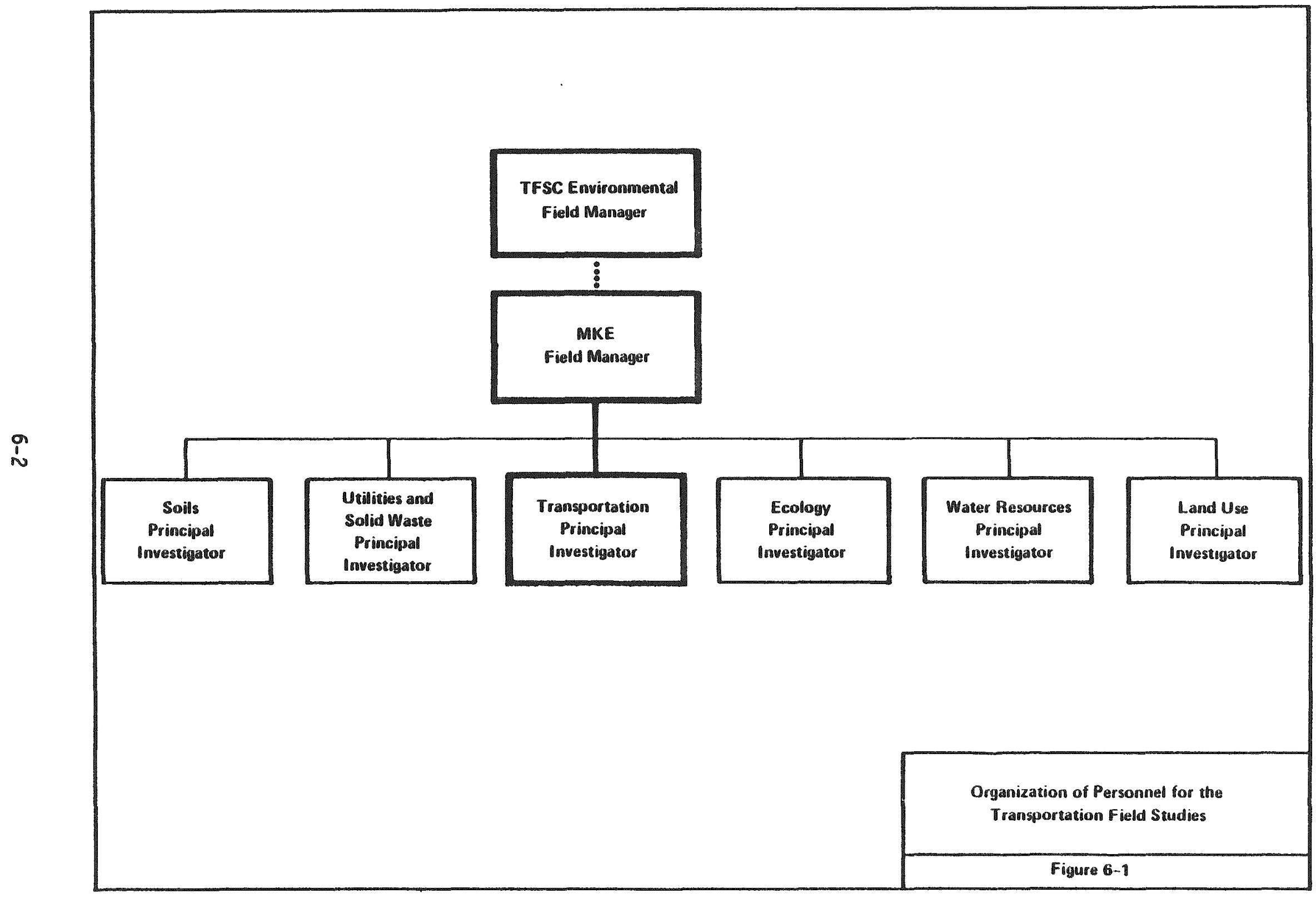




\subsubsection{Organization, Responsibilities, and Qualifications of Key Personnel}

The key personnel involved in the management and technical execution of the transportation investigations are shown on Figure 6-1.

\section{- Field Manager}

The MKE field manager will be the MKE contact for all communication between the Technical Field Services Contractor (TFSC) and MKE regarding transportation field work. The MKE field manager will report directly to the IFSC environmental field manager who will be on site approximately 100 percent of the time. The MKE field manager is also responsible for managing the field work for utilities, soils, terrestrial and aquatic ecology, water resources, and land use and is one of five subcontractors conducting environmental field investigations at the Deaf Smith County site. The MKE field manager is responsible for supervising the transportation principal investigator.

The MKE field manager must have, as a minimum, a Bachelor of Science degree in an environmental science or related discipline. The individual must also have 5 years of experience as a field manager, with 2 years of the 5 in the management of field studies. The person should also be knowledgeable about the Salt Repository Project.

\section{- Principal Investigator}

The principal investigator will direct the transportation studies that occur in the vicinity of the site as well as those that will be conducted in the offices of the following: Texas agencies responsible for transportation, regional councils of government and planning commissions, railroad companies, port authorities, the U.S. Department of Transportation, and others that may be identified.

The principal investigator will report the number of people in the field daily to the contractor field manager. He or she will also inform the contractor field manager of the need for shortterm support from the home office. Any occurrence or situation, including illness, unusual weather conditions, or accidents, that will or could affect the field study schedule will also be called to the attention of the contractor field manager.

The principal investigator will also prepare and submit weekly and monthly progress reports on the study work. The weekly reports will be letter reports; the monthly reports will be more formal in structure. The principal investigator will be assisted at the home office in data compilation by the part-time services of a database manager, a data managment coordinator, and a data technician. 
The PI will report directly to the MKE field manager. He or she will inform the MKE field manager of the need for additional short-term support and any occurrence or situation, including iliness, unusual weather conditions, or an accident, that will or could affect the field study schedule. Each week the PI will submit a letter report that statuses the data collection for the past week: each month the PI will submit a more comprehensive progress report summarizing data collection activities for the past month.

The PI for transportation must have, as a minimum, Bachelor of Science degree in civil engineering or a related discipline, with experience in transportation studies.

\subsection{SAMPLE MANAGEMENT}

The transportation studies do not directly involve sampling and testing operations. Environmental characterization of designated routes will involve discipline-specific operations covered by the sample management procedures for each environmental discipline.

\subsection{HEALTH AND SAFETY}

In accordance with DOE Order 6410.1 which deals with the management of construction projects, a safety plan will be established to describe implementation responsibilities as part of a comprehensive DOE field office health and safety program for the project. The potential hazards to be addressed in that plan are discussed below.

Personnel responsible for transportation field activities may be exposed to a number of situations which could threaten their heaith and safety. Personal risk may come from vehicle and pedestrian accidents and exposure to severe weather. Route condition inspections and traffic congestion monitoring are two of the studies which would require precautions to prevent accidents.

The Texas Panhandle area is known to experience severe weather that includes hot, dry, and windy conditions on one extreme and cold, stormy conditions on the other (NUS Corporation, 1984: U.S. Department of Commerce, 1968-1985: and Simiu, 1979). Tornados are frequent in this region and can occur at the site (Ramsdell and Andrews, 1986). In addition, the Southern High Plains is one of the regions of highest flash-flood potential in the conterminous United States (Beard. 1975).

The site region is also within the range of the Western Diamondback Rattlesnake, the Prairie Rattlesnake, and the Massasauga (Stebbins, 1966).

Ppior to commencing field investigations, SRP personnel will be briefed on safety concerns and the precautions that should be taken to ensure that studies are conducted in a safe way. Topics will include dehydration, exposure, areas to avoid during severe weather conditions, snakes and snakebites, 
protective clothing, physical assistance, and other preventive measures to ensure reasonable safeguards against potentially dangerous conditions. In addition, arrangements will be made with the nearest hospital to admit project personnel in the event of snakebite or other serious injury. 


\subsection{QUALITY ASSURANCE}

This section describes the quality assurance and quality control requirements as they apply to the site characterization program management for this site study plan. The work activities associated with the site studies shall be performed in accordance with a documented, implemented, and maintained quality assurance program that complies with the requirements of the Contractimposed Quality Assurance Specification.

The requirements in the Quality Assurance Specification have been graded to a complexity commensurate with the importance of the work activities identified in the Contract scope of work. The Quality Assurance Specification addresses the appropriate criteria and selected requirements to be applied to the quality assurance program as described by the American National Standards Institute/American Society of Mechanical Engineers NQA-1 (ANSI/ASME, 1986).

The quality program, that provides for achieving and verifying quality, is developed from requirements identified in the Quality Assurance Specification. This program is described in Morrison-Knudsen Engineers, Inc./ERT (the performing contractor) Quality Assurance Plan for the Physical Environment, Land Use, and Ecosystems Study for the Salt Repository Site Characterization (MKE/ERT, 1987): its implementing quality assurance administrative procedures: and associated technical procedures. See Section 3.4 for a description of the applicable technical procedures necessary to conduct the work activities for these studies.

The work activities addressed in this site study plan have been designated Quality Level (QL) 2. QL-2 (the intermediate quality level) is assigned to items and activities which are important to Department of Energy mission objectives. The following lists the proposed studies and assigned minimum Quality Levels.

Study

Minimum

Quality Level

Rail-Corridor-Characterization Studies

Survey of Existing Rail Systems in the Project Vicinity 2

Assembly of Repository-Generated Traffic Data 2

Identification of Rail-System Alternative Corridors 2

Assessment of Alternative Rail-Corridor Environmental 2

Conditions

Collection of Data to Confirm Preferred Rail Corridor 2

Highway-Corridor-Characterization Studies

Survey of Existing Roadway Systems in the Project 2

Vicinity

Assembly of Repository-Generated Traffic Data 2 
Alternative Statewide Route Characterization Studies

Identification of Statewide Multi-Modal-Transportation 2 Routes

Survey of Existing Statewide Transportation 2 Infrastructure

Survey of Accident and Incident Data Assessment of 2 Alternative Multi-Modal Route Environmental Conditions

Collection of Data to Confirm Preferred Statewide Multi-Modal Routes

2

2

2

2

Repository-Characterization Transportation-Impact Studies

Measure Public Road Congestion in the Project Vicinity 2

Assembly of Site Characterization Project Transportation Data

Aircraft-Overflight, Hazardous-Material-Transportation, and Emergency-Response-Preparedness Characterization Studies

Survey Aircraft-Overflight Patterns 2 Survey Hazardous-Materials Transport Patterns 2 Assemble Emergency-Response Data Along Statewide Multi- 2 Modal Routes

In lieu of generating and implementing two quality programs to address the Quality Levels of these and other studies, the performing contractor may elect to impose and commit to the highest level program. This means these studies may be conducted under QL-1 requirements, because MKE must perform other work at quality level 1.

The Quality Assurance Specification under which the above studies will be performed make the eighteen criteria (requirements) of NQA-1 applicable to these studies. The basic requirements from NQA-1 are stated below. However, supplementary requirements necessary to be invoked into a QL-2 quality program have not been included in the basic requirements description. These supplementary requirements are identified in the Contract-imposed Quality Assurance Specification and have been addressed in the MKE/ERT Quality Assurance Plan and implementing procedures.

The following sections 7.1 through 7.18 are a description of the requirements contained in the eighteen Basic Requirements of NQA-1. The numbering of the sections corresponds to that of NQA-1 except for the section designation $(7 . x)$. 


\subsection{ORGANIZATION}

The organizational structure, functional responsibilities, levels of authority, and lines of communication for activities affecting quality shall be documented. Persons or organizations responsible for assuring that an appropriate quality assurance program has been established and verifying that activities affecting quality have been correctiy performed shall have sufficient authority, access to work areas, and organizational freedom to do the following:

- identify quality problems

- initiate, recommend, or provide solutions to quality problems through designated channels

- verify implementation of solutions

- assure that further processing, delivery, installation, or use is controlled until proper disposition of a nonconformance, deficiency, or unsatisfactory condition has occurred.

Such persons or organizations shall have direct access to responsible management at a level where appropriate action can be effected. Such persons or organizations shall report to a management level such that required authority and organizational freedom are provided, including sufficient independence from cost and schedule considerations.

\subsection{QUALITY ASSURANCE PROGRAM}

A documented quality assurance program shall be planned, implemented, and maintained in accordance with NQA-1, or portions thereof. The program sha 11 identify the activities and items to which it applies. The establishment of the program shall include consideration of the technical aspects of the activities affecting quality. The program shall provide control over activities affecting quality to an extent consistent with their importance. The program shall be established at the earliest time consistent with the schedule for accomplishing the activities.

The program shall provide for the planning and accomplishment of activities affecting quality under suitably controlled conditions. Controlled conditions include the use of appropriate equipment, suitable environmental conditions for accomplishing the activity, and assurance that prerequisites for the given activity have been satisfied. The program shall provide for any special controls, processes, test equipment, tools, and skills to attain the required quality and for verification of quality.

The program shall provide for indoctrination and training, as necessary, of personnel performing activities affecting quality to assure that suitable proficiency is achieved and maintained.

Management of those organizations implementing the quality assurance program, or portions thereof, shall regularly assess the adequacy of that part of the program for which they are responsible and shall assure its effective implementation. 


\subsection{DESIGN CONTROL}

For the activities identified for this site study plan, design or design information are data wich are used for design activities. Design information includes test and experiment results, existing data, and computer codes. Data may be collected through literature searches, testing, or computer runs. Data acquisition includes initial data reduction and analysis. (Added for clarity)

The design shall be defined, controlled, and verified. Applicable design inputs shall be appropriately specified on a timely basis and correctly translated into design documents. Design interfaces shall be identified and controlled. Design adequacy shall be verified by persons other than those who designed the item. Design changes, including field changes, shall be governed by control measures commensurate with those applied to the original design.

\subsection{PROCUREMENT DOCUMENT CONTROL}

Applicable design bases and other requirements necessary to assure adequate quality shall be included or referenced in documents for procurement of items and services. To the extent necessary, procurement documents shall require suppliers to have a quality assurance program consistent with the applicable requirements of NQA-1.

\subsection{INSTRUCTIONS, PROCEDURES AND ORAWINGS}

Activities affecting quality shall be prescribed by and performed in accordance with documented instructions, procedures, or drawings of a type appropriate to the circumstances. These documents shall include or reference appropriate quantitative or qualitative acceptance criteria for determining that prescribed activities have been satisfactorily accomplished.

\subsection{DOCUMENT CONTROL}

The preparation, issue, and change of documents that specify quality requirements or prescribe activities affecting quality shall be controlled to assure that correct documents are being employed. Such documents, including changes thereto, shall be reviewed for adequacy and approved for release by authorized personnel.

\subsection{CONTROL OF PURCHASED ITEMS ANO SERVICES}

The procurement of items and services shall be controlled to assure conformance with specified requirements. Such control shall provide for the following as appropriate: source evaluation and selection, evaluation of objective evidence of quality furnished by the supplier, source inspection, audit, and examination of items or services upon delivery or completion. 


\subsection{IDENTIFICATION AND CONTROL OF ITEMS}

Controls shall be established to assure that mnly correct and accepted items are used or installed. Identification shall be maintained on the items or in documents traceable to the items, or in a manner which assures that identification is established and maintained.

\subsection{CONTROL OF PROCESSES}

Processes affecting quality of items or services shall be controlled. Special processes that control or verify quality, when identified, shall be performed by qualified personnel using qualified procedures in accordance with specified requirements. (Modified from NQA-1).

\subsection{INSPECTION}

Inspections and survelllances required to verify conformance of an item or activity to specified requirements shall be planned and executed. Characteristics to be inspected and inspection methods to be employed shall be specified. Inspection results shall be documented. Inspection for acceptance shall be performed by persons other than those who performed or directly supervised the work being inspected. (Modified from NQA-1).

\subsection{TEST CONTROL}

Tests required to verify conformance of an item to specified requirements and to demonstrate that items will perform satisfactorily in service shall be planned and executed. Characteristics to be tested and test methods to be employed shall be specified. Test results shall be documented and their conformance with acceptance criteria shall be evaluated.

Test required to collect data, such as for siting or design input, shall be planned, executed, documented, and evaluated.

\subsection{CONTROL OF MEASURING AND TEST EQUIPMENT}

Tools, gages, instruments, and other measuring and test equipment used for activities affecting quality shall be controlled and at specified periods calibrated and adjusted to maintain accuracy within necessary iimits.

\subsection{HANOLING, STORAGE, AND SHIPPING}

Handling, storage, cleaning, packaging, shipping, and preservation of items shall be controlled to prevent damage or loss and to minimize deterioration. 


\subsection{INSPECTION, TEST, AND OPERATING STATUS}

The status of inspection and test activities shall be identified either on the items or in documents traceable to the items where it is necessary to assure that required inspections and tests are performed and assure that items which have not passed the required inspections and tests are not inadvertently installed, used, or operated. Status shall be maintained through indicators, such as physical location and tags, markings, shop travelers, stamps, inspection records, or other suitable means. The authority for application and removal of tags, marking, labels, and stamps shall be specified. Status indicators shall also provide for indicating the operating status of systems and components, such as by tagging values and switches, to prevent inadvertent operation.

\subsection{CONTROL OF NONCONFORMING ITEMS}

Items that do not conform to specified requirements shall be controlled to prevent inadvertent installation or use. Controls shall provide for identification, documentation, evaluation, segregation when practical, and disposition of nonconforming items, and for notification to affected organizations.

\subsection{CORRECTIVE ACTION}

Conditions adverse to quality shall be identified promptly and corrected as soon as practical. In the case of a significant condition adverse to quality, the cause of the condition shall be determined and corrective action taken to preclude recurrence. The identification, cause, and corrective action for significant conditions adverse to quality shall be documented and reported to appropriate levels of management: follow-up action shall be taken to verify implementation of this corrective action.

\subsection{QUALITY ASSURANCE RECORDS}

Records that furnish documentary evidence of quality shall be specified, prepared, and maintained. Records shall be legible, identifiable, and retrievable. records shall be protected against damage, deterioration, or loss. Requirements and responsibilities for record transmittal, distribution, retention, maintenance, and disposition shall be established and documented.

\subsection{AUDITS}

Planned and scheduled audits shall be performed to verify compliance with all aspects of the quality assurance program and to determine its effectiveness. These audits shall be performed in accordance with written procedures or checklists by personnel who do not have direct responsibility for performing the activities being audited. Audit results shall be documented and reported to and reviewed by responsible management. Follow-up action shall be taken where indicated. 


\subsection{REFERENCES*}

\subsection{REFERENCES LISTED BY AUTHOR}

American Society of Mechanical Engineers, 1986. Quality Assurance Program Requirements for Nuclear Facilities, ANSI/ASME NQA-1-1986, prepared for American National Standards Institute, New York, NY.

ASME, see American Society of Mechanical Engineers.

Beard, L. R., 1975. Generalized Evaluation of Flash-Flood Potential, Technical Report Crwr-124, Center for Research in Water Resources, University of Texas, Austin, TX.

Box, P. C., and J. C. Oppenlander, 1976. Manual of Traffic Engineering Studies, 4th edn., Institute of Transportation Engineers, Arlington, VA.

DOE, see U.S. Department of Energy.

MKE/ERT, see Morrison-Knudsen Engineers, Inc.

Morrison-Knudsen Engineers, Inc., 1987. Quality Assurance Plan, Denver, CO.

U.S. Department of Commerce, 1968-1985. Climatological Data - Texas, Volumes 73 to 90 , National Climatic Data Center, Asheville, NC.

NuS Corporation, 1983. Radiological Impacts of Transporting High-Level Radioactive Waste to sites in the Palo Duro Basin, prepared for office of Nuclear Waste Isolation, Battelle Memorial Institute, Columbus, $\mathrm{OH}$, in preparation.

NUS Corporation, 1984. Meteorological and Air Quality Characterization of the Deaf Smith and Swisher County Locations in the Palo Duro Bas in, Texas, BMI/ONWI-527, prepared for Office of Nuclear Waste Isolation, Battelle Memorial Institute, Columbus, $\mathrm{OH}$.

NUS Corporation, 1986, Rail Transportation Corridor Analysis Report: Deaf Smith County Location in the Palo Duro Bas in, Texas, BMI/ONWI-617, prepared for Office of Nuclear Waste Isolation, Battelle Memorial Institute, COlumbus, $\mathrm{OH}$.

Office of Nuclear Waste Isolation, 1987b. Salt Repository Project Transportation Program Plan, Battelle Memorial Institute, Columbus, $O H$ in preparation.

* References with stike are not currently acceptable for citation in a published report. These references must be reviewed and cleared for citation by the time the SSP is published or they will be deleted. 


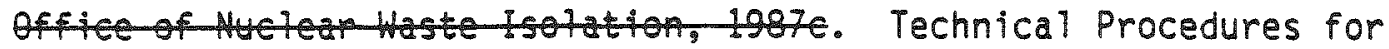
Implementation of Transportation Site Studies, preliminary draft, Battelle Memorial Institute, Columbus, $\mathrm{OH}$.

Ramsde 11, J. V., and G. L. Andrews, 1986. Tornado Climatology of the Contiquous United States, NUREG/CR-4461, U.S. Nuclear Regulatory Commission, office of Nuclear Reactor Regulation, Washington, DC.

Salt Repository Project Office, 1986. Systems Engineering Management Plan for the Salt Repository Project, ONWI/BMI-14(SRP/B-12), prepared for the U.S. Department of Energy by the Office of Nuclear Waste isolation, Battelle Project Management Division, Columbus, $\mathrm{OH}$.

Sult Repositopy paject Office, 1987. Salt Repository Project Requirements Document, DOE $/ \mathrm{CH}-x \times x x$, prepared for U.S. Department of Energy by office of Nuclear Waste Isolation, Battelle Project Management Division, Columbus, $\mathrm{OH}$, in preparation.

SRPO, see Sait Repository Project Office.

Simiu, E., et al., 1979. Extreme Wind Speeds at 129 Stations in the Contiquous United States, NBS Buiding Science Series 118, National Bureau of Standards, Washington, $D C$.

Stebbins, R. C., 1966. A Field Guide To Western Reptiles and Amphibians. Houghton Mifflin Company, Boston, MA.

ONWI, see Office of Nuclear Waste Isolation.

U.S. Department of Energy, 1986. Environmental Assessment, Deaf Smith County Site, Texas, Nuclear Waste Policy Act (Section 112), Vols. 1 to 3, DOERW-0069, Office of Civilian Radioactive Waste Management, Washington, $D C$.

\subsection{FEDERAL AND STATE STATUTES AND REGULATIONS AND EXECUTIVE ORDERS}

10 CFR Part 60, Disposal of High-Level Radioactive Wastes in Geologic Repositories.

10 CFR Part 960, Nuclear Waste Policy Act of 1982: General Guidelines for the Recommendation of Sites for the Nuclear Waste Repositories (Final Siting Guidelines) (42 USC Secs. 10101-10226).

10 CFR Part 1021, Compliance with the National Environmental Policy Act.

40 CFR Part 191. Environmental Standards for the Management and Disposal of Spent Nuclear Fuel. High-Level and Transuranic Radioactive Wastes; Final Rule, September 19, 1985.

40 CFR Parts 1500-1508, Regulations for Implementing the Procedural Provisions of the National Environmental Policy Act (42 USC Secs. 4321-4331, 4333-4361). 
49 CFR Part 177.825 Routing and Training Requirements for Radioactive Materials.

49 CFR Parts 100-179, Transportation.

National Environmental Policy Act of 1969, 42 USC Secs. 4321-4331, 4333-4361.

Nuclear Waste Policy Act of 1982, 42 USC Sections 10101-10226.

EO 11514, as amended by EO 11991, cited with National Environmental Policy Act of 1969; Environmental Quality Improvement Act of 1970 and Clean Air Act.

EO 11991, Relations to Protection and Enhancement of Environmental Quality.

EO 12088, cited with Clean Air Act, as amended; Federal Water Pollution Control Act, Solid Waste Disposal Act; Noise Control Act, and Safe Drinking Water Act.

DOE N.6410.1, Chapter I, Section 3,1 (05-26-83): 